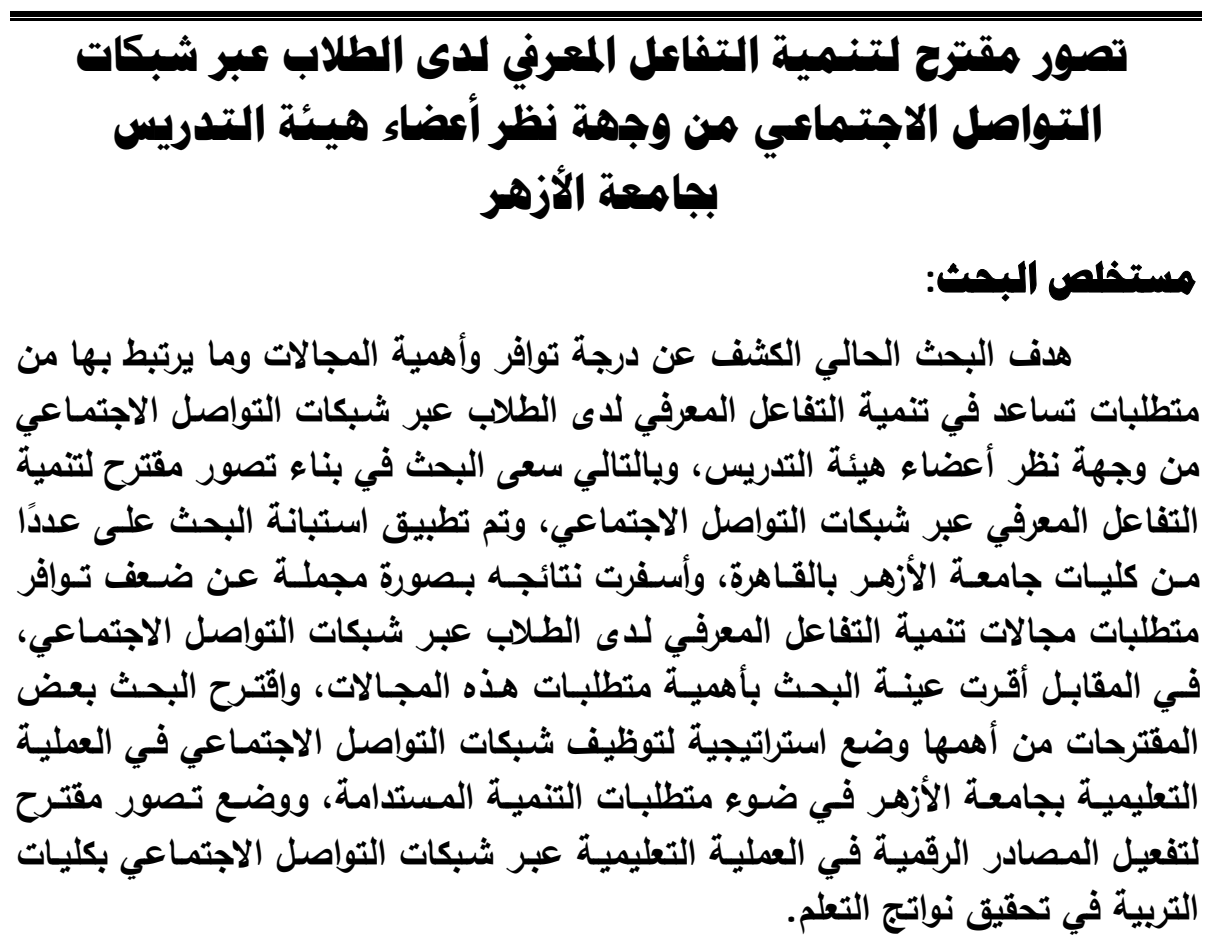

\title{
ABSTRACT
}

A Proposed Perspective for Developing Cognitive Interaction via Social Networks from the Viewpoints of the Faculty Staff Members at Al-Azhar University

BY:

Dr. Maha Mohammad Ahmad Mohammad Abdul-Kader

Associate Professor of Fundamentals Education, Faculty of Education for Girls (Cairo), Al-Azhar University

The current research aimed at uncovering the availability degree of the cognitive interaction development fields, their importance and the related requirements assisting in the development of such fields via the social networks from the viewpoints of the faculty staff members. Therefore, the present research aimed at developing a proposed perspective for developing the cognitive interaction via the social networks. A questionnaire was administered to the research participants at a number of faculties at Al-Azhar University. The overall results showed lack of the availability of the fields requirements of cognitive interaction development among the students through social networks. On the other hand, the research participants confirmed the importance of the requirements of such fields. The research recommended 
developing a strategy for employing social networks in the educational process at Al-Azhar University in the light of the requirements of the sustainable development and proposing a perspective for activating the digital resources in the educational process via the social networks at the faculties of education in order to achieve the best learning outcomes.

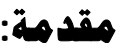

تعد مؤسسة الجامعة عنصراً فاعلاً وداعماً لمجتمع المعرفة؛ حيث تشكل مصدراً

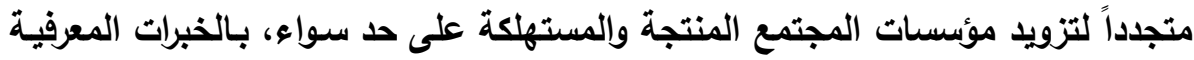

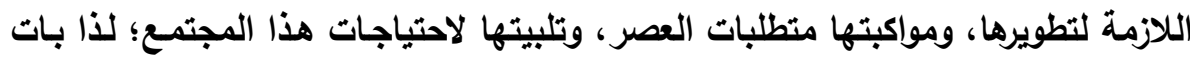

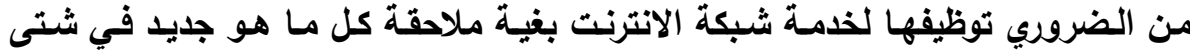

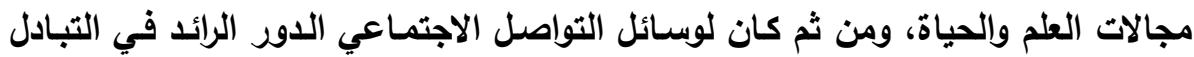

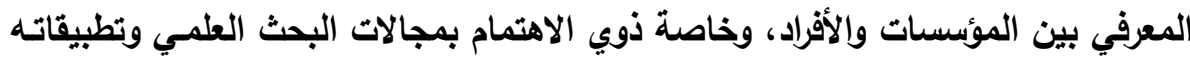

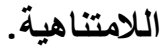

وحري بالذكر أن خدمة الانترنت انتشرت في العالم العريب، فقد كان لجمهوريـة

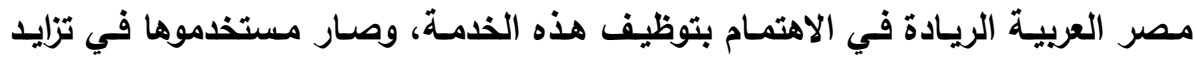

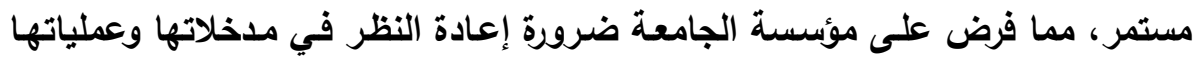

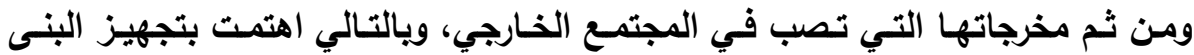

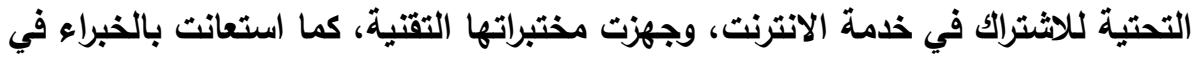

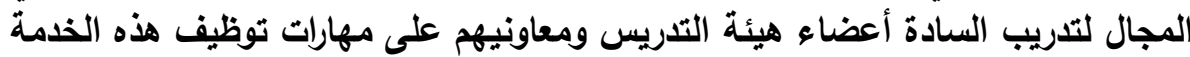

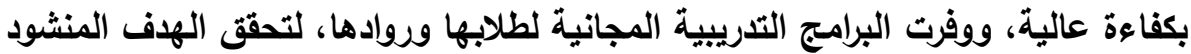

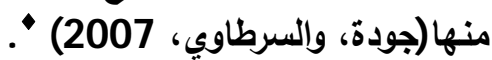

ونظراً لنجاح توظيف الانترنت في العملية التعليمية؛ حيث سمحت بمشاركة إدارة

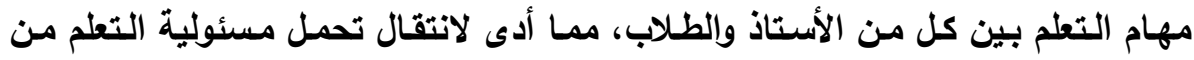

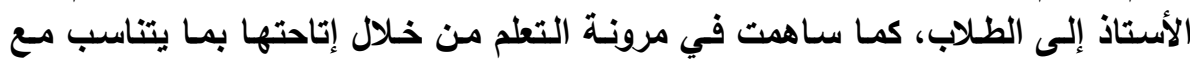

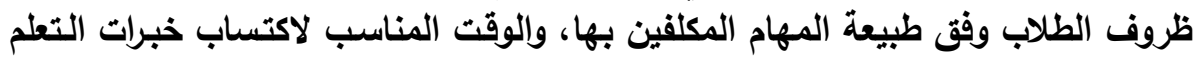

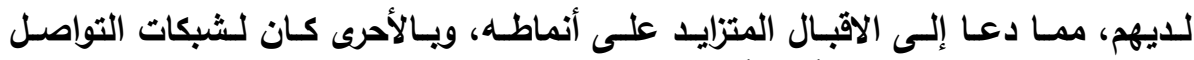

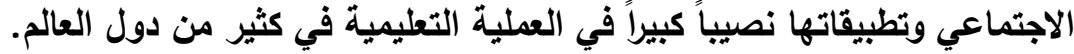

• اتبعت الباحثة في توثيقها للمراجع العربية والأجنبية (APA) الإصدار السادس للجمعية الأمريكية لعلم النفس American Psychological Association (APA $6{ }^{\text {th }}$ Edition) 
مجلة كلية التربية، جامعة الأزهر، العدد: (183، الجزء الثاني) يوليو لسنة 2019م

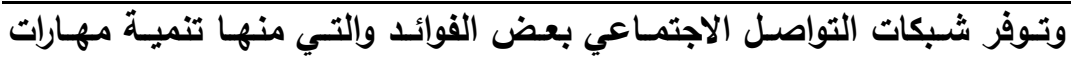

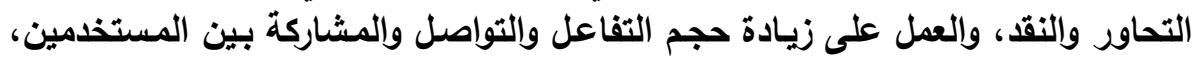

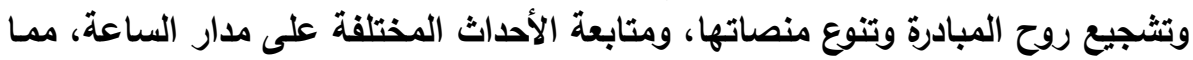

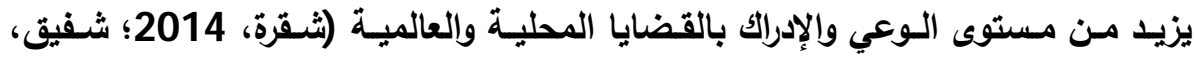

ويالتالي تعمل شبكات التواصل الاجتماعي على توطيد الصلة بين الطلاب بشكل

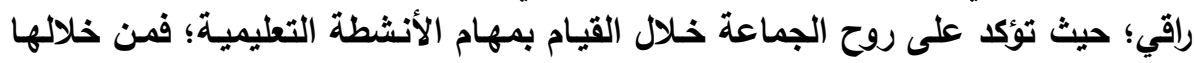

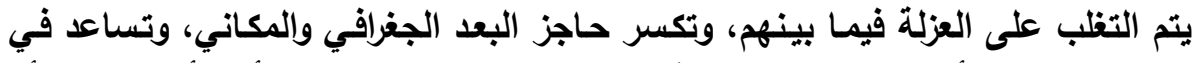

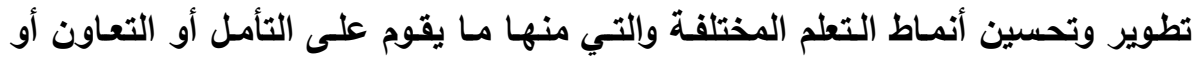

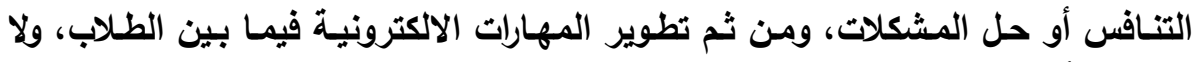

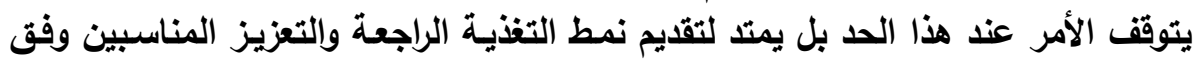

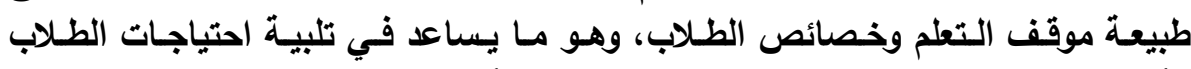

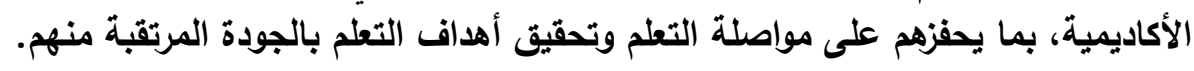

وطبيعة التعليم الجامعي تتطلب مواكبة احتياجات سوق العمل المتغيرة؛ إذ ينبغي

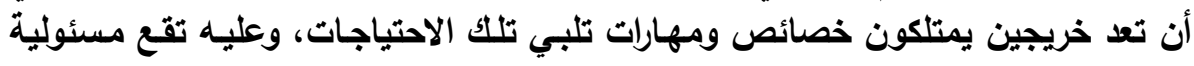

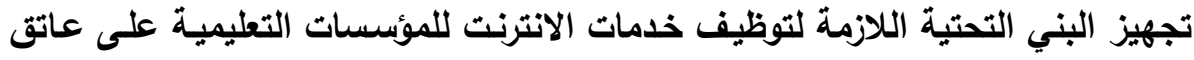

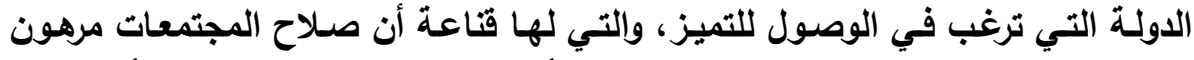

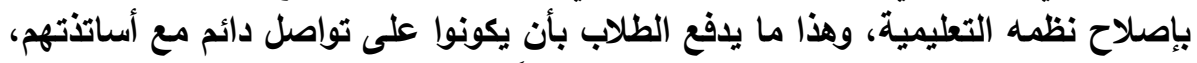

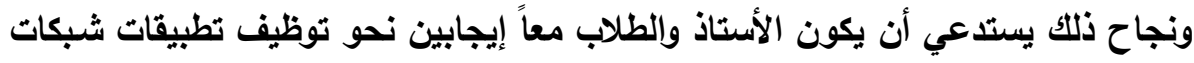

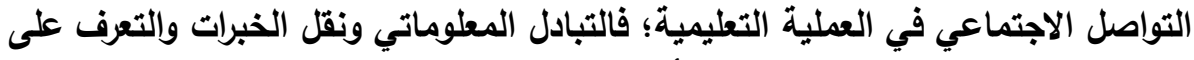

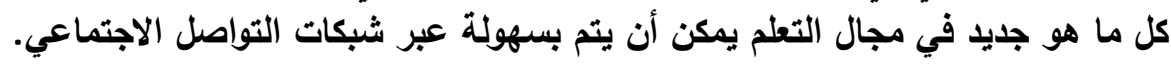

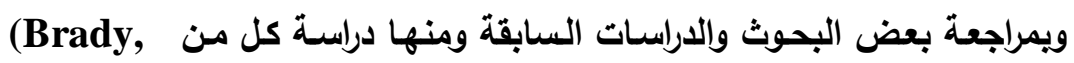

HolComb, \& Smith, 2010; Buzzetto- More, 2012; Corbeil, \& Corbeil, 2011; Dalsgaard, 2013; Farb. \& Pregibon, 2011; Miah, Omar, \& Golding, 2012; Munguatosha , Muyinda, \& Lubega, بوأن 2011; Panckhurst, 2013; Stanciu, Mihai, \& Aleca, 2012) بواسطة تصميم الأنشطة التعليميـة التي تستهدف تنميـة الابتكار بعد تعرف احتياجـات

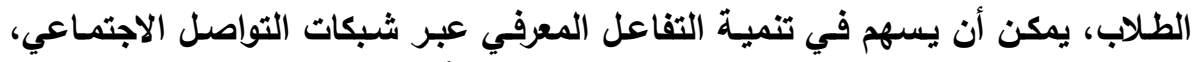

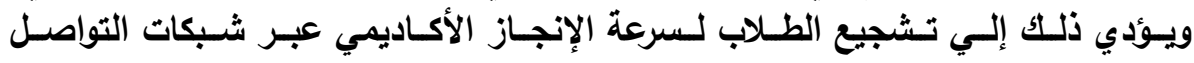
الاجتماعي، خاصة عند أداء مهام أنثطة التعلم الجماعية.

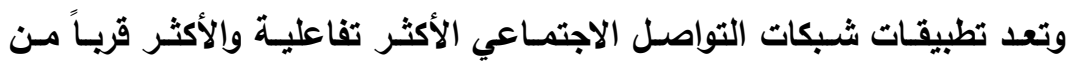

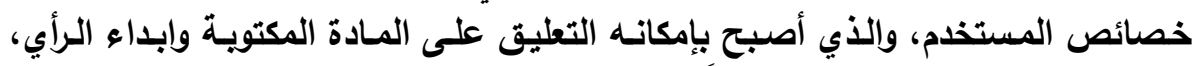
والإضافة إلى محتوى الصفحة وأيضاً التغيير في المحتوى التعليمي، وهذا ما يتيح التئي التفاعل 
مع الآخرين من خلال الأنشطة المختلفة من خلال المجموعات التي يمكن تكوينها داخل

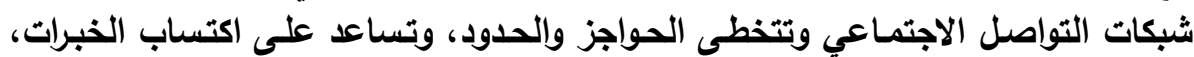

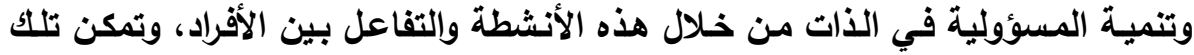

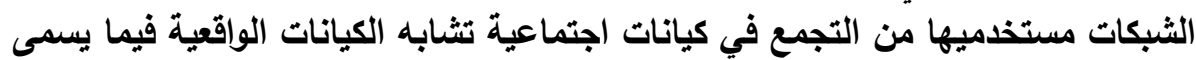

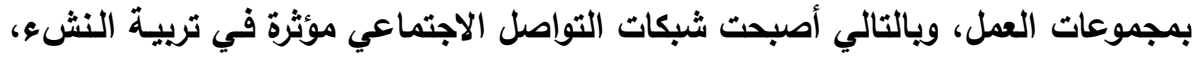

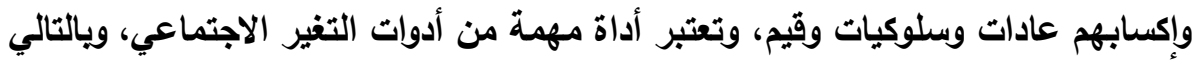

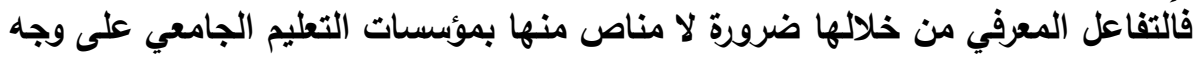
الخصوص (Richardson, 2007).

ويمكن تنمية التفاعل المعرفي بين مجموعات الطلاب من خلال ربط المستفيدين

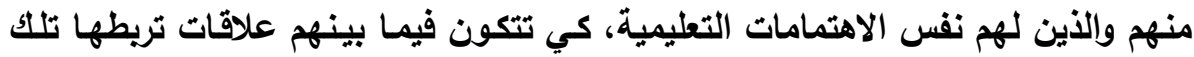

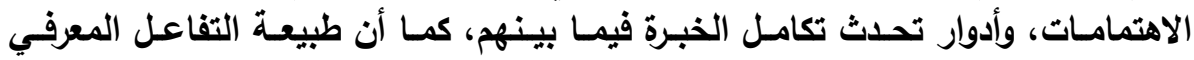

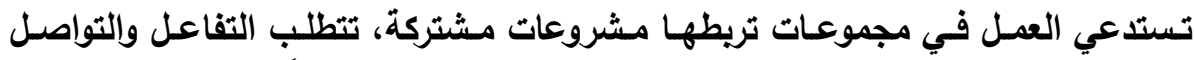

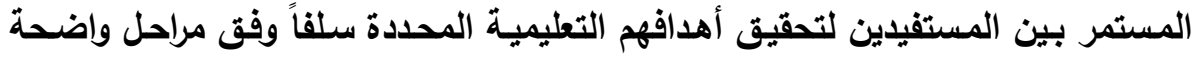

تحكمها التشاركية (Boulos Kamel, 2007).

والتفاعل المعرفي يدعم بقوة مجتمع المعلومات الذي يعتمد على استثمار التقنية

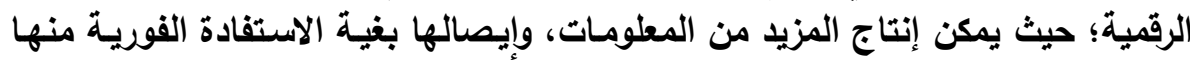

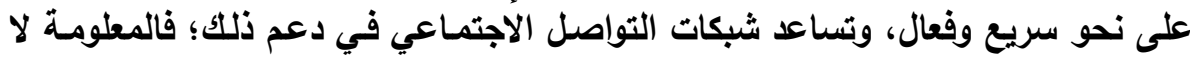

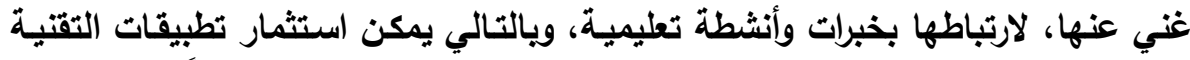

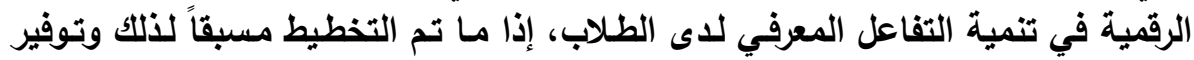
المنطلبات التي تدعم نجاحها في العملية التعليمية.

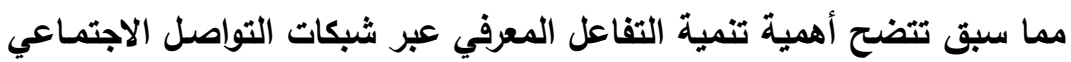

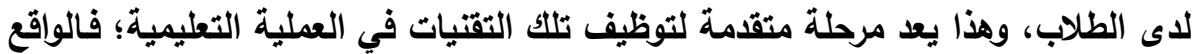

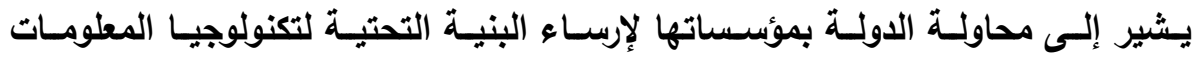

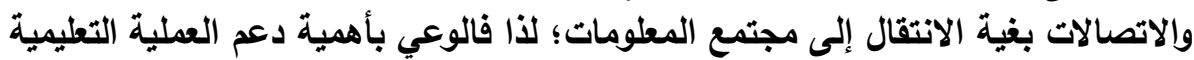

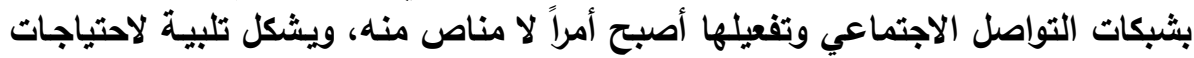
الطلاب التعليمية والنفسية.

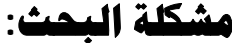

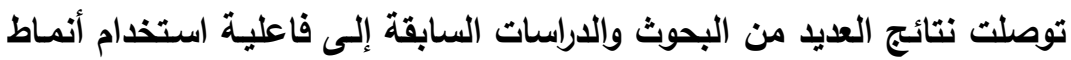

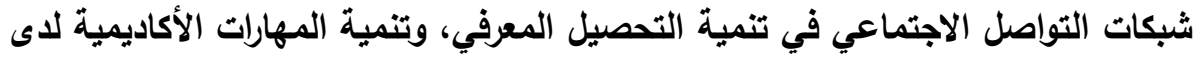

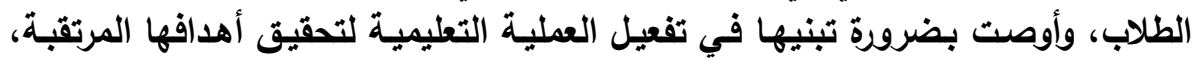

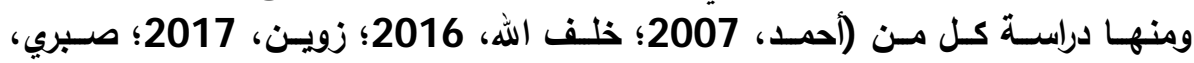


مجلة كلية التربية، جامعة الأزهر، العدد: (183، الجزء الثاني) يوليو لسنة 2019م

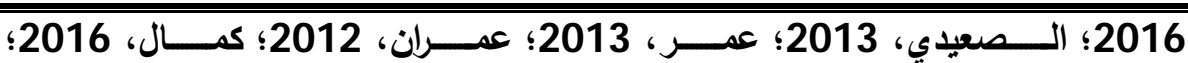

محمود،2012)

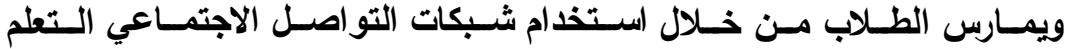

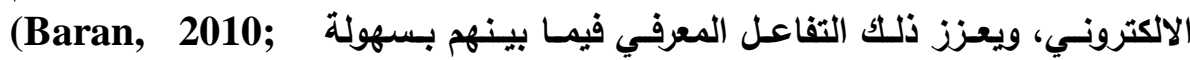
Roblyer, Mcdaniel, Webb, Herman \& Witty, 2010)

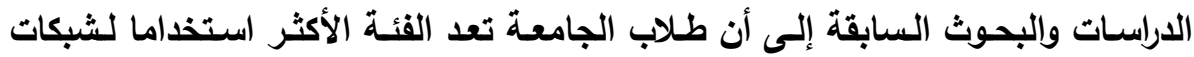

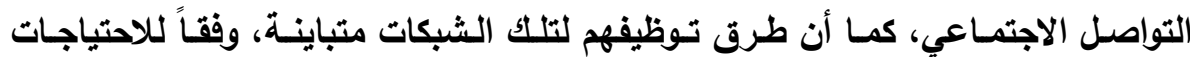
المتطلبة لايهم، وأوصت بأن يكون هناك ضوابط تعمل على تحقيق الاستفادة القصوى جراء التعامـل مـع شبكات التواصل الاجتمـاعي (Corbeil, \& Corbeil, 2013; Gulbahar, 2013; Judd,. \& Johnston, 2012; Kuppuswamy, 2010; lego- Munoz, \& towner, 2009; Ophus, J. D. \& Abbitt, 2009)

وفي البيئة العربية أظهرت نتائج دراسـة (السدحان، 2015) أن استخدام أفراد

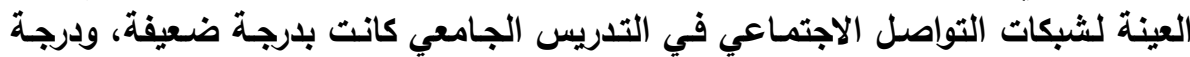

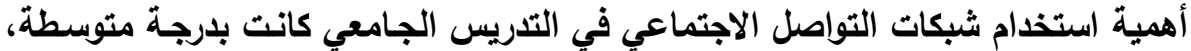

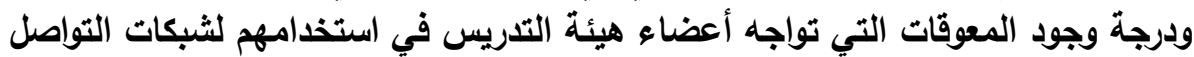

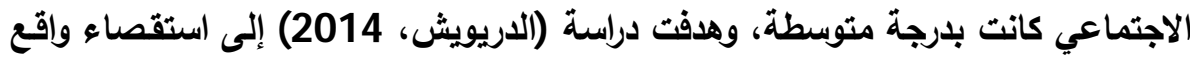

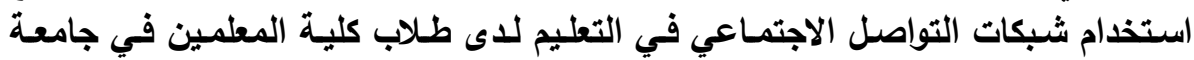

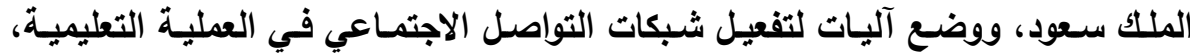

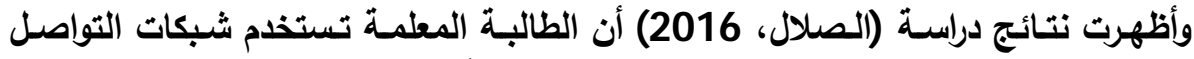

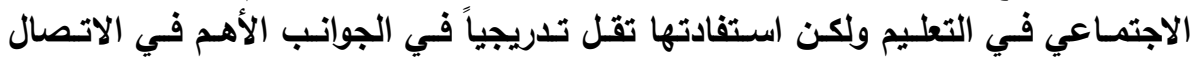

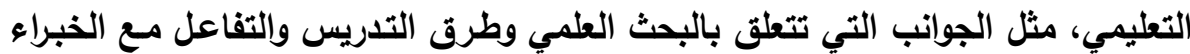

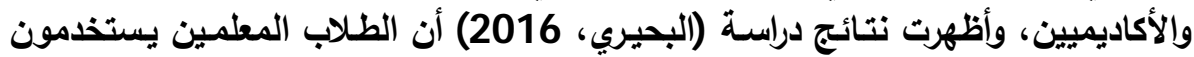

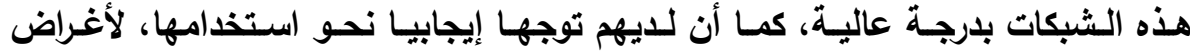

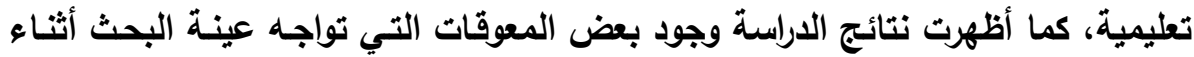

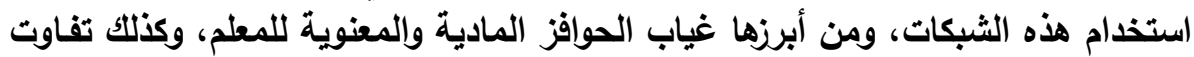

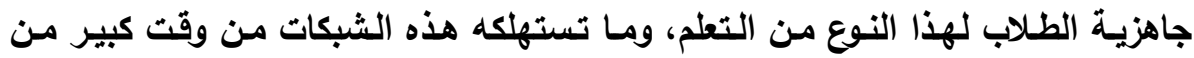
الطرفين (المعلم والطالب).

وفي البيئة المصرية فقد أثارت نتائج دراسة عبد الحي (2013) إلى أن طلاب

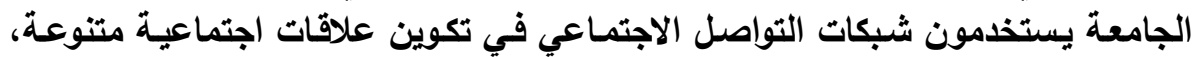

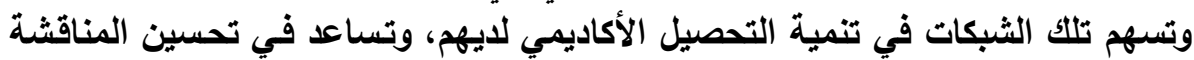

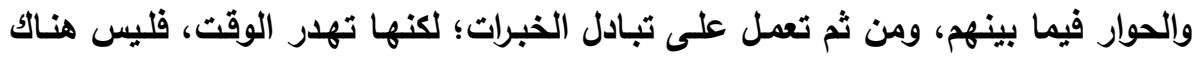

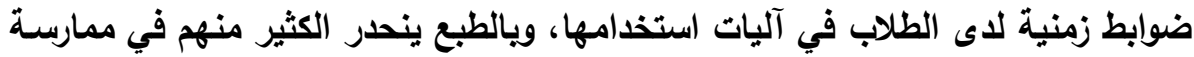

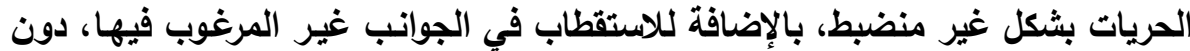


تثكيل للوعي الصحيح لمجريات الأحداث، وهدفت دراسـة (إبراهيم، 2016) إلى الكشف

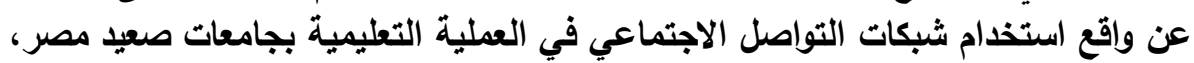

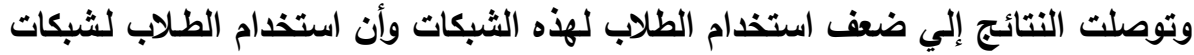

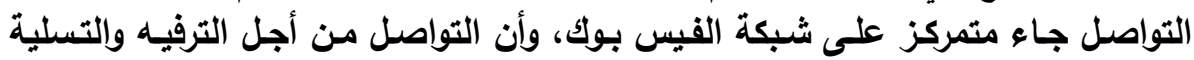

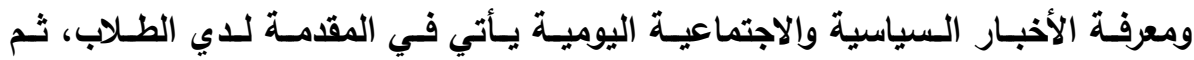

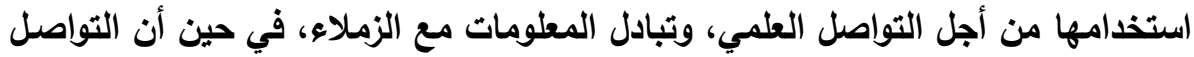

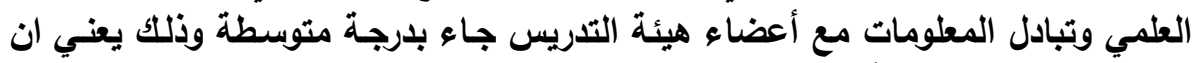

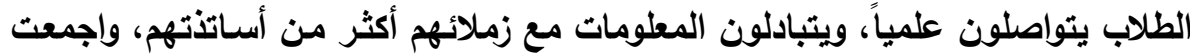

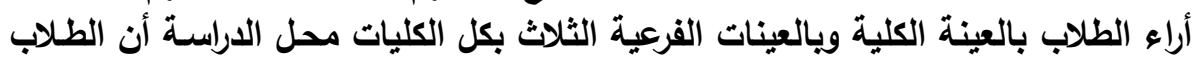

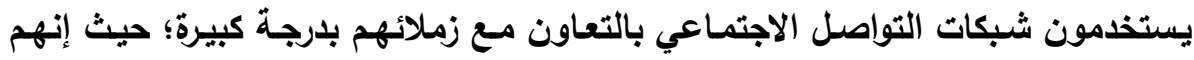

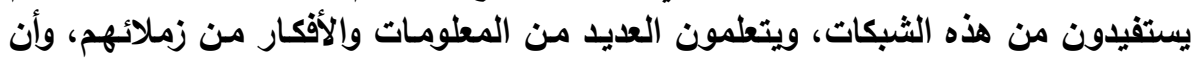

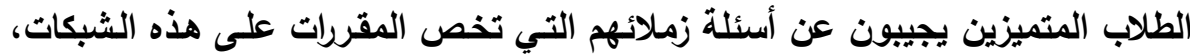

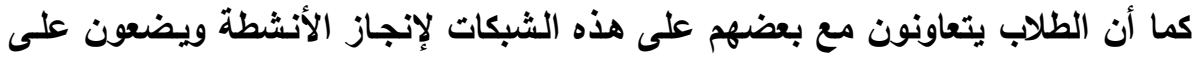

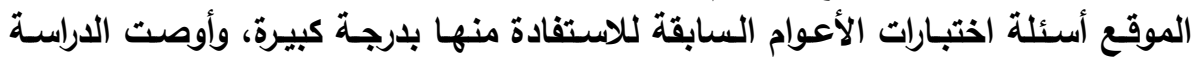

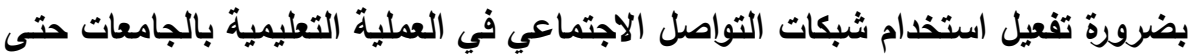
يعود عليها بالفائدة العلمية.

لكن الواقع الحالي يشير إلى أن آليات الاستفادة من شبكات التواصل الاجتماعي

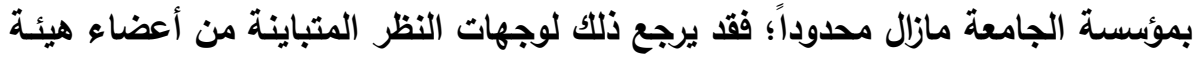

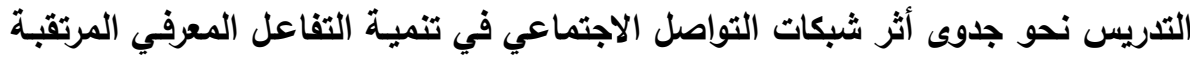

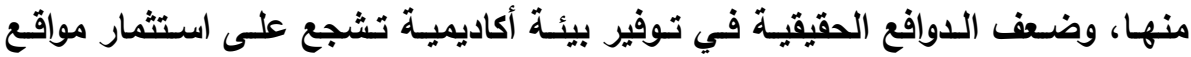

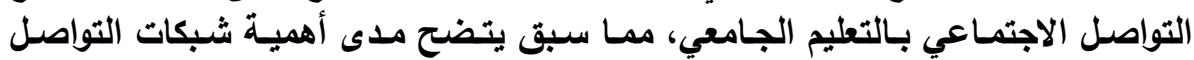

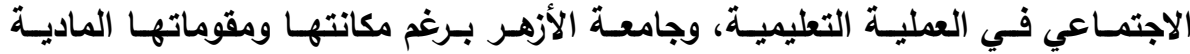

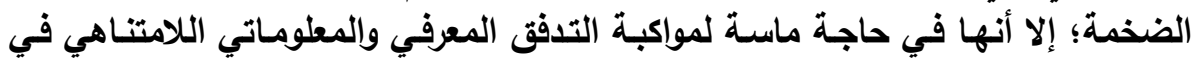

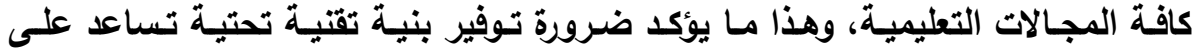
استثمار شبكات التواصل الاجتماعي في تحقيق أهدافها.

ويالرجوع إلى الذطة الاستراتيجية لجامعة الأزهر (2018 -2022) والتي تشير

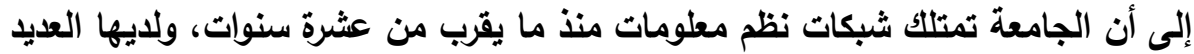

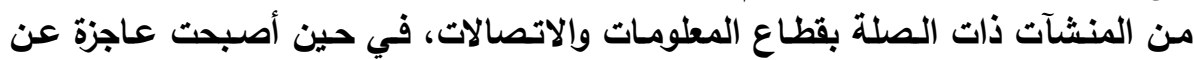

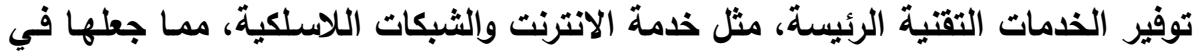

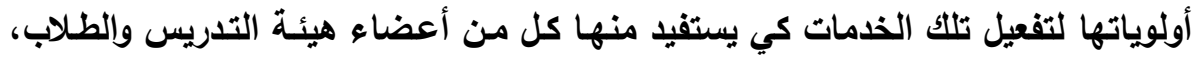

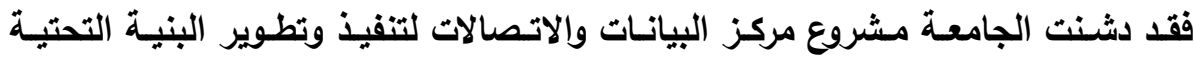
الأساسية لشبكة المعلومات (الألياف الضوئية) لنقل البيانات عبر خطوط سريعة وآمنـة، 
مجلة كلية التربية، جامعة الأزهر، العدد: (183، الجزء الثاني) يوليو لسنة 2019م

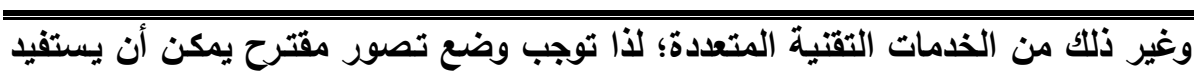

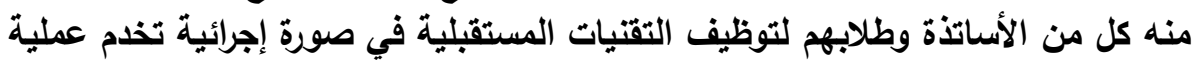

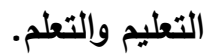

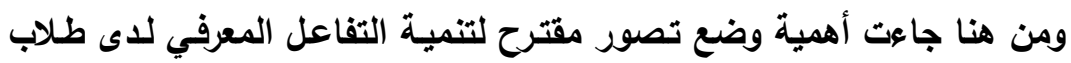

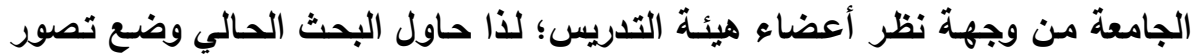

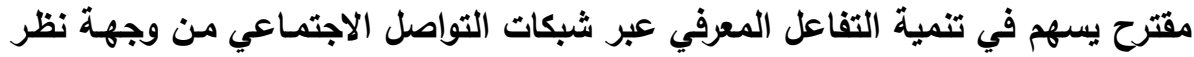

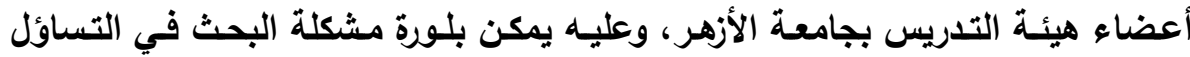

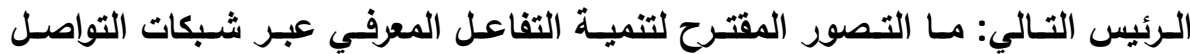
الاجتماعي من وجهة نظر أعضاء هيئة التدريس بجامعة الأزهر؟، ويتفرع منـه التساؤلات

1) ما الإطار المفاهيمي للتفاعل المعرفي عبر شبكات التواصل الاجتماعي؟

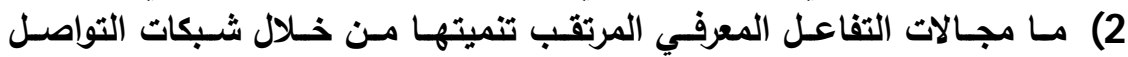
الاجتماعي من وجهة نظر أعضاء هيئة التدريس بجامعة التهاعة الأزهر؟

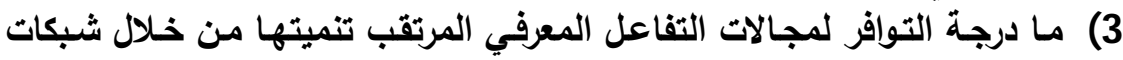

التواصل الاجتماعي من وجهة نظر أعضاء هيئة التدريس بجامعة الأزهر؟

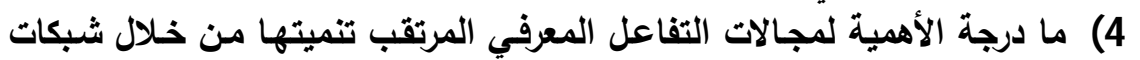

التواصل الاجتماعي من وجهة نظر أعضاء هيئة التدريس بجامعة الأبة الأزهر؟

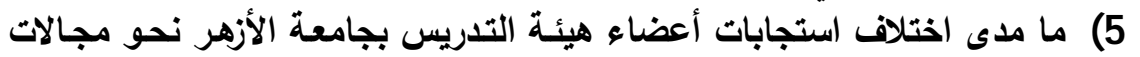

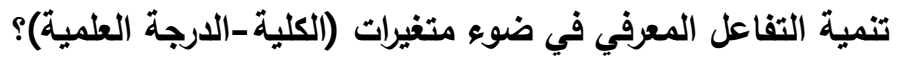
6) ما آليات التصور المقترح الذي قـ يسهم في تنمية التفاعل المعرفي عبر شبكات

التواصل الاجتماعي من وجهة نظر أعضاء هيئة التدريس بجامعة الأزهر؟

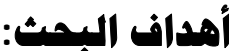

وضع إطار مفاهيمي يتناول تنمية التفاعل المعرفي عبر شبكات التواصل

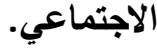

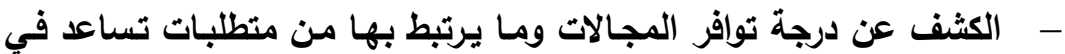

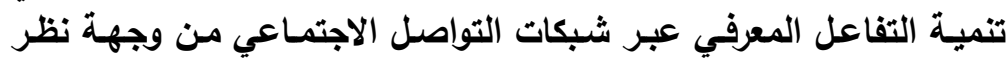
أعضاء هيئة التدريس.

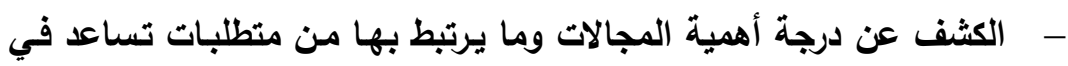

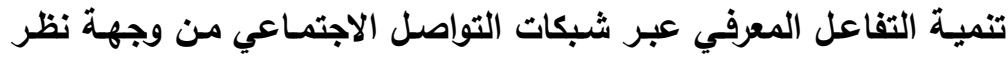
أعضاء هيئة التدريس. 


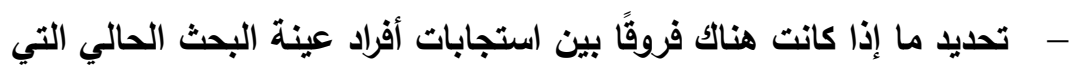

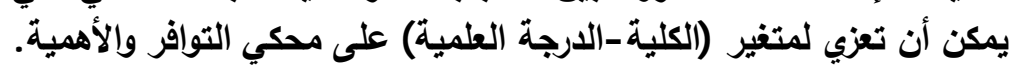

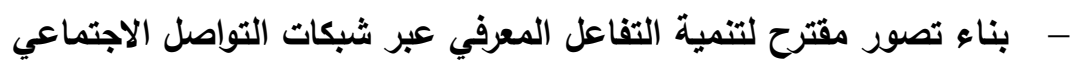

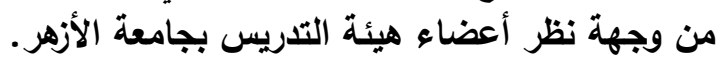

\section{أهمية البهث:}

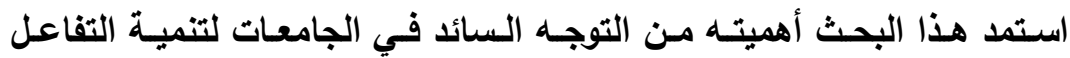

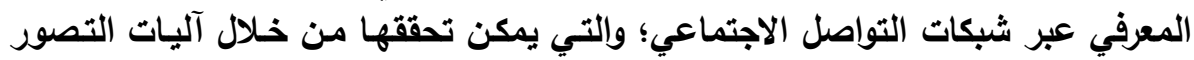

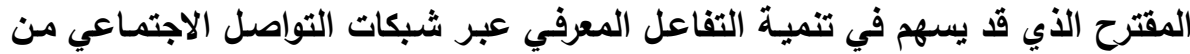

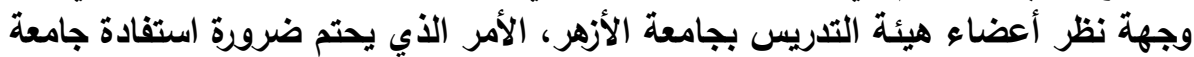

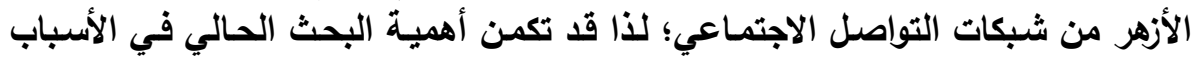

- - تناول البحث لمتغيرات جديدة، لم يسبق تناولها في البيئة العربية، خاصة تنمية

$$
\text { التفاعل المعرفي لاى طلاب الجامعة. }
$$

- - طبيعـة التعليم الجـامعي الأزهري والذي يسعى إلى بنـاء مجتمـع يمتلك أبنـاؤه

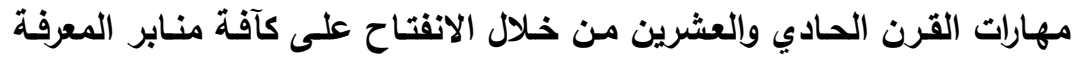

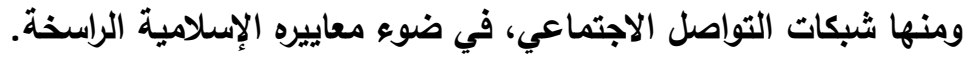

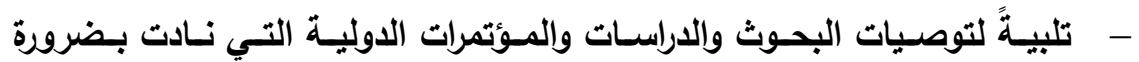

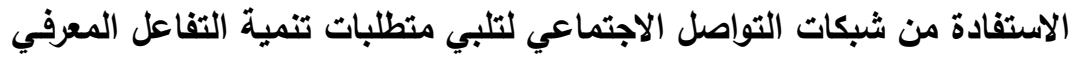
المرتبطة بمجالات العملية التعليمية.

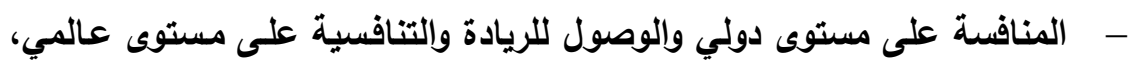

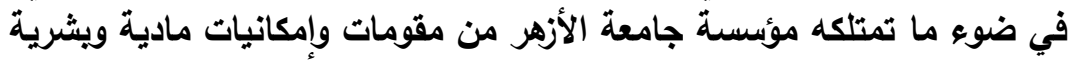

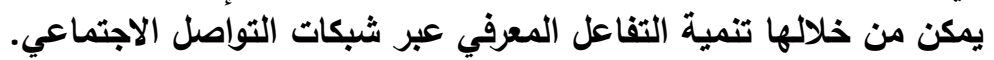
- - الوقوف على مجـالات التفاعل المعرفي المرتقب تنميتهـا مسن خـلال شـبكات

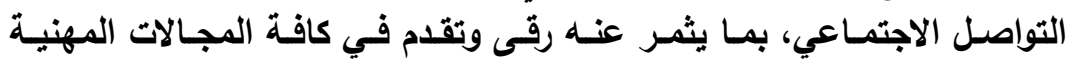

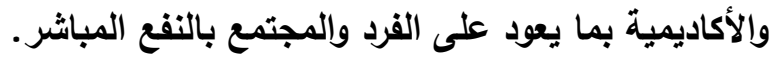
- الوصول لتصور متكامل لمتطلبات تنمية التفاعل المعرفي عبر شبكات التواصل

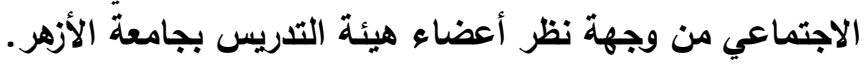


مجلة كلية التربية، جامعة الأزهر، العدد: (183، الجزء الثاني) يوليو لسنة 2019م

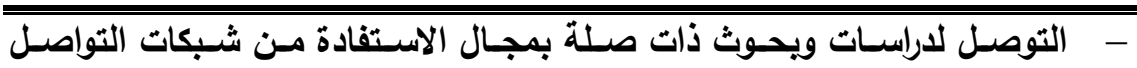

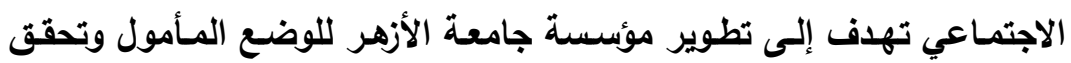

رويتها ورسالتها.

منهفة البمث:

إن طبيعة البحث هو الذي يفرض المنهج الذي يتلاوم معه وميع أهدافه، ولأن

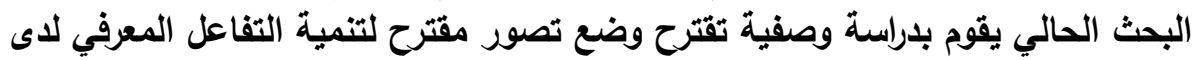

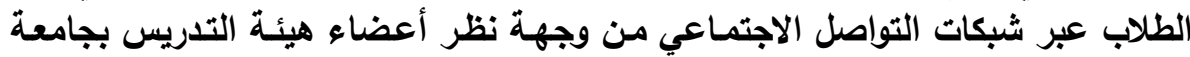

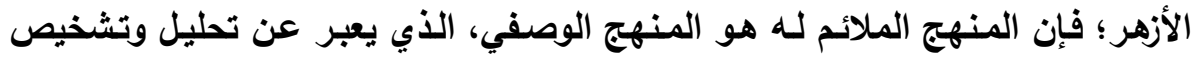

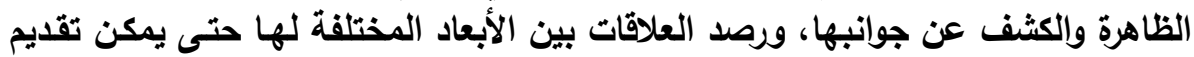

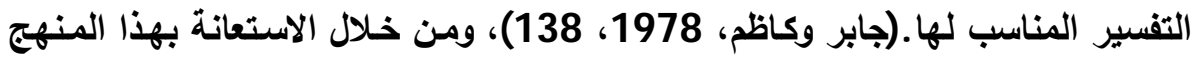

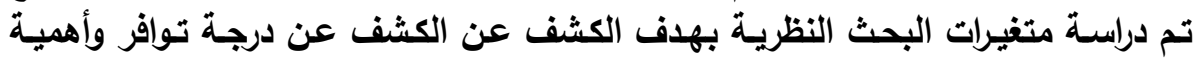

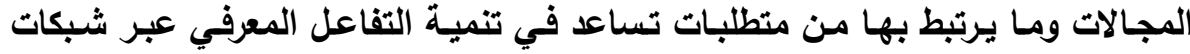

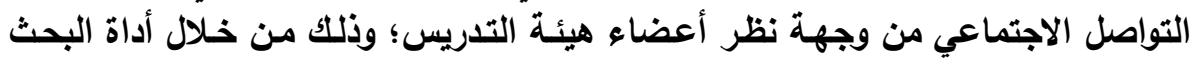

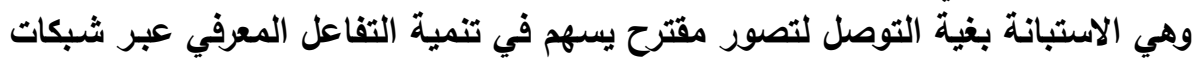
التواصل الاجتماعي من وجهة نظر أعضاء هيئة التدريس بجامعة الأزهر .

\section{هدود البمث:}

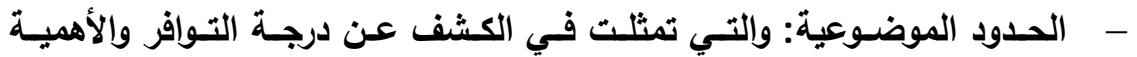

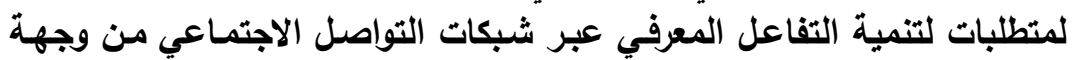
نظر أعضاء هيئة التدريس بجامعة الأزهر والتي اقتصرت على التهات (التخطيط لتحديد

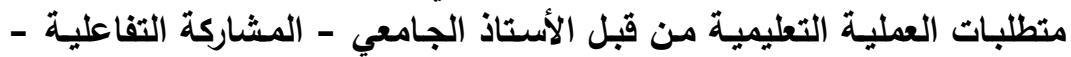

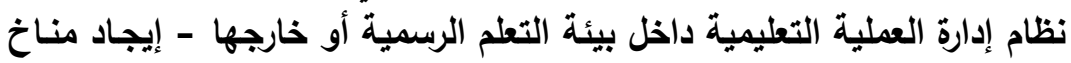

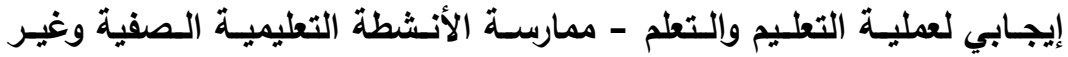

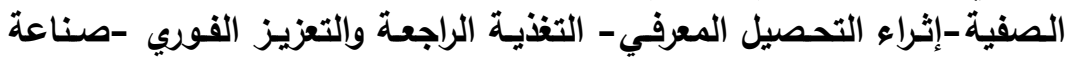

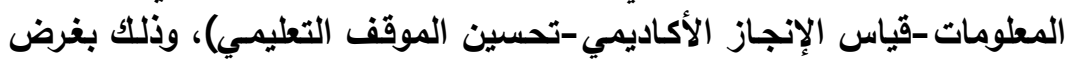

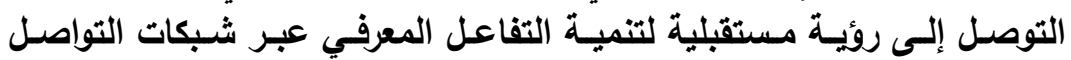

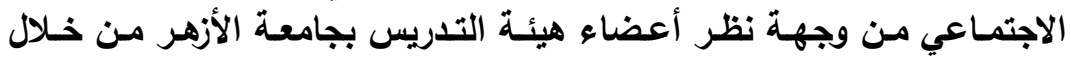

التصور المقترح.

- - الحدود المكانية: تم تطبيق استبانة البحث على عددًا من كليات جامعة الأزهر

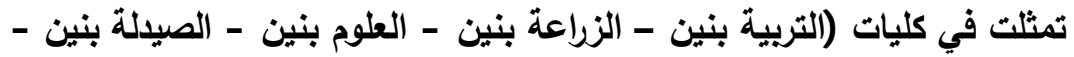

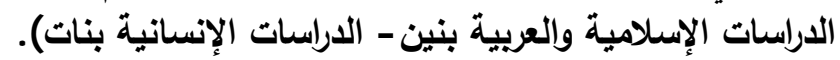




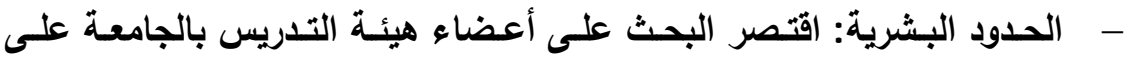
اختلاف درجاتهم العلمية (مدرس - أستاذ مساعد - أستاذ).

\section{الماهييم الأساسية للبمث:}

تتحدد مصطلحات البحث الحالي في متغيراته، والتي تمثلت في مفهومي التفاعل

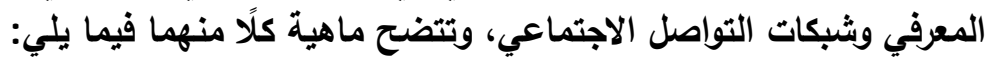

Developing Cognitive Interaction تنمية التفاعل المعرفي

المشاركة في تشكيل البنى المعرفيـة لدى الطلاب، والمرتبطة بمجالات التعلم

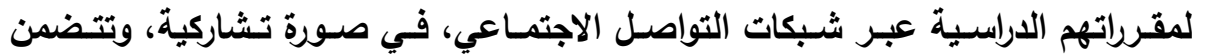

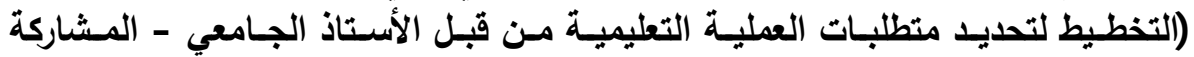

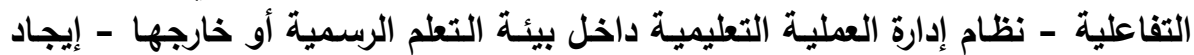

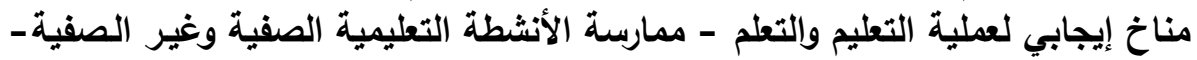

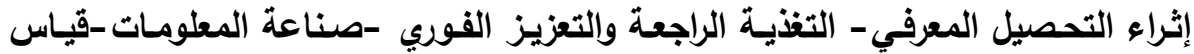

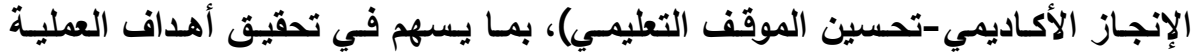

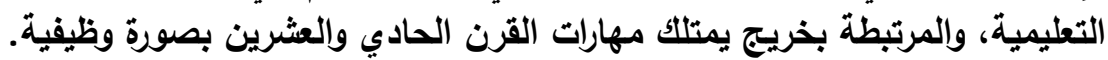

\section{Social Network شبكات التواصل الاجتماعي}

صفحات تفاعلية رقمية تعتمد على ما تقدمه من خدمات، ومـا تسمح بـه للأفراد

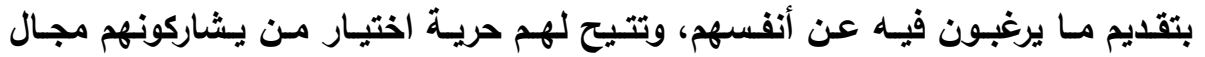

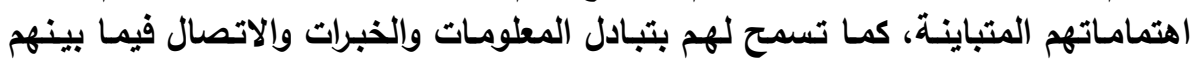

بأثكال متعددة (Lianghuan Liu, Long Wang Feng Fu, 2008)

كما تعرف بأنها مواقع أو تطبيقات مخصصة لإتاحة القدرة للمستخدمين للتواصل

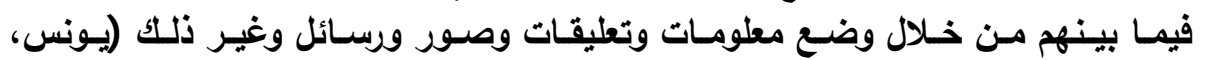

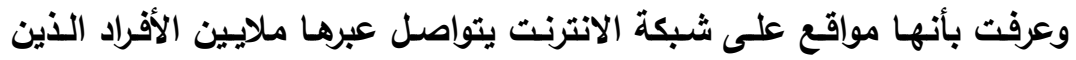

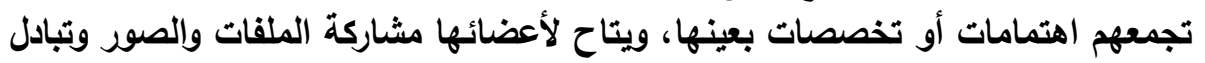

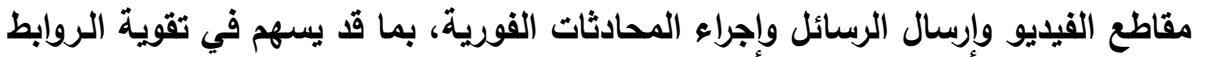
بين أعضائها من خلال فضاء الأنترنت (عمر، 2013)

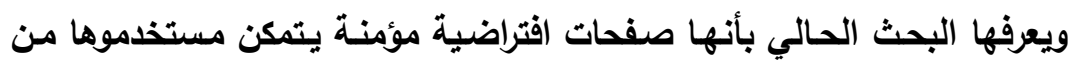
التواصل بواسطة أدوات متنوعة للتفاعل المعرفي فيما بينهم بصورة وظيفية، ينجزون من من فئن 
مجلة كلية التربية، جامعة الأزهر، العدد: (183، الجزء الثاني) يوليو لسنة 2019م

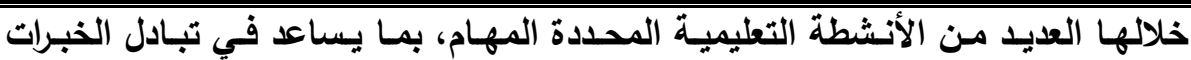
واكتساب الجديد منها بواسطة طرح الأفكار ومناقشتها بينهم.

\section{الإطار النظري والدراسات السابقة ذات الصلة بمتغيرات البحث:}

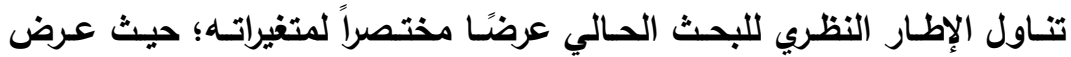

لخصائص شبكات التواصل الاجتماعي في العملية التعليمية، ومن ثم للأسـاس القلسفي

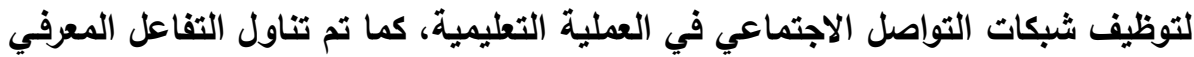

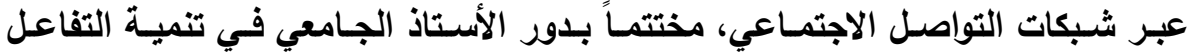

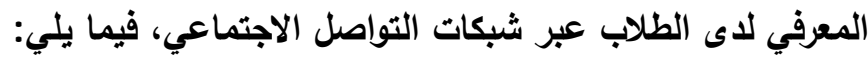

\section{خصائص شبكات التواصل الاجتماعي في العملية التعليمية:}

تنفرد شبكات التواصل الاجتماعي بخصائص مشتركة برغم من تنوعها؛ فنجد أن

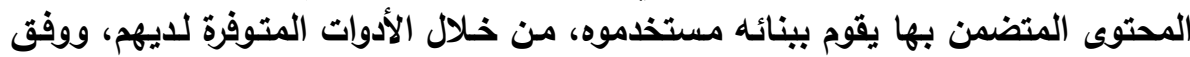

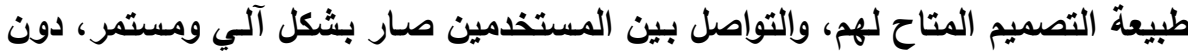

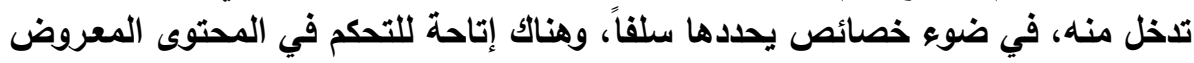

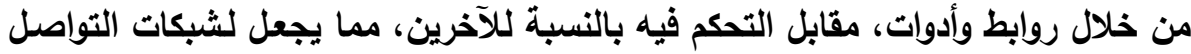

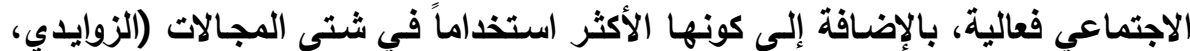

وللتعلم عبر شبكات التواصل الاجتمـاعي خصائص تكمن في التفاعليـة، والتتي

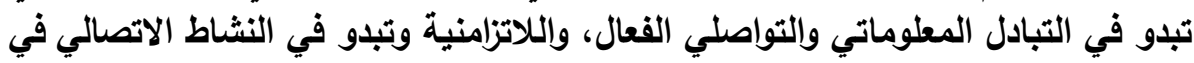
الوقت المناسب للفرد أو المجموعة، والشيوع والانتشار بين الطلاب، والقابلية للتحويل

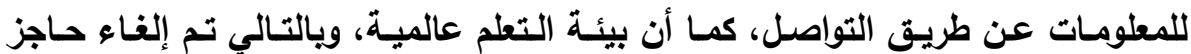

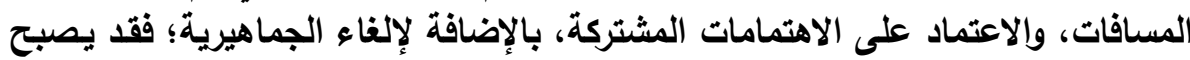
التواصل بين أفراد أو مجموعات فقط ) (Manca,2014; Bissessar, 2014)

وتعمل شبكات التواصـل الاجتمـاعي على تحقيـق المتعـة في العمليـة التعليميـة

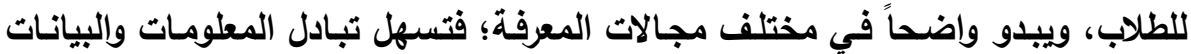
وتمكن من الوصول إليها بطرق متنوعة تتسم بالجاذبية والسرعة، ولا تكلف الطلاب جهات فئاً

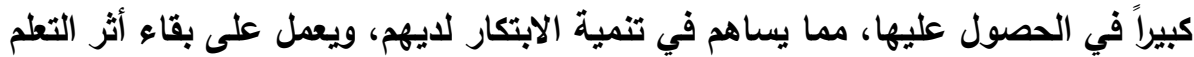

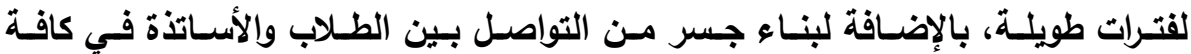

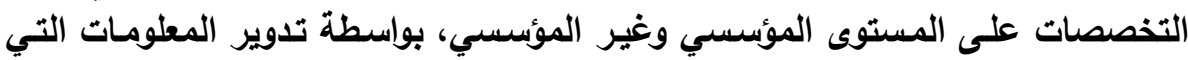
تساعد في تحقيق مهام أنثطة التعلم وأهدافه المرتقبة.

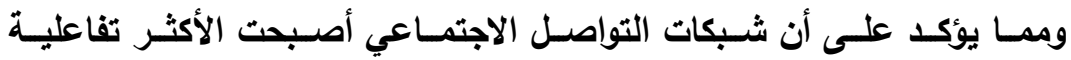

واستخداماً، إتاحتها إمكانية تبادل الآراء والخبرات، مما أدى لتكوين جماعات نشئ ألثة مهتمة 
بمجالات بعينها، تتخطي من خلالها حواجز الزمان والمكان، وتتحمل مسئولياتها في ضوء

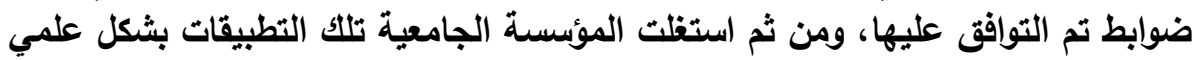

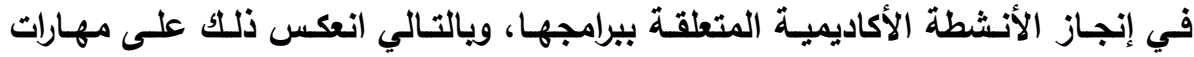

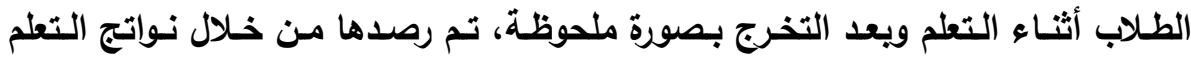

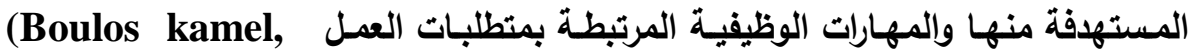

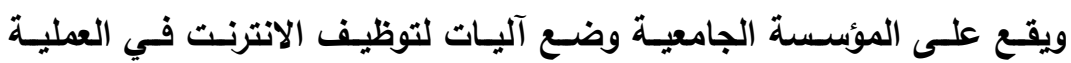

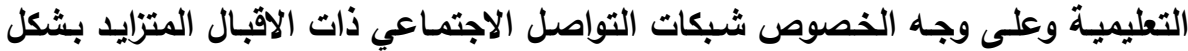

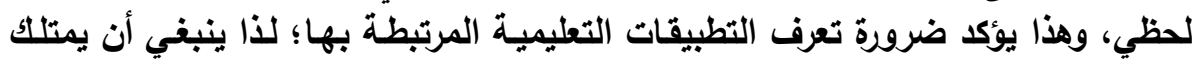

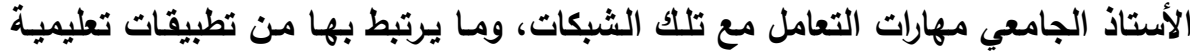

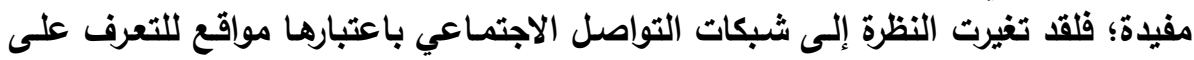

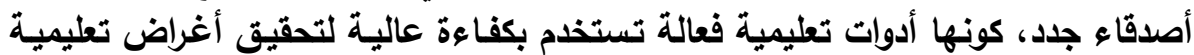

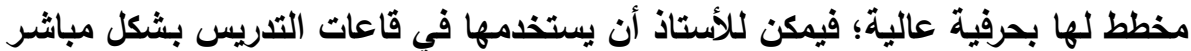

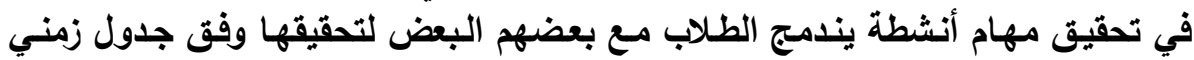

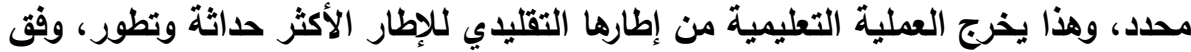

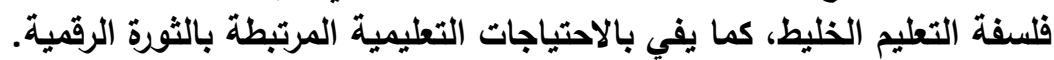

وفي ذات السياق فقد أوصت البحوث والدراسات السابقة بضرورة توظيف شبكات

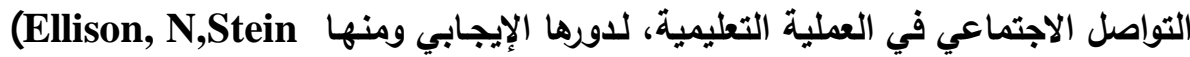
Field, C Lampe, C, 2007 ; Arqcuero , J. L. \& Romero, E. 2011; Gulbahar, Y. 2013)

وعليه تتعدد خصائص شبكات التواصل الاجتماعي في العملية التعليمية، كونها

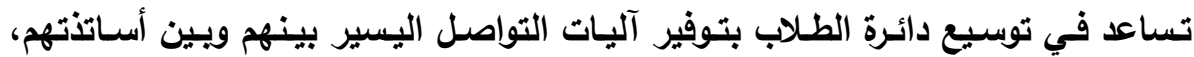

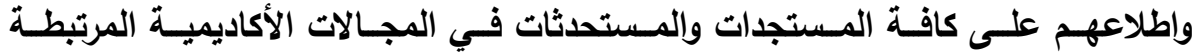

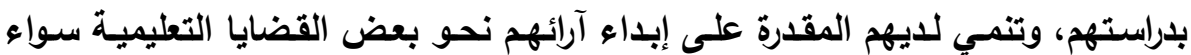

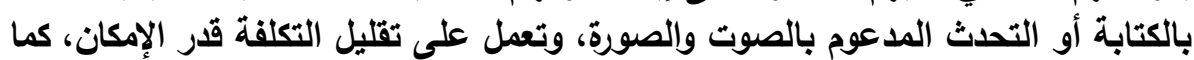

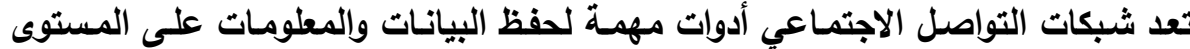

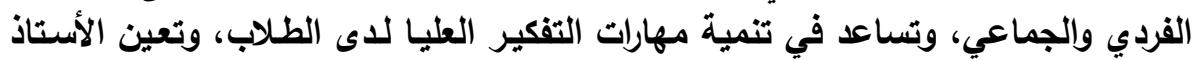

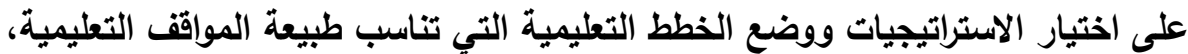
بالإضافة إلى تبادل الخبرات على المستويين الداخلي والخارجي للمؤسسات الجامعية. 
الأساس الفلسفي لتوظيف شبكات التواصل الاجتماعي في العملية التعليسية:

يقوم استخدام شبكات التواصل الاجتماعي في التعليم على نظرية الدوافع، وتلبية

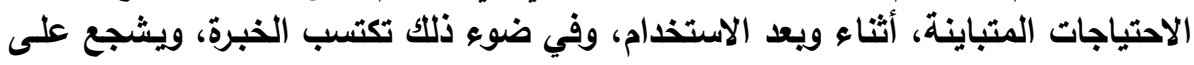

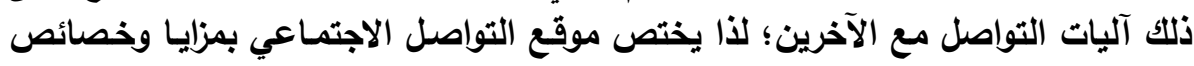

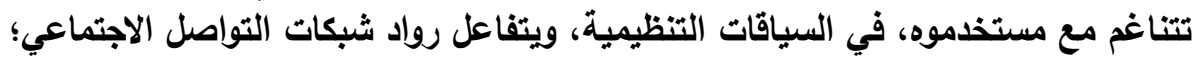

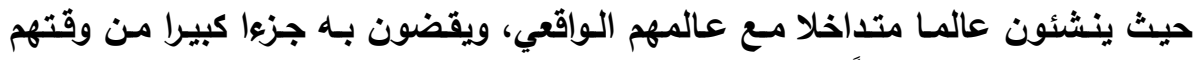

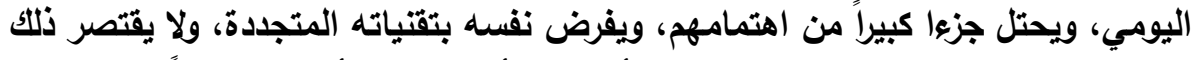

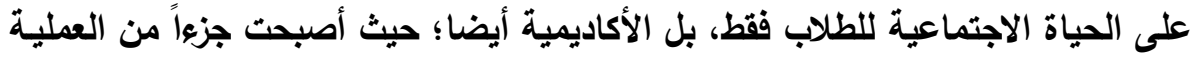

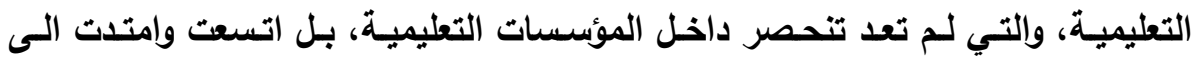

خارجها (Bicena, H. \& Cavus, N., 2011).

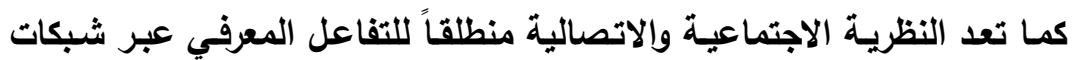

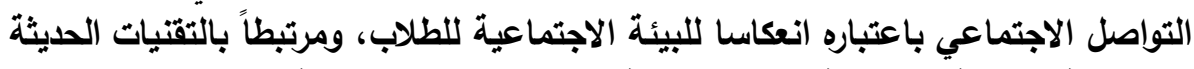

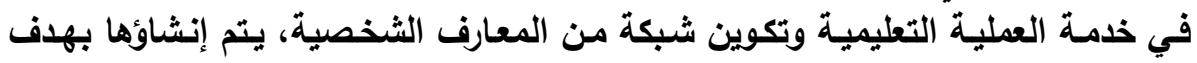

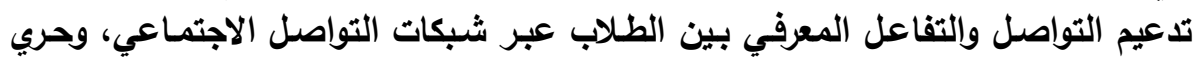

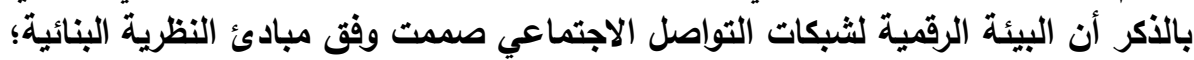

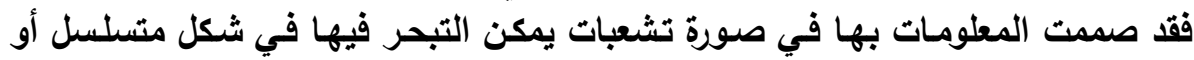

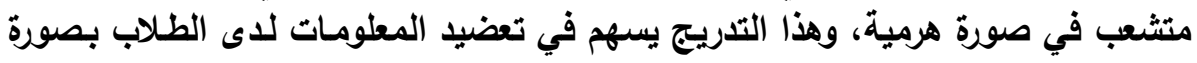

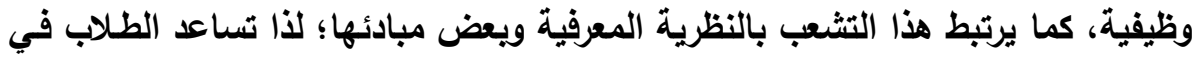

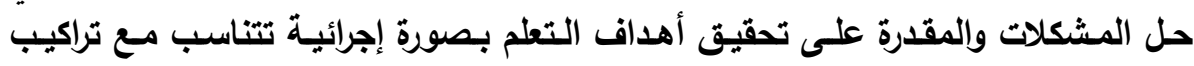

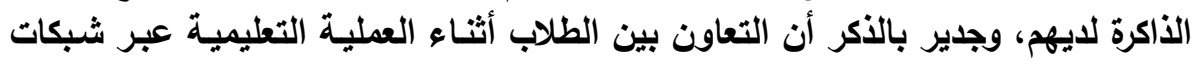

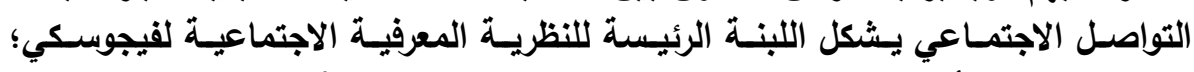

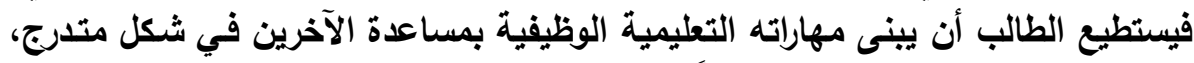

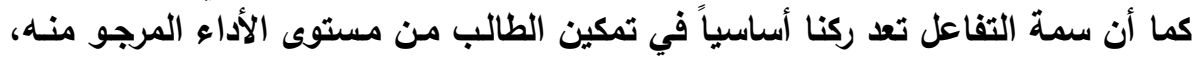

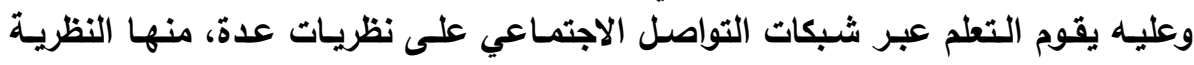

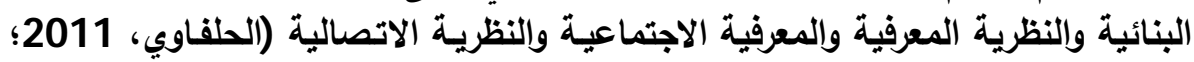
حمد الله، 2017؛ شقرة، 2014) .

\section{التفاعل المعرفي عبر شبكات التواصل الاجتماعي:}

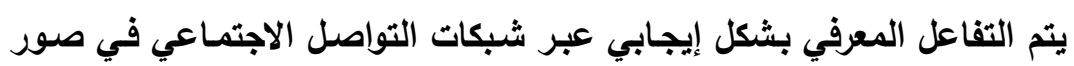

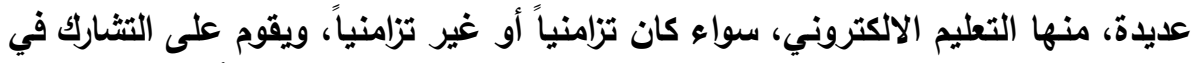

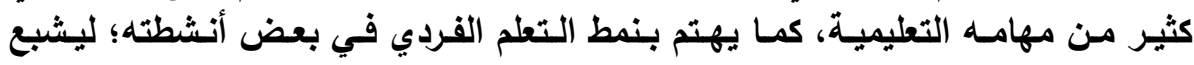

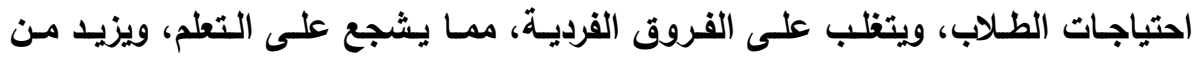
الإنجاز الأكاديمي، ويعمل على توسيع أفقى التفكير لاى الطلاب الفيل (الحلفاوي، 2011). 
وينشأ التفاعل المعرفي عبر شبكات التواصل الاجتماعي في ضوء مبدأ المشاركة

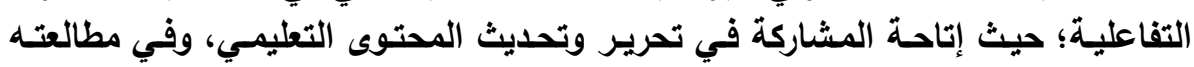

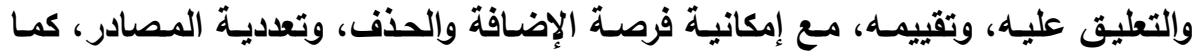

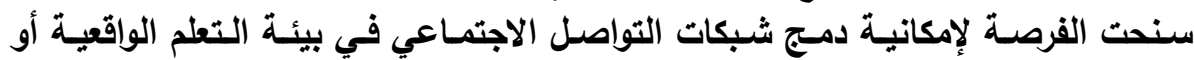

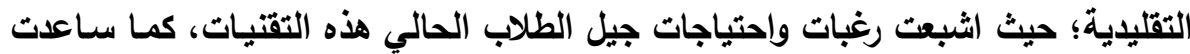

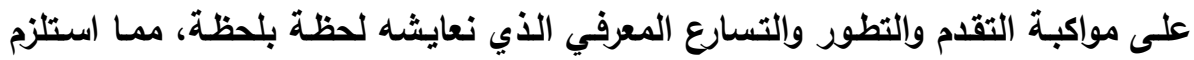
ضرورة الاستفادة القصوى من كافة شبكات التواصل والته الاجتماعي بشكل وظيفي (عماشـة، 2011؛ عبد الحافظ، 2012).

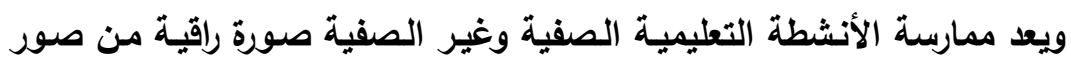

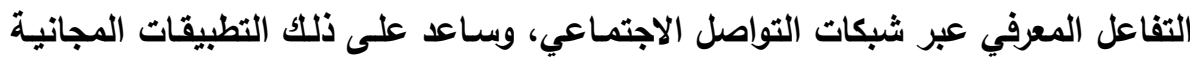

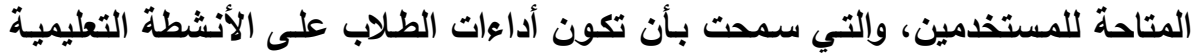

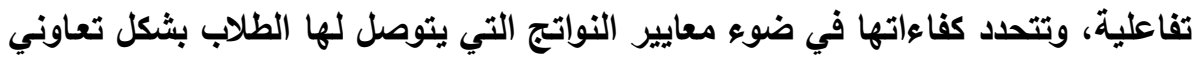

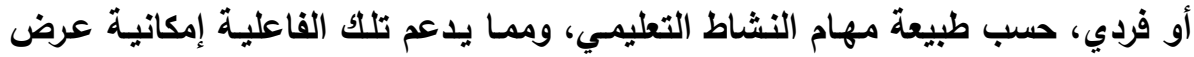

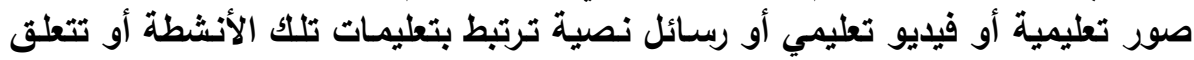

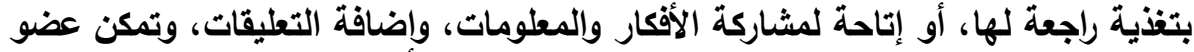

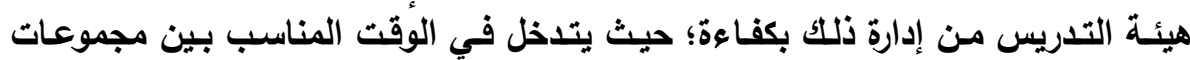

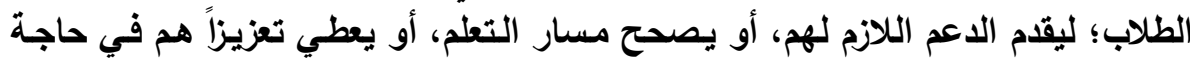

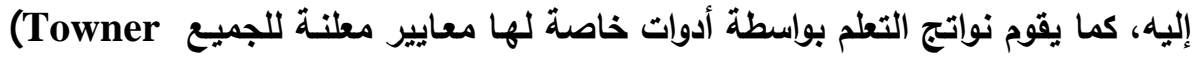
.and Munoz, 2009)

وتعد شبكات التواصل الاجتمـاعي مصدراً لا ينضب مـن المعلومـات المتجدادة

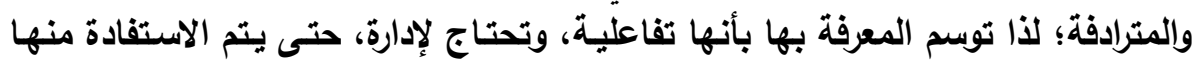

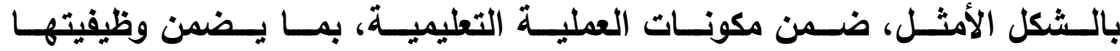
(Bandyopadhyay, Shaw, Banerjee, and, nag, 2013; Charoensukmongkol, and Sasatanum, 2017)

وتتعدد الخصائص التعليمية المميزة لشبكات التواصل الاجتماعي؛ حيث إن بيئة

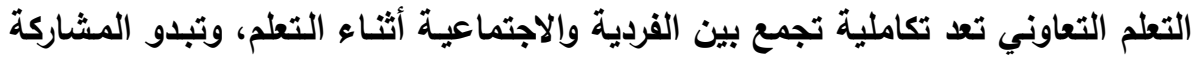

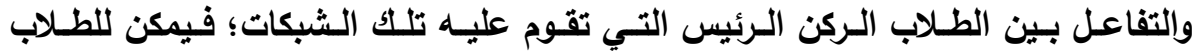

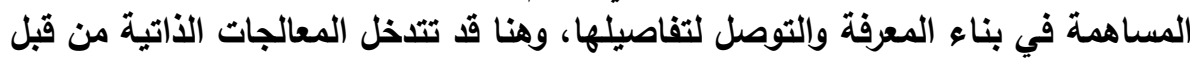
الطلاب من خلال الحوار والمناقشة التي قد ينتج عنها خبرة جديدة، ويالتالي تنمو لدايهم

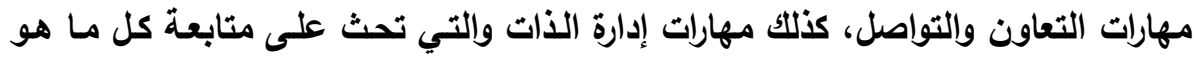

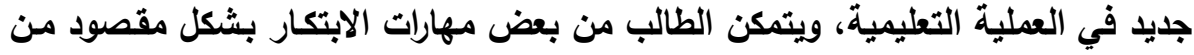


مجلة كلية التربية، جامعة الأزهر، العدد: (183، الجزء الثاني) يوليو لسنة 2019م

خلال مهام الأنشطة التي يؤديها عبر شبكات التواصل الاجتماعي(إبراهيم، 2014، 2014؛ أبو الأبر التردئ درب، 2014؛ البحيري، 2016)

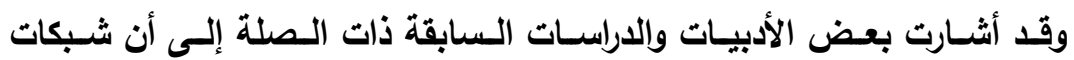

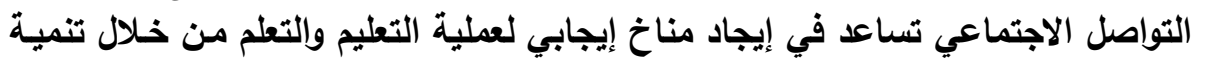

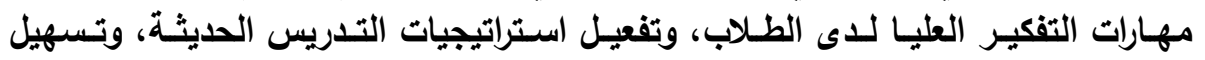

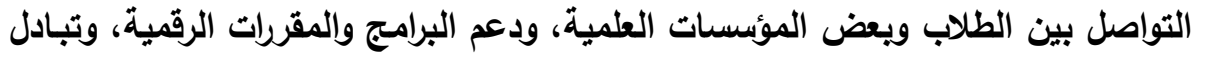

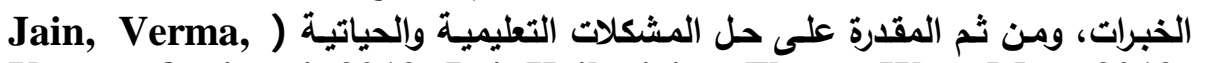
Verma, \&taiwari, 2012; Lei, Krilavicius, Zhang, Wan, Man, 2012; Ractham, Fi rpo, 2011; ZaidiehJ. 2012; Zanamwe, Rupere, \& Kuf, 2013)

كما توصلت نتائج البحوث والدراسات السابقة إلى أن شبكات التواصل الاجتماعي

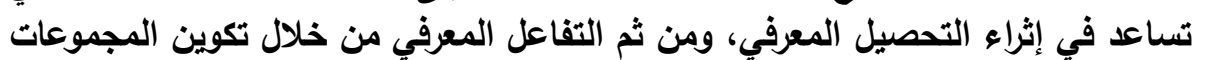

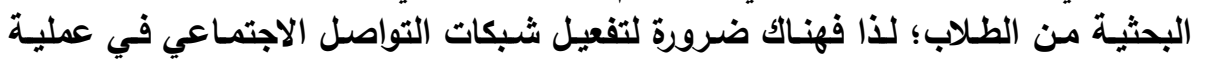

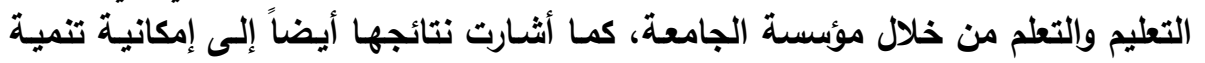

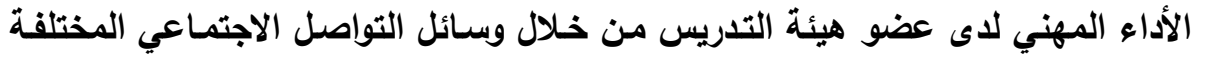
(Baecelos, \& Batista, 2013; Coutinho, \& Lisbôa, 2013; Hagan,

.2013)

مما سبق يتضح أن التفاعل المعرفي عبر شبكات التواصل الاجتمـاعي يجعل

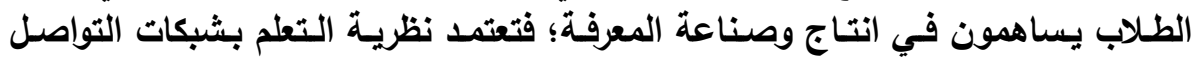

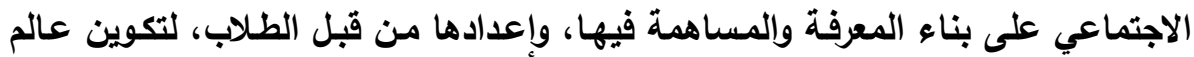

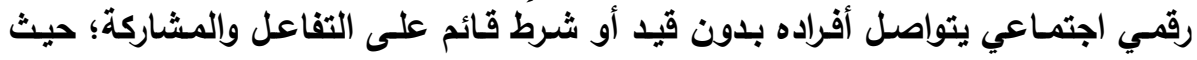

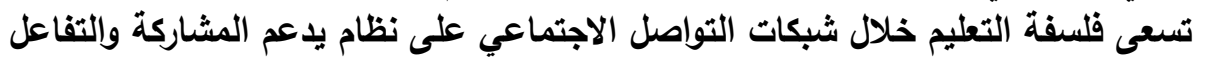
بين عناصر العملية التعليمية في تحقيق أهدافها.

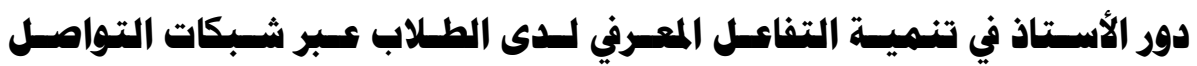

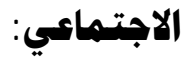

يلدعم التفاعل المعرفي عبر شبكات التواصل الاجتمـاعي عضو هيئة التدريس

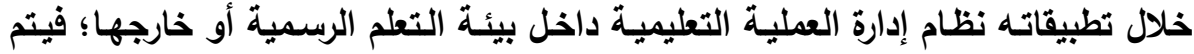

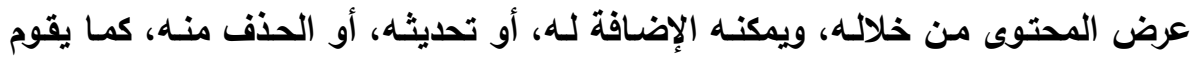

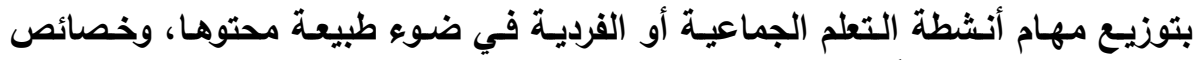

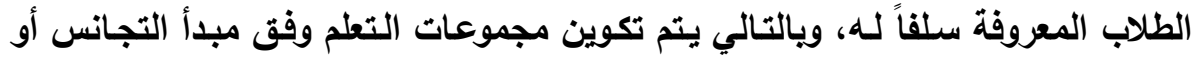

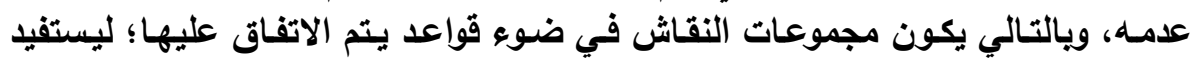

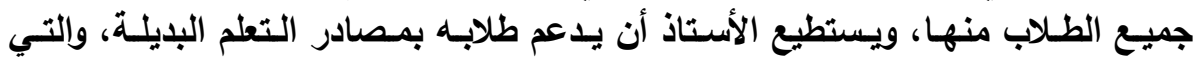


تتناسب مـع مفردات وموضوعات التعلم المقدمـة لهم عبر شبكات التواصل الاجتمـاعي

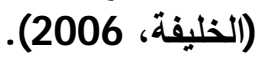

لقد بات التفاعل المعرفي عبر شبكات التواصل الاجتمـاعي متمثتلاً في تمكين

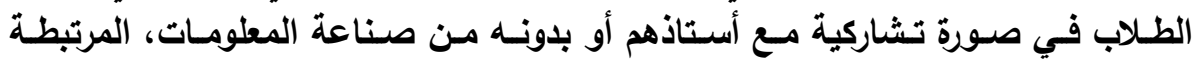

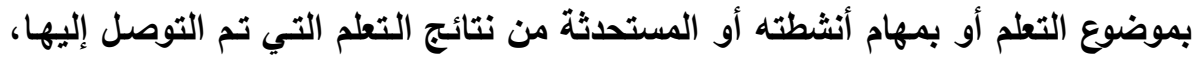

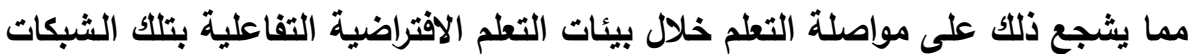

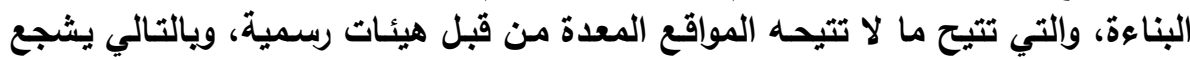

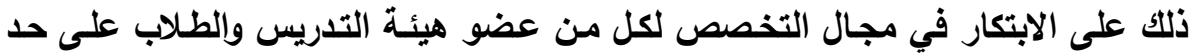

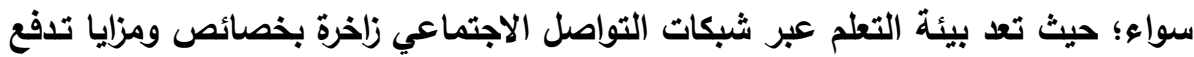

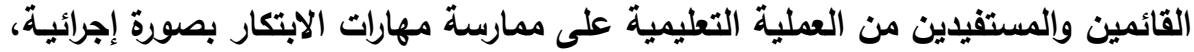

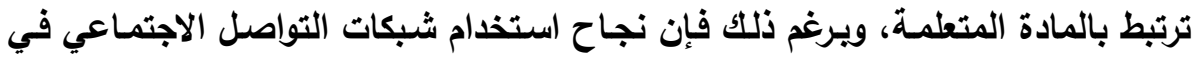

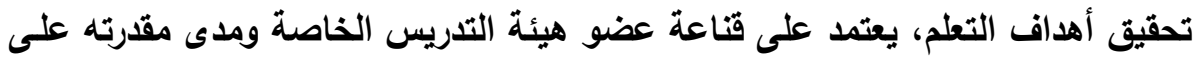
توظيفها في العملية التعليمية على النحو الصحيح الذي يسهر في تحقيق أهدافئ التها.

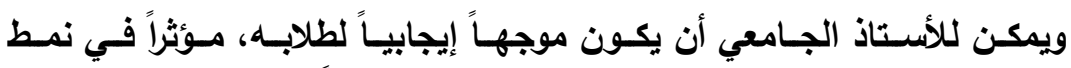

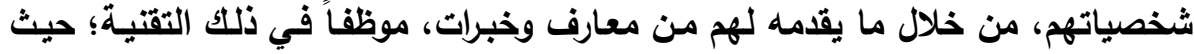

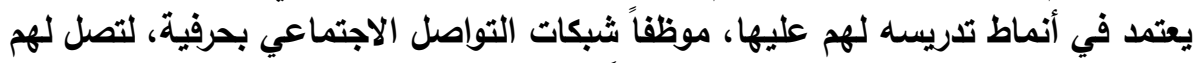

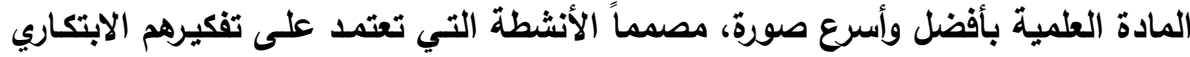

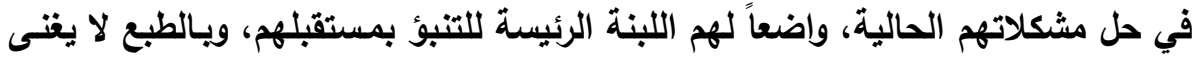

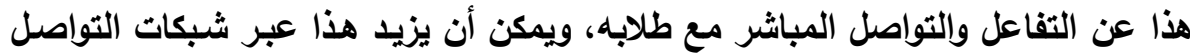

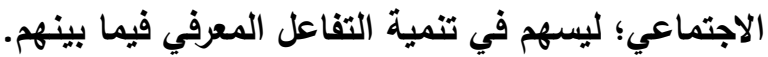

ويتحتم على عضو هيئة التدريس في مرحلة تخطيطه لآليات توظيف شبكات

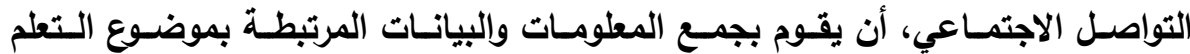

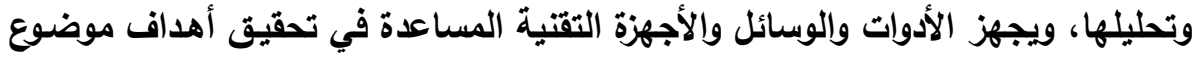

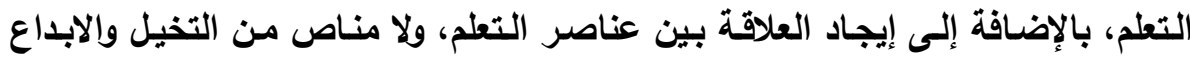

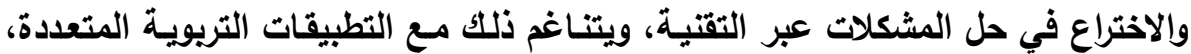

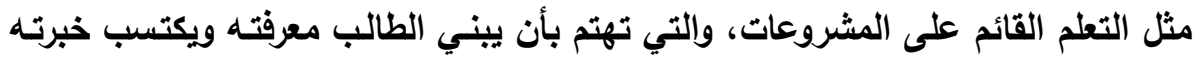

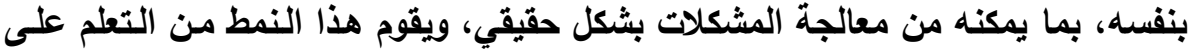

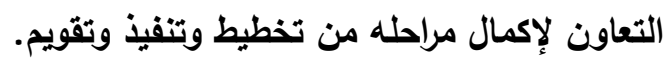

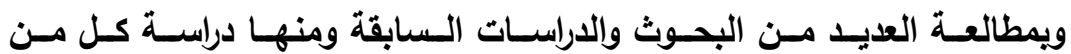

(Alvareg,. \&smith, 2013; Bennett, Owers, pitt, \& Tucker, 2010; Brady, HolComb, \& Smith, 2010; Buzzetto- More, 2012; Corbeil, \& Corbeil, 2011; Dalsgaard, 2013; Farb. \& Pregibon, 2011; Miah, 
مجلة كلية التربية، جامعة الأزهر، العدد: (183، الجزء الثاني) يوليو لسنة 2019م

Omar, \& Golding, 2012; Munguatosha, Muyinda, \& Lubega, 2011; Panckhurst, 2013; Stanciu, Mihai, \& Aleca, 2012; Tariq, Mehboob, yar-kan, \& ullah, 2012; Zaidieh, 2012)

التفاعل المعرفي عبر شبكات التواصل الاجتماعي بالجامعة من خلال:

- التخطيط الجيا والمسبق من عضو هيئة التدريس؛ كي يتسنى لـه تحقيق أهداف موضوع المحاضرة.

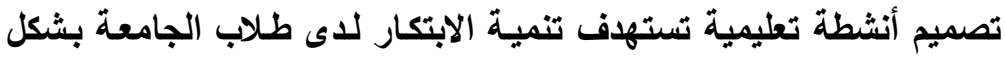

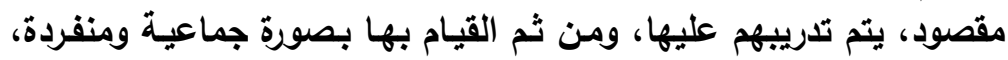

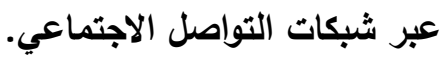

تحويل المحتوى المعرفي من صورته النظرية النماعية لمهام تتضمنها أنشطة يؤديها

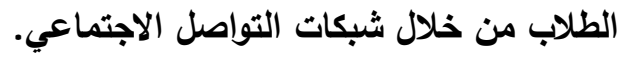

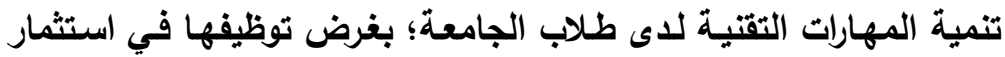

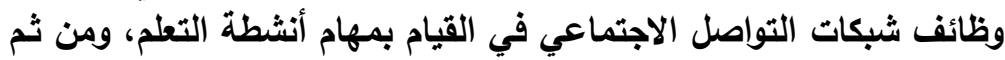

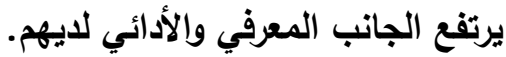

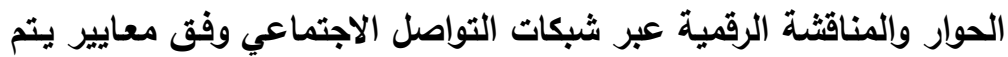
الاتفاق عليها؛ كي تؤتي ثمارها، وتسهم في تنمية التئية التفاعل المعرفي للى الدي طلاب الجامعة.

تقـسيم المجموعـات مـن خـلال الأعمـال المـشتركة فـي القيـام بالأنشـطة

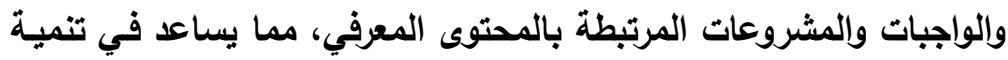

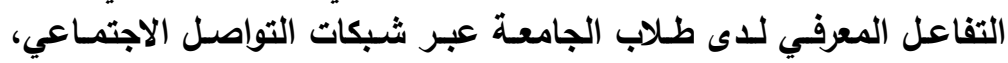

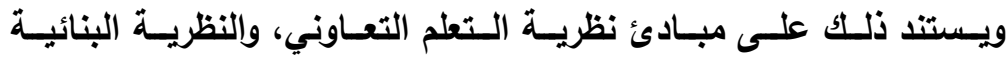
الاجتماعية.

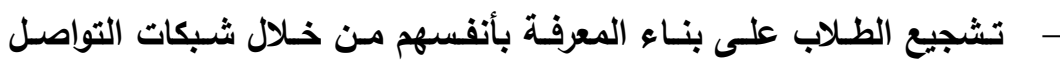

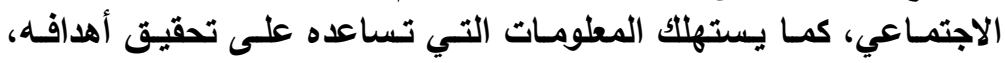
ويتسق هذا مع ما تنادي به به نظرية البنائية.

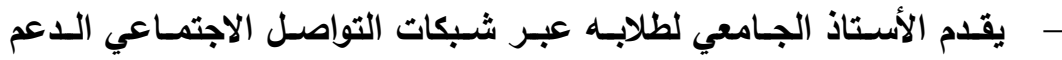

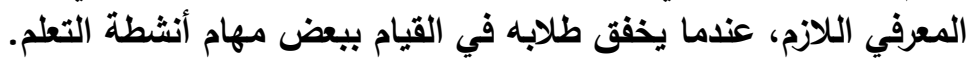

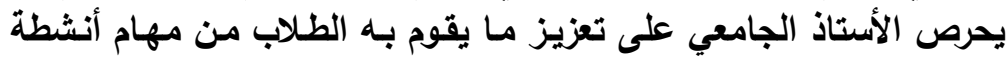

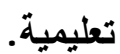
استغلال ما تتضمنه شبكات التواصل الاجتماعي من أسـاليب للترفيه لتحفز

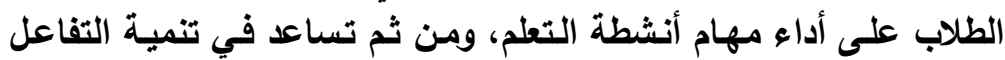

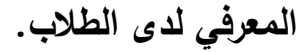




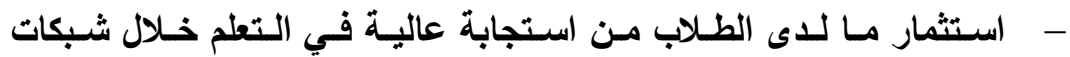

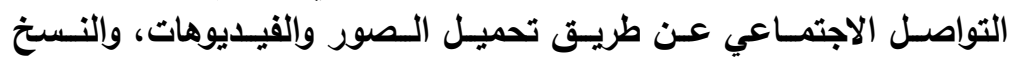

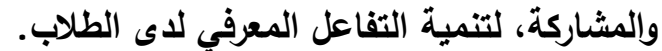

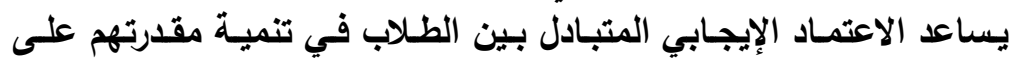

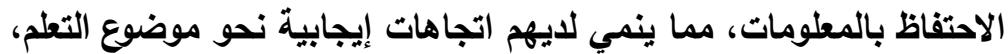

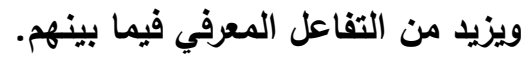

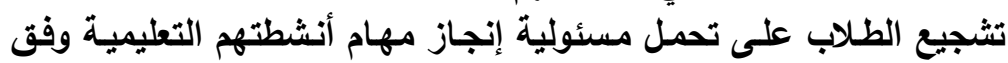

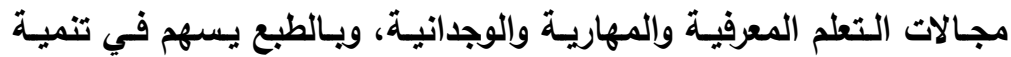

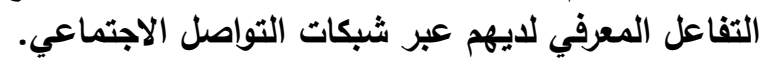

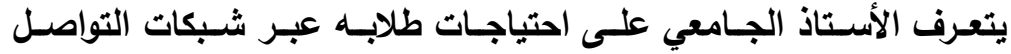

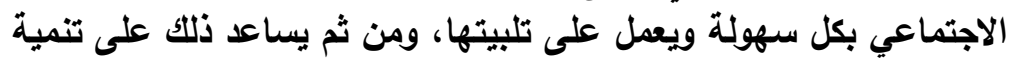
التفاعل المعرفي فيما بينهم .

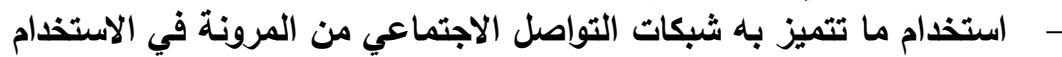

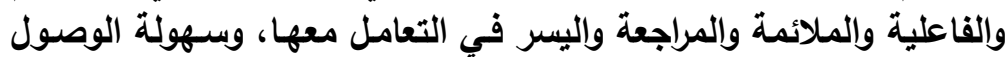

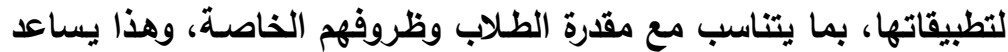

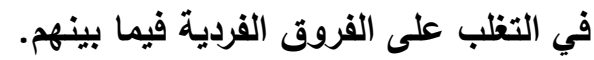

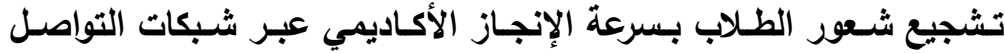

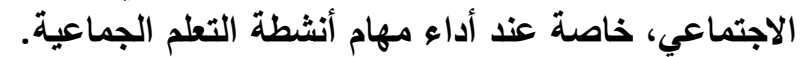

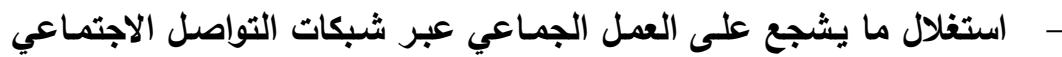

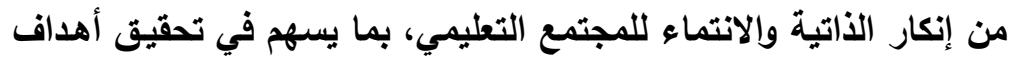

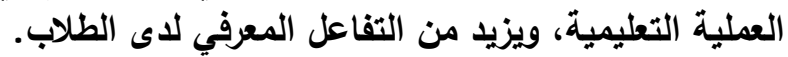

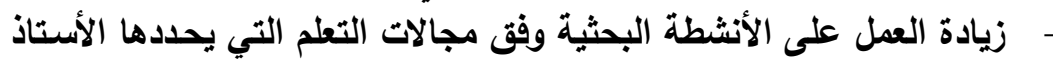

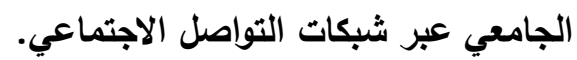

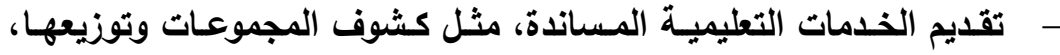

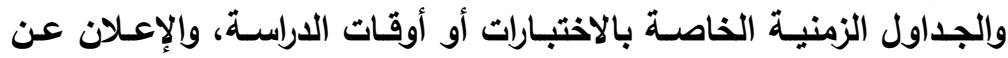

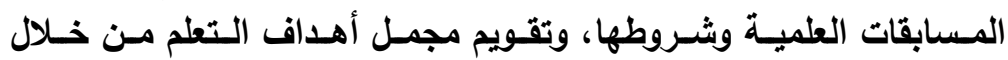

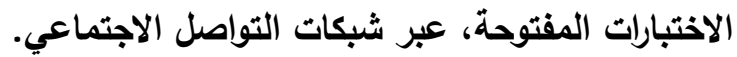

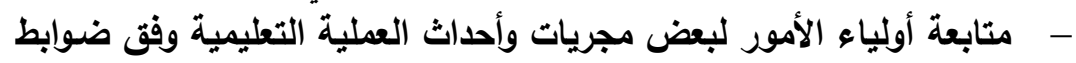

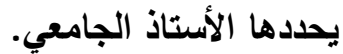
- - مرح قضايا ومشكلات حياتية يتطلب معالجتها من قبل الطلاب عبر شبكات

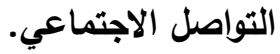

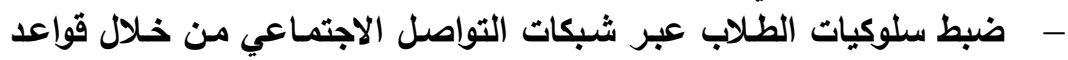

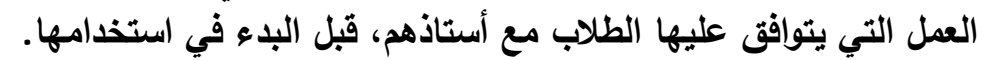


تضمنت إجراءات البحث على تحديد مجالات التفاعل المعرفي، ويناء أداة البحث

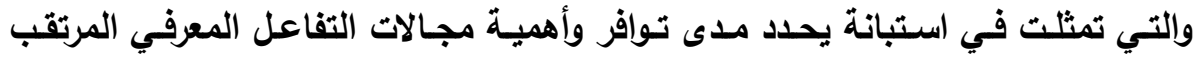

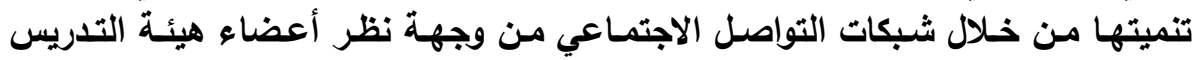

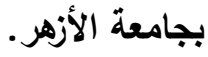

\section{تهديد هبالات التفاعل المعرفي:}

تم عمل قائمة بالمجالات المرتبطة بالتفاعل المعرفي، وعرضها على مجموعة من

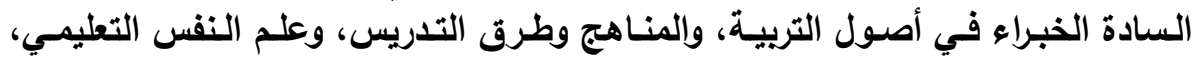

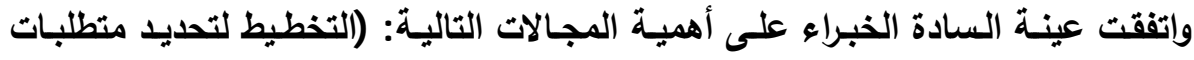

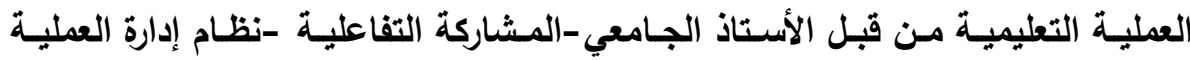

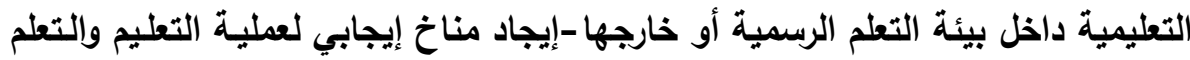

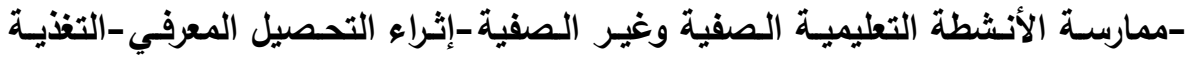

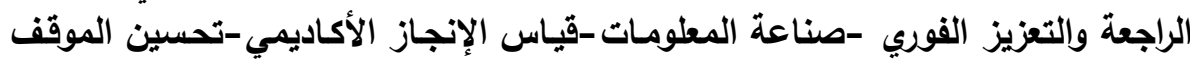

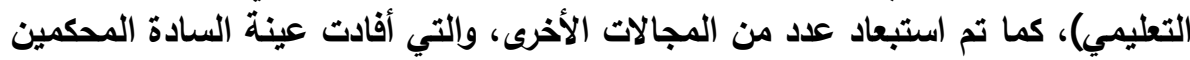
بضعف ارتباطها بالتفاعل المعرفي عبر شبكات التواصن الاصل الاجتماعي.

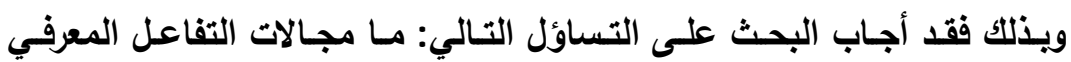

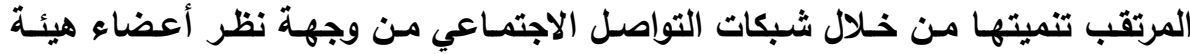

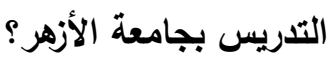

واعتمد البحث الحالي في تحقيت أهدافه على استبانة للتوصل إلى التصور

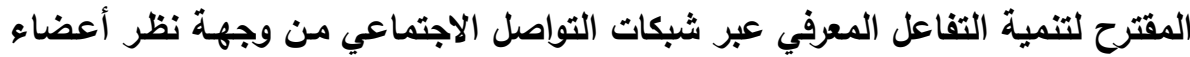

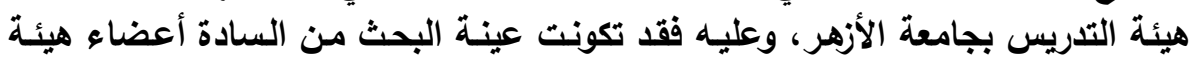

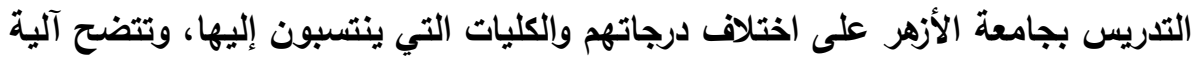

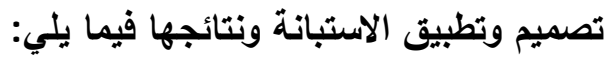

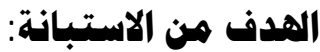

حاول البحث الحالي من خلال الاستعانة بهذه الاستبانة أن يجيب عن الأسئلة الميدانية والتي تنص على اليث

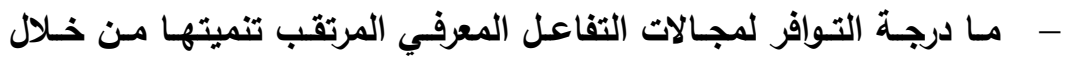

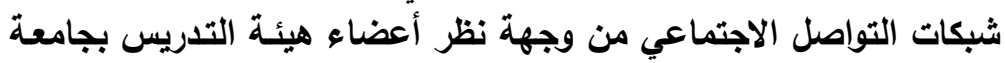


- - مـا درجـة الأهميـة لمجـالات التفاعل المعرفي المرتقب تنميتها مـن خـلال

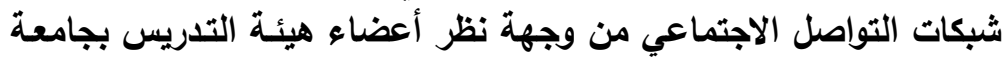

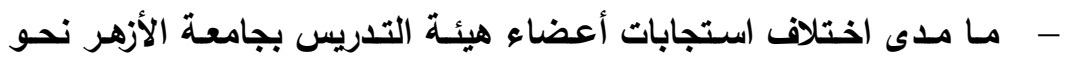

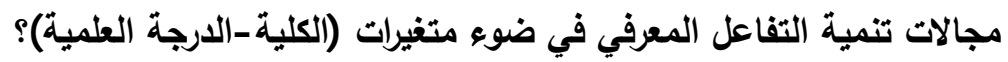

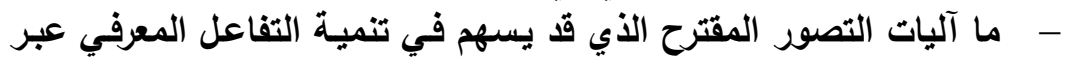

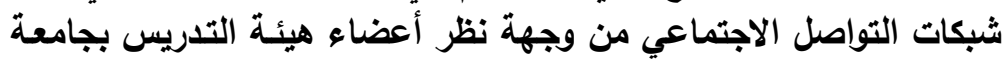

ويعد الإجابة عن تلك الأسئلة تم وضع تصور مقترح يهـف إلى تنمية التفاعل

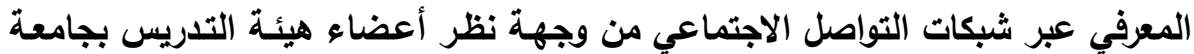

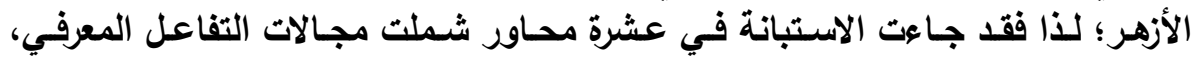

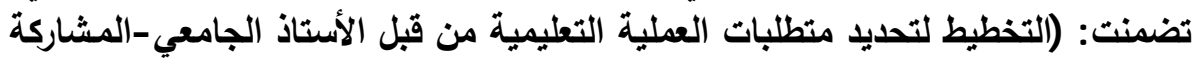

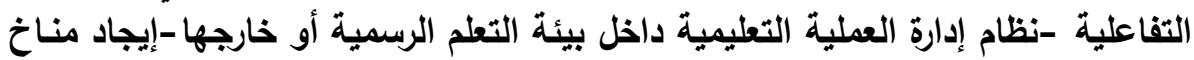

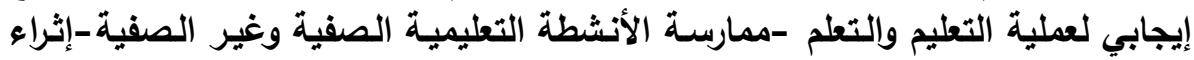

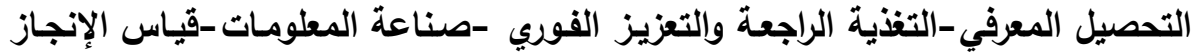

الأكاديمي -تحسين الموقف التعليمي).

\section{مستوى الاستجابة على عبارات الاستبانة:}

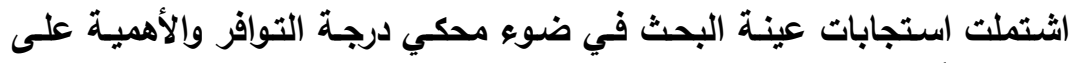

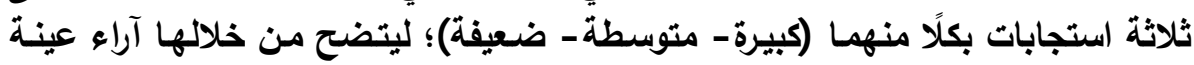

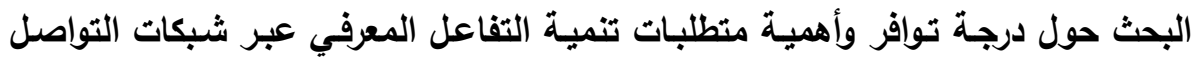
الاجتماعي من وجهة نظرهم.

صدق الاستبانة: - مدي

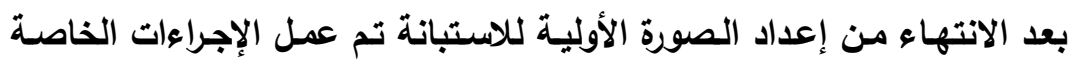

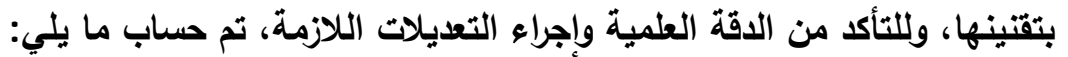
صدق المتتوى أو الاضشمون:

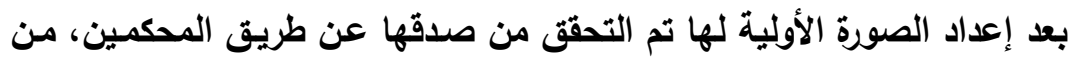

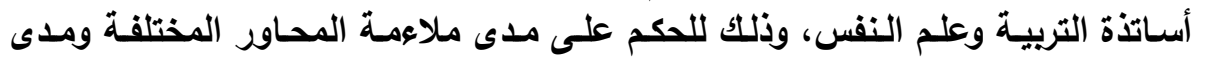

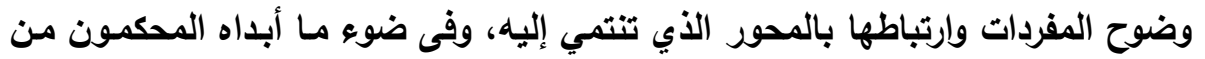

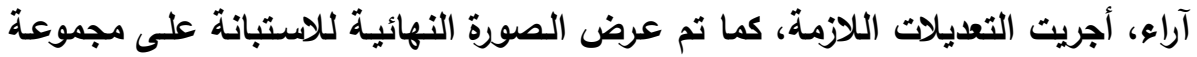

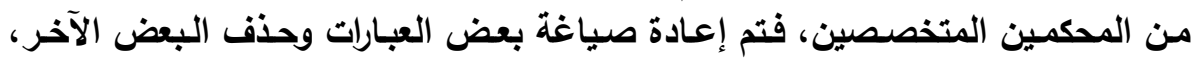


مجلة كلية التربية، جامعة الأزهر، العدد: (183، الجزء الثاني) يوليو لسنة 2019م

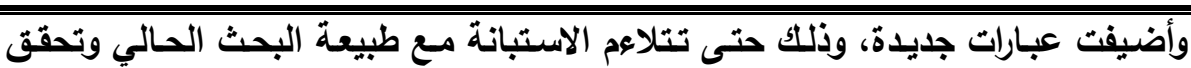
أهدافه وتصبح صالحة للتطبيق.

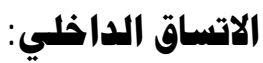

تم حساب معاملات الارتباط بين كل عبارة والدرجة الكلية للاستبانة، وقد أظهرت

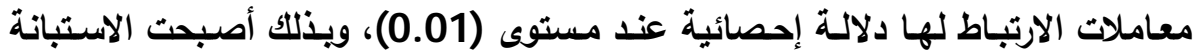
تتمتع بدرجة عالية من الاتساق الإخلي.

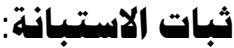

تم حساب ثبات الاستبانة باستخدام معامل ألفا كرومباخ وذلك باستخدام البرنامج

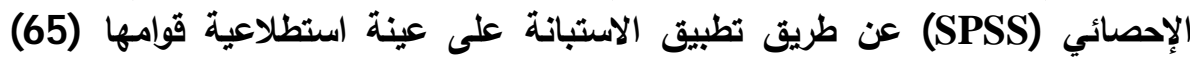

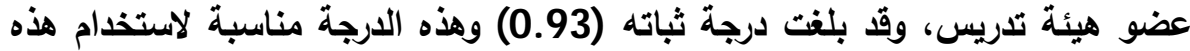

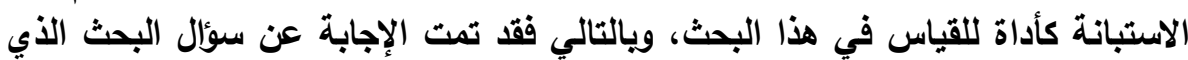

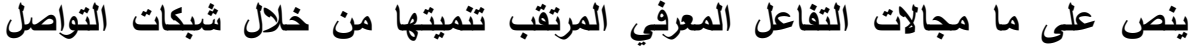

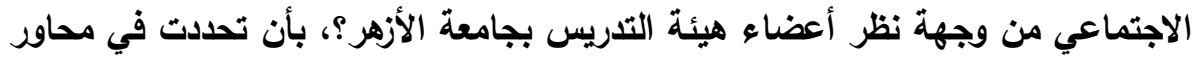
الاستبانة العشرة سالفة الأكر، والتي اتفق علئه اعثياء السادة المحكمين في صورة الاستبانة

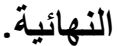

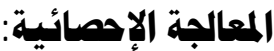

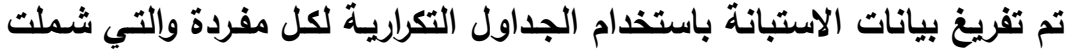

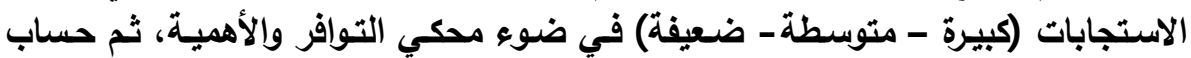

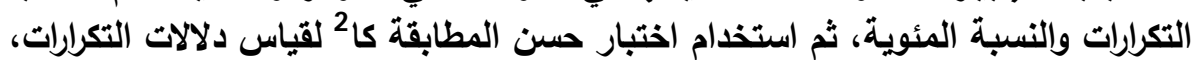
وقد تم استخدام البرنامج الإحصائي (SPSS) في إجراء تلك العمليات.

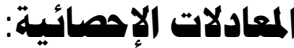

تم تفريغ الاستجابات التي تم العصول عليها بصورة مجملة لأفراد العينة من أعضاء

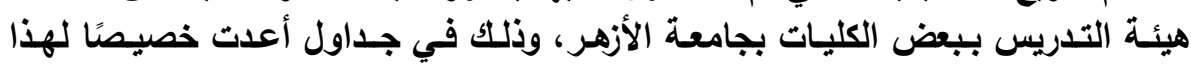
الغرض، وقد تم استخدام الأساليب الإحصائية التالية في معالجة البيانات .

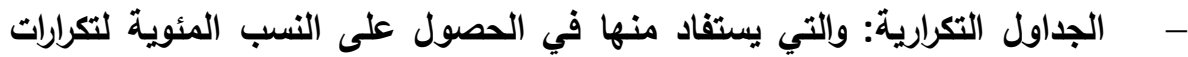

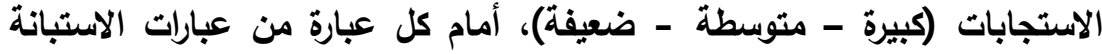

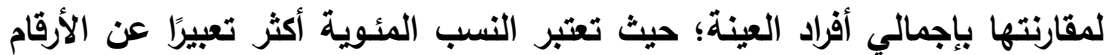

الوزن النسبي: وهو عبارة عن التقدير الرقمي على مجموع أفراد العينة؛ حيث

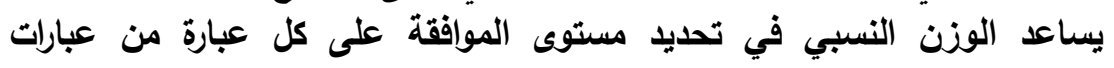


الاستبانة وترتيبها حسب وزنها النسبي لكل عبارة، وتم حساب التقدير الرقمي

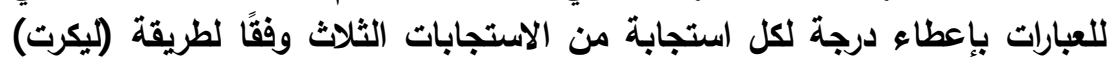

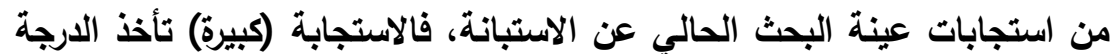
(3) والاستجابة (متوسطة) تأخذ الارجة (2) والاستجابة (ضعيفة) تأخذ الارجة الإنة

والجدول التالي رقم (1) يوضح مستوى ومدى التوافر والأهمية لكل استجابة من الاستجابات الثلاث في الاستبانة.

$$
\text { جدول (1) }
$$

درجة التوافر والأهمية وإلمدى لكل استجابة من استجابات عينة البحث الحالي على الاستبانة

\begin{tabular}{|c|c|}
\hline المـــى & درجة التوافر والأهمية \\
\hline $2.34-3$ & كبيرة \\
\hline $1.67-2.33$ & متوسطة \\
\hline $1-1.66$ & ضعيفة \\
\hline
\end{tabular}

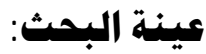

تم تطبيق الاستبانة على عينـة من أعضاء هيئة التدريس بالكليات المختلفة

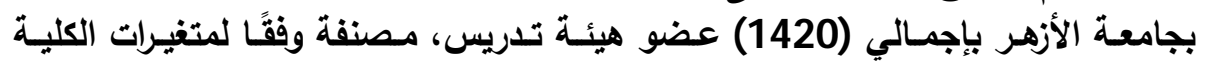
والدرجة العلمية كما بالجدول (2):

جدول (2)

تصنيف عينة البحث في ضوء متغيرات (الكلية - النوع - الارجة العلمية)

\begin{tabular}{|c|c|c|}
\hline العدد & التصنيف & المتغيرات \\
\hline 240 & مدرس & \multirow{3}{*}{ الارجة العلمية } \\
\hline 400 & أستاذ مساعد & \\
\hline 780 & أستاذ & \\
\hline 160 & التربية بنين & الكلية \\
\hline
\end{tabular}


مجلة كلية التربية، جامعة الأزهر ، العدد: (183، الجزء الثاني) يوليو لسنة 2019م

\begin{tabular}{|c|c|c|}
\hline العدد العد & التصنيف & المتغيرات \\
\hline 210 & الزراعة بنين & \\
\hline 378 & العلوم بنين & \\
\hline 86 & الصيدلة بنين & \\
\hline 114 & الدراسات الإسلامية والعربية بنين & \\
\hline 75 & التجارة بنين & \\
\hline 84 & الاعوة الإسلامية & \\
\hline 143 & الدراسات الإنساتية بنات & \\
\hline 170 & كلية الدراسات الإسلامية والعربية & \\
\hline \multicolumn{2}{|r|}{1420} & المجموع \\
\hline
\end{tabular}

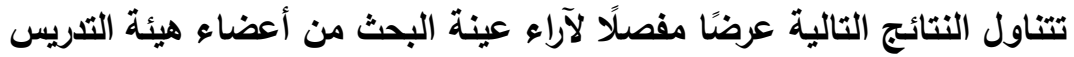

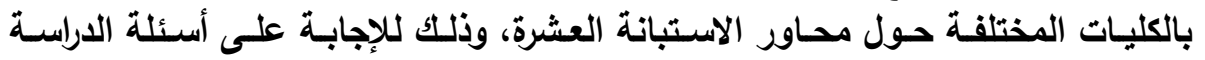

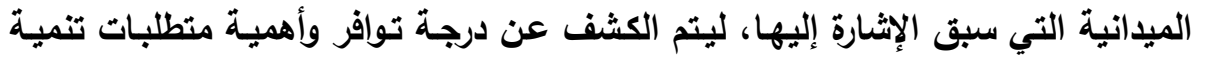

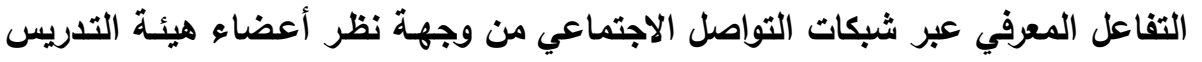

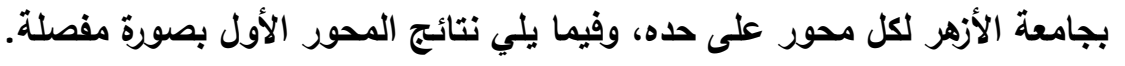
المحور الأول: التخطيط لتمديد هتطلبات العمليسة التعليميسة هـن قبـل الأسـتاذ البامهي

جاء محور التخطيط كأحل مجالات التفاعل المعرفي، والذي قد يسهم في تنميتها عبر شبكات التواصل الاجتماعي في (11) عبارة، تمخضت نتائجها عن الآتي: 
(3) جدول

درجة ومستوى التوافر والأهمية والوزن النسبي لمحور التخطيط كأحد مجالات التفاعل

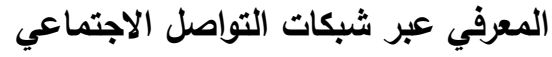

\begin{tabular}{|c|c|c|c|c|c|c|c|c|c|}
\hline \multirow{4}{*}{ 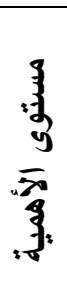 } & \multirow{4}{*}{$\begin{array}{l}\overline{3} \\
\overline{3} \\
\overline{7} \\
\overline{3}\end{array}$} & \multicolumn{3}{|c|}{ درجة الأهمية } & \multirow{4}{*}{ 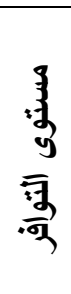 } & \multirow{4}{*}{ 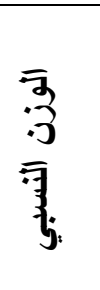 } & \multicolumn{3}{|c|}{ درجة التوافر } \\
\hline & & ضعيفة & متوسطة & كبيرة & & & ضعيفة & متوسطة & كبيزة \\
\hline & & ك & ك5 & ك & & & ك & ك & ك \\
\hline & & 1053 & 4705 & 9769 & & & 11114 & 3785 & 721 \\
\hline \multirow{3}{*}{ 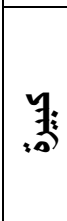 } & \multirow{2}{*}{2.55} & درجة & درجة & & \multirow{3}{*}{ ". } & \multirow{2}{*}{1.33} & & درجة & درجة \\
\hline & & 1053 & 9410 & 29307 & & & 11114 & 7570 & 2163 \\
\hline & \multicolumn{4}{|c|}{39770} & & \multicolumn{2}{|c|}{20847} & \multicolumn{2}{|c|}{ المجموع الكلي } \\
\hline
\end{tabular}

باستقراء بيانات الجدول السابق يتضح أن مكونات التخطيط غير متوفرة بالقدر

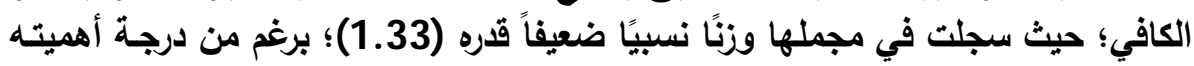

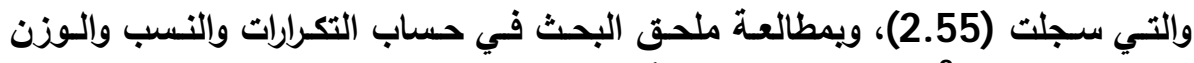

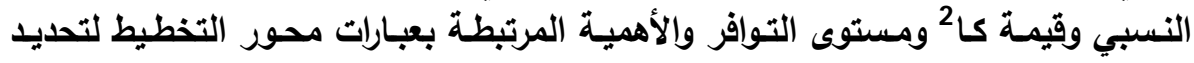
منطلبات العملية التعليمية من قبل الأستاذ الجامعي، وجد أنها: أنها:

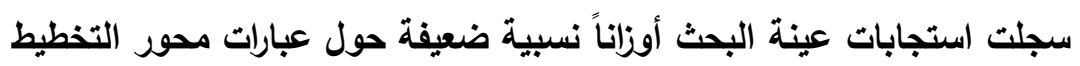

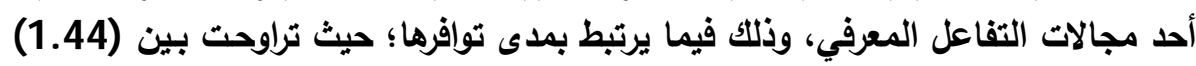

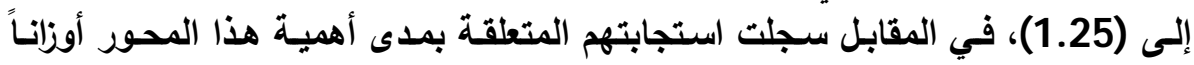

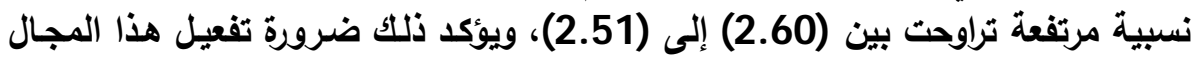
بما يساعد في تنمية التفاعل المعرفي عبر شبكات التواصل الاجتماعي بصورة وظيفية. وأكلت استجابات عينة البحث على ضرورة صياغة أهداف موضوعات ألهات التعلم

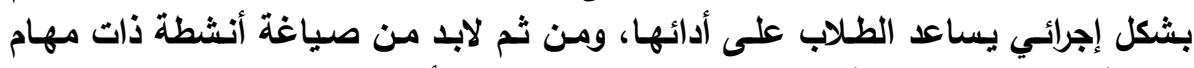

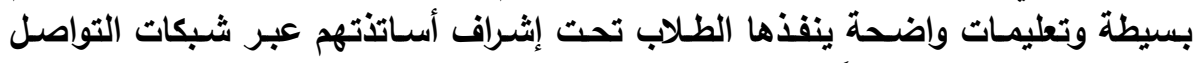

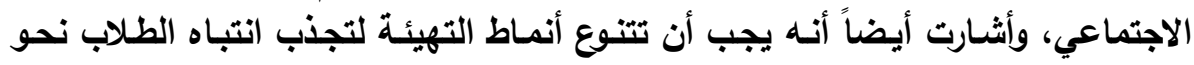

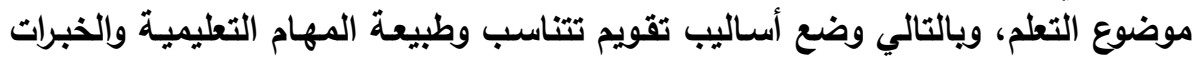
المراد إكسابها للطلاب.

ويمارس الأستاذ الجامعي مهارات التخطيط سـالفة الذكر في التدريس السائد،

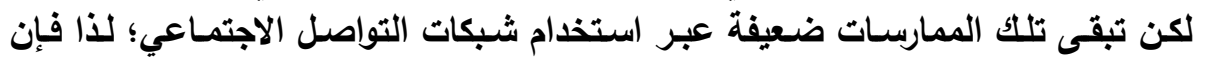


مجلة كلية التربية، جامعة الأزهر ، العدد: (183، الجزء الثاني) يوليو لسنة 2019م

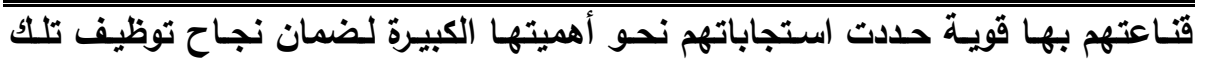

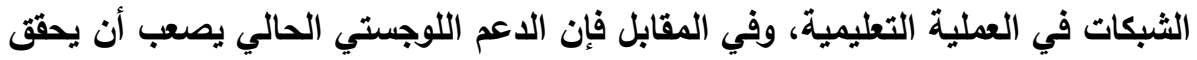
وظيفية شبكات التواصل الاجتماعي في العملية التعليمية على النحو المرتبة التبع. المور الثاني: المشاركة التفاعلية عبر شبكات التواصل الاجتماعي:

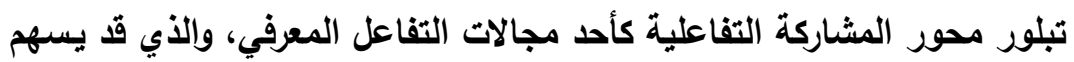

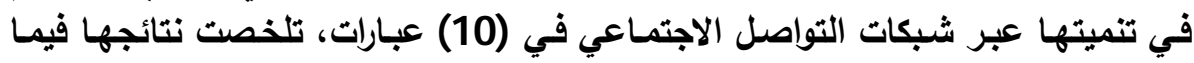

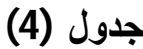

درجة ومستوى التوافر والأهمية والوزن النسبي لمحور المشاركة التفاعلية عبر شبكات التواصل الاجتماعي كأحد مجالات تنمية التفاعل المعرفي عبر شبكات التواصني التول الاجتماعي

\begin{tabular}{|c|c|c|c|c|c|c|c|c|c|}
\hline \multirow{4}{*}{ 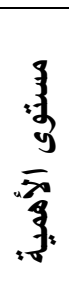 } & \multirow{4}{*}{$\begin{array}{l}\overline{3} \\
3 \\
\overline{7} \\
\overline{3}\end{array}$} & \multicolumn{3}{|c|}{ درجة الأهمية } & \multirow{4}{*}{ 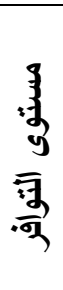 } & \multirow{4}{*}{$\begin{array}{l}\overline{3} \\
\overline{3} \\
\overline{7} \\
3\end{array}$} & \multicolumn{3}{|c|}{ درجة التوافر } \\
\hline & & ضعيفة & متوسطة & كبيرة & & & ضعيفة & متوسطة & كبيرة \\
\hline & & ك & ك & ك & & & ك & ك & ك \\
\hline & & 972 & 4031 & 9197 & & & 10389 & 3142 & 669 \\
\hline \multirow{3}{*}{ 噄 } & \multirow{2}{*}{2.58} & درجة & درجة & درجة & \multirow{3}{*}{ 拏 } & \multirow{2}{*}{1.32} & جة & درجة & درجة \\
\hline & & 972 & 8062 & 27591 & & & 10389 & 6284 & 2007 \\
\hline & \multicolumn{4}{|c|}{36625} & & \multicolumn{2}{|c|}{18680} & \multicolumn{2}{|c|}{ المجموع الكلى } \\
\hline
\end{tabular}

بالنظر إلى بيانات الجدول السابق يتضح أن منطلبات مجال المشاركة التفاعلية

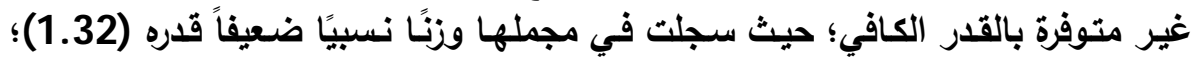
برغم من درجة أهميته والتي سجلت (2.58)، ويالرجوع إلى ملحق البحث في حساب

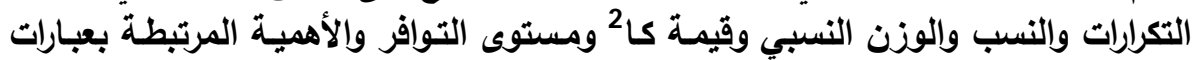
محور المشاركة التفاعلية عبر شبكات التواصل الاجتماعي، وجد أنه:

رصدت استجابات عينة البحث أوزاناً نسبية ضعيفة حول عبارات محور المشاركة

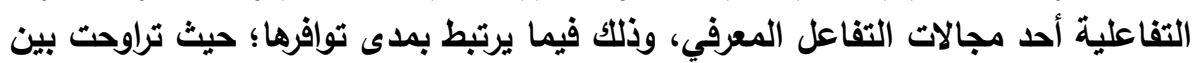

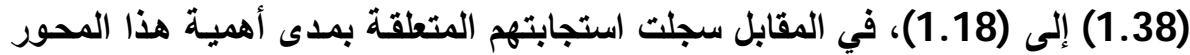

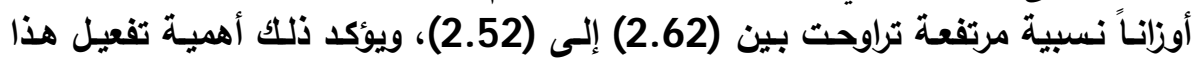

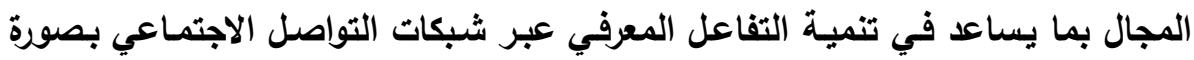


وعبرت عينة البحث على مدى أهمية توفير المصادر والمراجع الرقمية المرتبطة

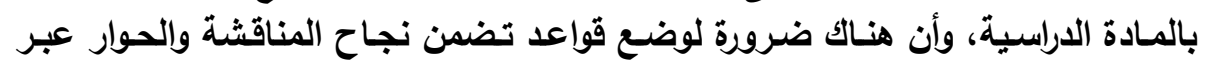

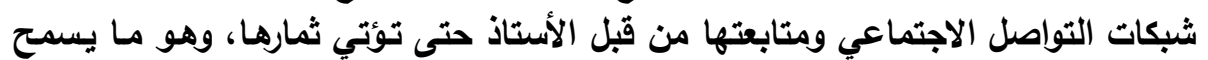

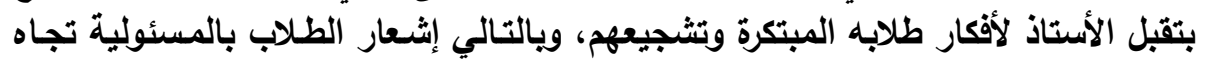

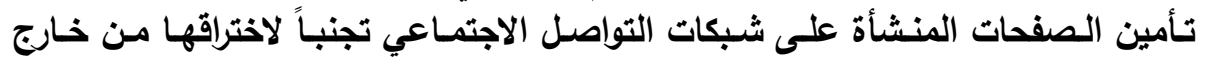
مجموعاتهم.

وأثشارت استجابات عينة البحث إلى أن المشاركة في صورتها التفاعلية ينبغي

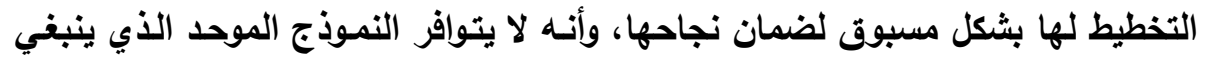

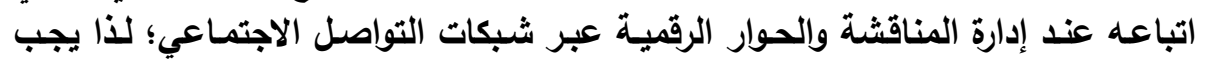

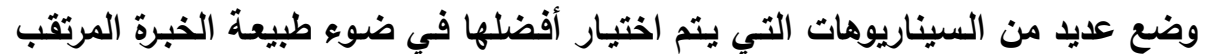
إكسابها للطلاب.

المهور الثالث: نظام إدارة العملية التعليميسة داخل بيئة التتعلم الرسميسة أو خارجها

جاء محور نظام إدارة العملية التعليمية كأحد مجالات التفاعل المعرفي، والذي قات يسهم في تنميتها عبر شبكات التواصل الاجتماعي في (10) عبارات، تمثلت نتائجها في: (5) جدول

درجة ومستوى التوافر والأهمية والوزن النسبي لمحور نظام إدارة العملية التعليمية داخل

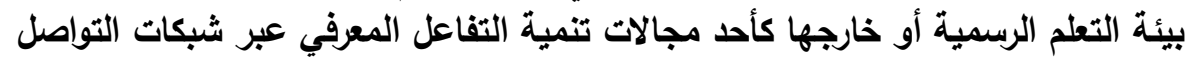
الاجتماعي

\begin{tabular}{|c|c|c|c|c|c|c|c|c|c|}
\hline \multirow{4}{*}{ 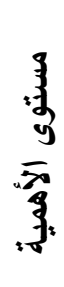 } & \multirow{4}{*}{$\begin{array}{l}\overline{3} \\
.3 \\
\overline{7} \\
\underline{3}\end{array}$} & \multicolumn{3}{|c|}{ درجة الأهمية } & \multirow{4}{*}{ 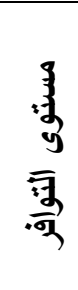 } & \multirow{4}{*}{$\begin{array}{l}\overline{3} \\
.3 \\
\overline{7} \\
3\end{array}$} & \multicolumn{3}{|c|}{ درجة التوافر } \\
\hline & & ضعيفة & متوسطة & كبيرة & & & ضعيفة & متوبطة & كبيرة \\
\hline & & ك5 & ك & ك5 & & & ك & ك5 & ك5 \\
\hline & & 1065 & 4301 & 8834 & & & 9670 & 4194 & 336 \\
\hline & 255 & درجة & درجة & درجة & & 134 & درجة & درجة & درجة \\
\hline 鞋 & & 1065 & 8602 & 26502 & 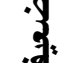 & & 9670 & 8388 & 1008 \\
\hline & & & 169 & & & 19 & 66 & الكلي & المجه \\
\hline
\end{tabular}


مجلة كلية التربية، جامعة الأزهر ، العدد: (183، الجزء الثاني) يوليو لسنة 2019م

باستقراء بيانات الجدول السابق يتضح أن مكونـات نظام إدارة العملية التعليمية

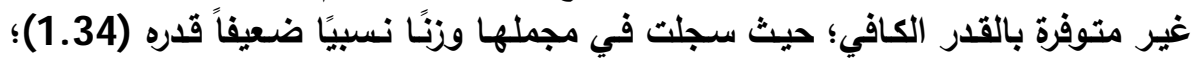
برغم من درجة أهميته من وجهة نظر عينة البحث، والتي سجلت (2.55)، ويالنظر إلى في التى

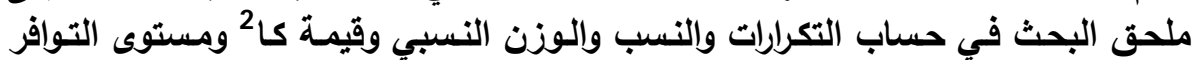
والأهمية المرتبطة بعبارات محور نظام إدارة العملية التعليمية داخل بيئة التعلم الرسمية أو

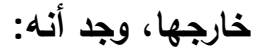

سجلت استجابات عينة البحث أوزاناً نسبية ضعيفة حول عبارات محور نظام

إدارة العملية التعليمية أحد مجالات التفاعل المعرفي، وذلك فيما يرتبط بمدى توافرها؛ حيث البئ

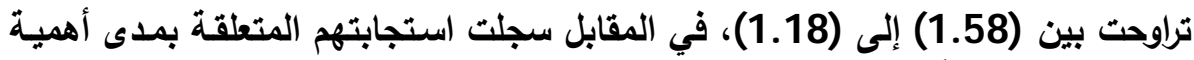

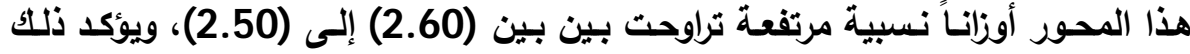

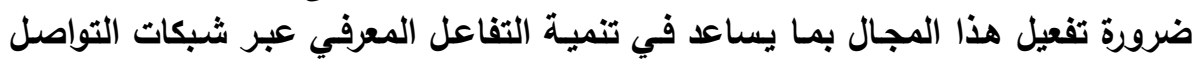
الاجتماعي بصورة وظيفية.

وأكلت عينة البحث على أهية أن يحرص الأستاذ على تنمية العلاقات الإنسانية

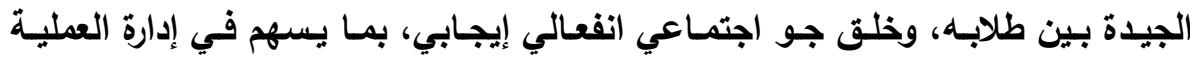

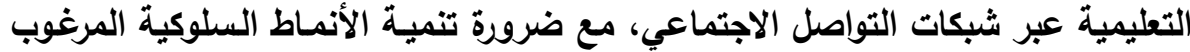

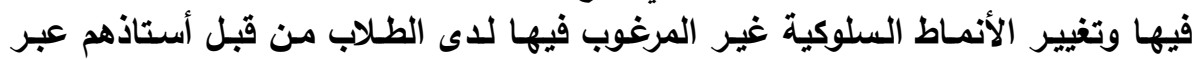

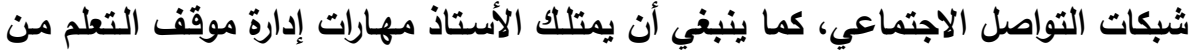

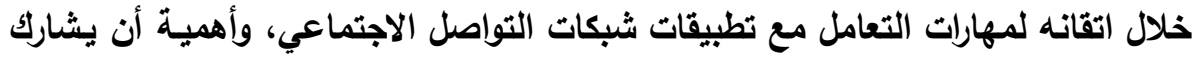

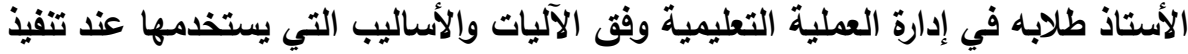

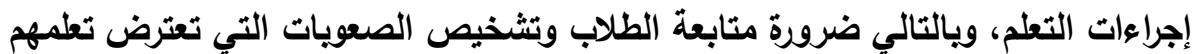

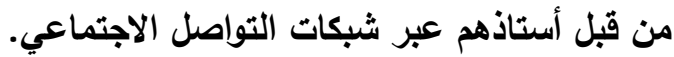

ويؤكد محور نظام إدارة العملية التعليمية على ضرورة قناعة الأستاذ بفعالية

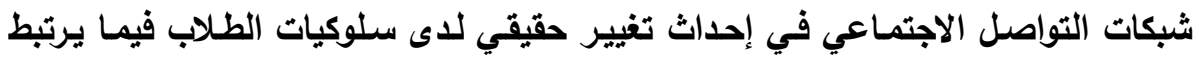

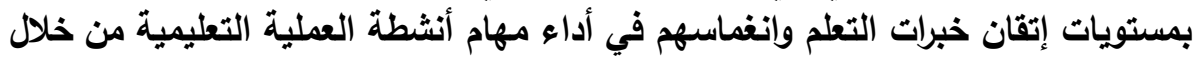

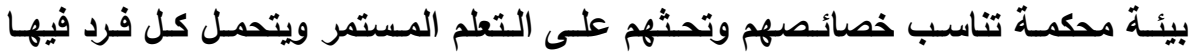

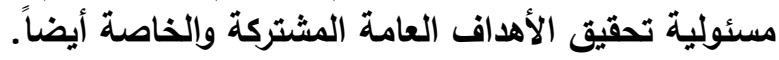

\section{المور الرابع: إيجاد هناخ إيبابي لعملية التعليم والتعلم}

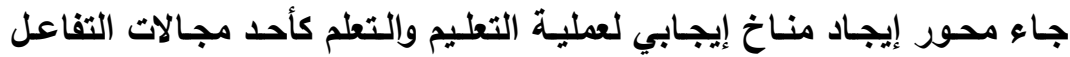
المعرفي، والذي قا يسهم في تنميتها عبر شبكات التواصل الاجتماعي في (10) عبارات،

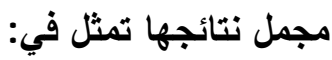


(6) جدول

درجة ومستوى التوافر والأهمية والوزن النسبي لمحور إيجاد مناخ إيجابي لعملية التعليم

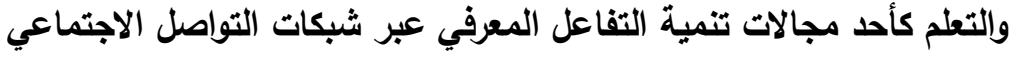

\begin{tabular}{|c|c|c|c|c|c|c|c|c|c|}
\hline \multirow{3}{*}{ 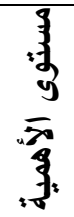 } & \multirow{3}{*}{ 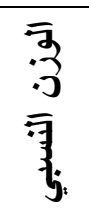 } & \multicolumn{3}{|c|}{ درجة الأهمية } & \multirow{3}{*}{ 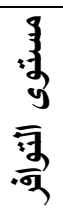 } & \multirow{3}{*}{$\begin{array}{l}\overline{3} \\
3 \\
\overline{3} \\
\overline{3}\end{array}$} & \multicolumn{3}{|c|}{ درجة التوافر } \\
\hline & & ضعيفة & متوسطة & كبيرة & & & ضعيفة & |متوسطة | & كبيرة \\
\hline & & $\frac{5}{954}$ & $\frac{5}{4544}$ & $\begin{array}{c}\text { 5 } \\
8702\end{array}$ & & & $\frac{5}{8781}$ & 4793 & ك5 \\
\hline \multirow{3}{*}{ 虫 } & \multirow{2}{*}{2.55} & درجة & درجة & درجة & \multirow{3}{*}{ 䠵 } & \multirow{2}{*}{1.43} & درجة & درجة & درجة \\
\hline & & 954 & 9088 & 26106 & & & 8781 & 9586 & 1878 \\
\hline & \multicolumn{4}{|c|}{36148} & & \multicolumn{2}{|c|}{20245} & \multicolumn{2}{|c|}{ المجموع الكلي } \\
\hline
\end{tabular}

باستقراء بيانات الجدول السابق يتضح أن مكونـات محور إيجاد مناخ إيجابي

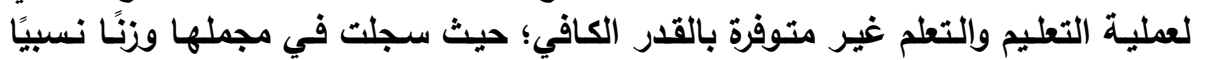

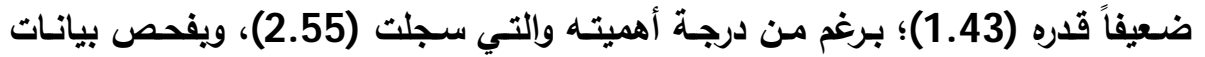

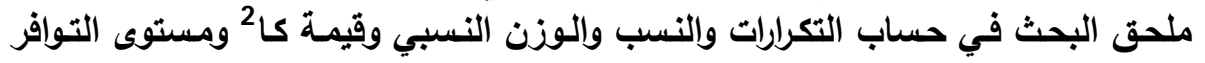
والأهمية المرتبطة بعبارات محور إيجاد مناخ إيجابي لعملية التعليم والتعلم، وجد أنه: سجلت استجابات عينة البحث أوزاناً نسبية ضعيفة حول عبارات محور إيجاد

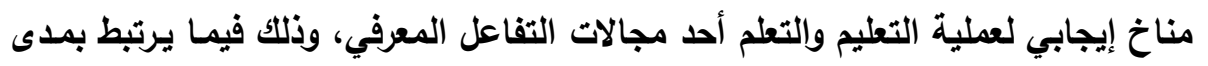

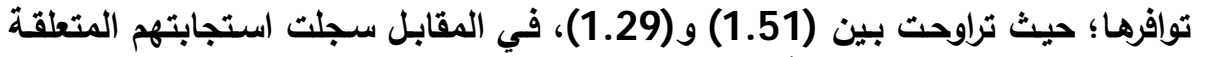

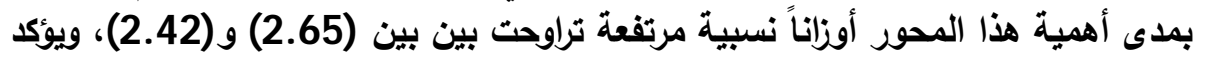

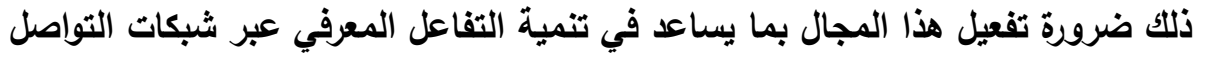
الاجتماعي بصورة وظيفية.

وأكلات عينة البحث على ضرورة أن يتقبل الأستاذ لوجهات نظر الطلاب فيما

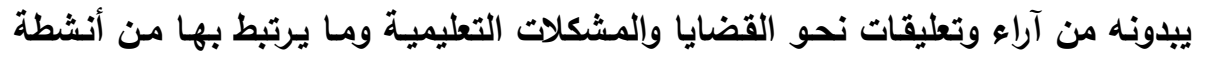

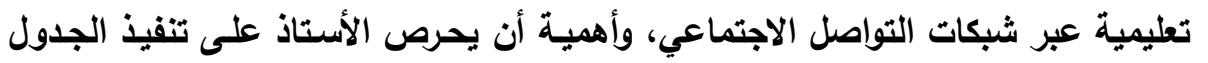

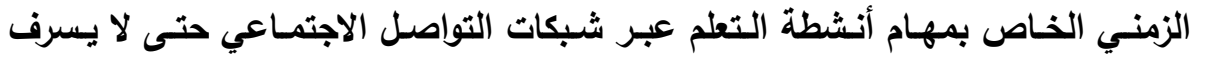

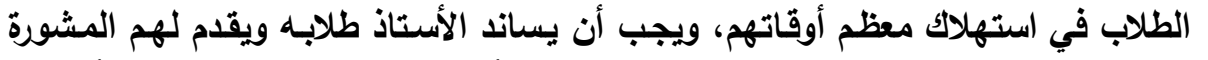

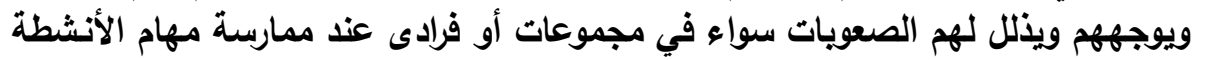

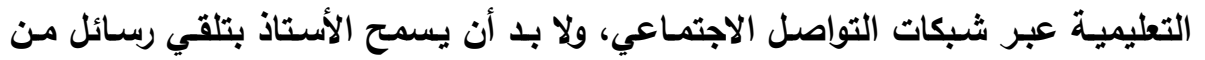

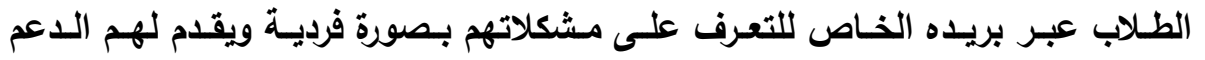
والمشورة والحلول التي تساعدهم في استكمال تعلمهم عبر شبكات التواصل الاجتماعي. 
مجلة كلية التربية، جامعة الأزهر، العدد: (183، الجزء الثاني) يوليو لسنة 2019م

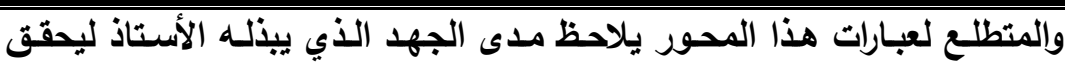

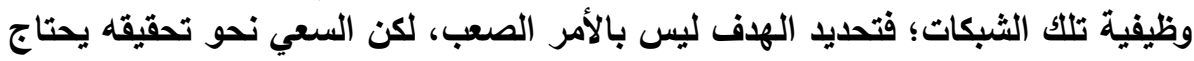
لتخطيط ويذل شغل ويالتالي تهيئة القائمين على تحقيقه بتوفير المناخ الأاعم لذلتك، ويركز

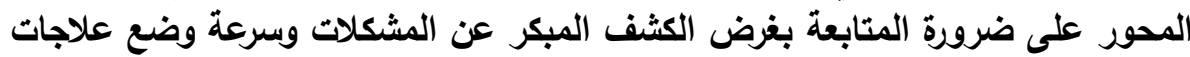

مناسبة لها بهاف الوصول لنتائج مرضية.

الحمور الخامس: همارسة الأنشطة التعليسية الصفية وغير الصفية

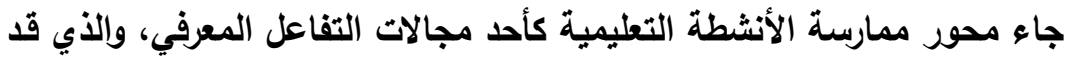

يسهم في تنميتها عبر شبكات التواصل الاجتماعي في (11) عبارة، تمخضت نتائجة الأبها عن

الآتي: - (n)

جدول (7)

درجة ومستوى التوافر والأهمية والوزن النسبي لمحور ممارسة الأنثطة التعليمية الصفية

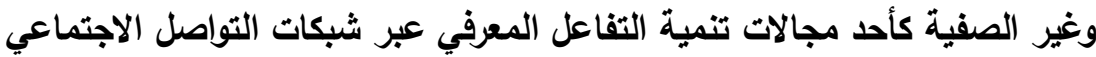

\begin{tabular}{|c|c|c|c|c|c|c|c|c|c|}
\hline \multirow{4}{*}{ 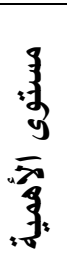 } & \multirow{4}{*}{$\begin{array}{l}\overline{3} \\
3 \\
\overline{3} \\
\overline{3}\end{array}$} & \multicolumn{3}{|c|}{ درجة الأهمية } & \multirow{4}{*}{ 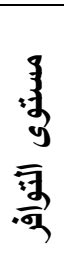 } & \multirow{4}{*}{$\begin{array}{l}\bar{a} \\
3 \\
\overline{3} \\
\overline{3}\end{array}$} & \multicolumn{3}{|c|}{ درجة التوافر } \\
\hline & & ضعيفة & متوسطة & كبيزة & & & ضعيفة & متوسطة & كبيرة \\
\hline & & ك & ك5 & ك & & & ك5 & ك5 & ك5 \\
\hline & & 1112 & 4992 & 9516 & & & 10654 & 4252 & 714 \\
\hline \multirow{3}{*}{ 寻 } & \multirow{2}{*}{2.54} & درجة & درجة & درجة & \multirow{3}{*}{ 身 } & \multirow{2}{*}{1.36} & درجة & درجة & درجة \\
\hline & & 1112 & 9984 & 26106 & & & 10654 & 8504 & 2142 \\
\hline & \multicolumn{4}{|c|}{37202} & & \multicolumn{2}{|c|}{21300} & \multicolumn{2}{|c|}{ المجموع الكلي } \\
\hline
\end{tabular}

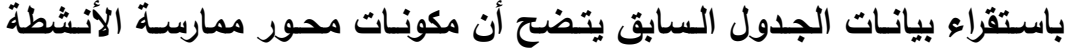

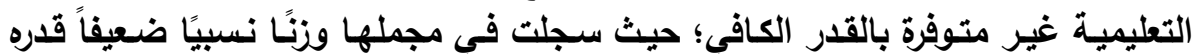
(1.36)؛ برغم من درجة أهميته والتي سجلت (2.54)، ويالرجوع إلى ملحق البحث في

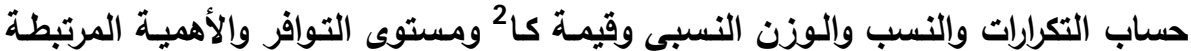
بعبارات محور ممارسة الأنثطة التعليمية الصفية وغير الصفية، وجية والنداب أنها:

سجلت استجابات عينة البحث أوزاناً نسبية ضعيفة حول عبارات محور ممارسـة

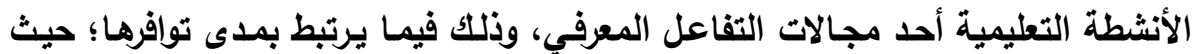

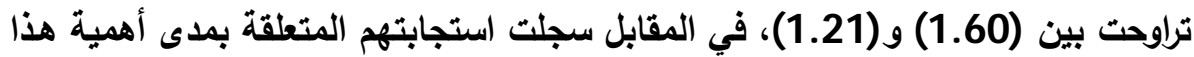

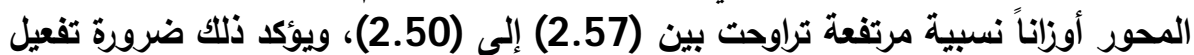


هذا المجال بما يساعد في تنمية التفاعل المعرفي عبر شبكات التواصل الاجتماعي بصورة

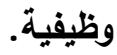

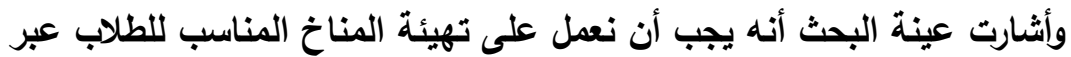

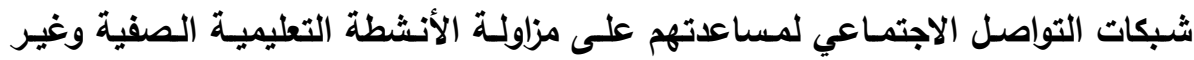

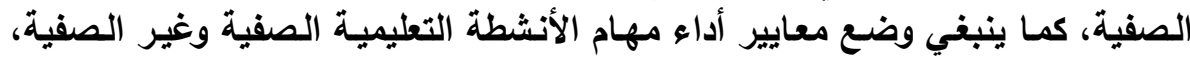

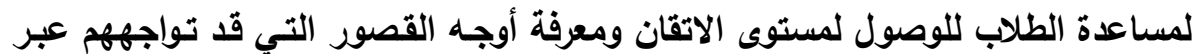

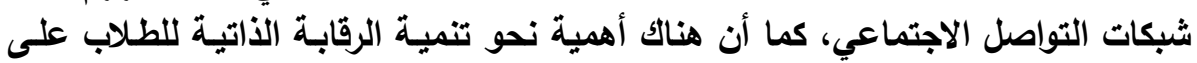

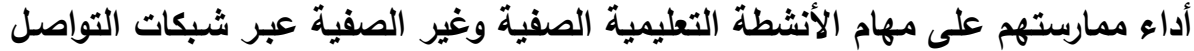

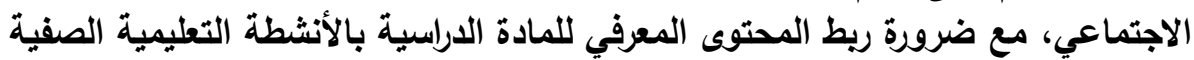

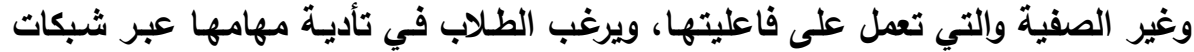
التواصل الاجتماعي.

ويرغم من تحمل الطلاب أداء مهام الأنشطة المرتبطة بالمحتوى التعليمي بصورة

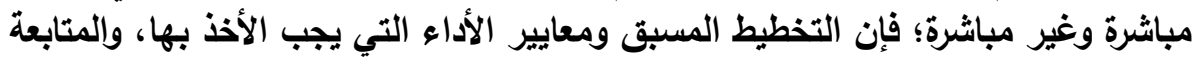

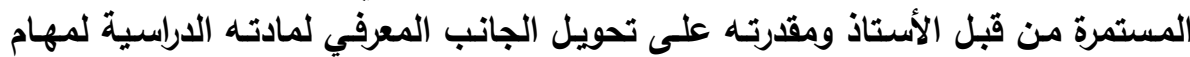
إجرائية يؤديها الطلاب، كل ذلك مجتمعاً يعمل على تحقيق أهداف الأنشطة بكافة أنماطها.

\section{المحور السادس: إثراء التصصيل المعرفي}

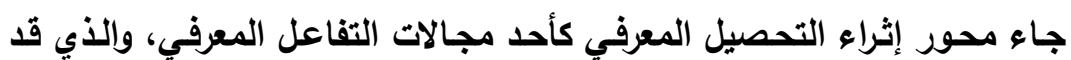
يسهم في تتميتها عبر شبكات التواصل الاجتماعي في (10) عبارات، تمخضت الترفي نتائجها

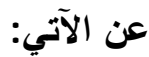

جدول (8)

درجة ومستوى التوافر والأهمية والوزن النسبي لإجمالي محور إثراء التحصيل المعرفي

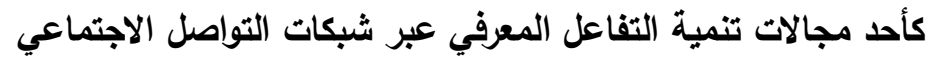

\begin{tabular}{|c|c|c|c|c|c|c|c|c|c|}
\hline \multirow{4}{*}{$\frac{3}{3}$} & \multirow{4}{*}{$\begin{array}{l}\overline{3} \\
3 \\
3 \\
3 \\
3\end{array}$} & \multicolumn{3}{|c|}{ درجة الأهمية } & \multirow{4}{*}{$\begin{array}{l}3 \\
\text { 多 } \\
\text { 哥 }\end{array}$} & \multirow{4}{*}{$\begin{array}{l}\overline{3} \\
: 3 \\
\overline{7} \\
\mathbf{3}\end{array}$} & \multicolumn{3}{|c|}{ درجة التوافر } \\
\hline & & ضعيفة & متوسطة & كبيرة & & & ضعيفة & متوسطة & كبيرة \\
\hline & & ك & ك & ك & & & ك & ك5 & ك \\
\hline & & 938 & 4305 & 8957 & & & 10303 & 3246 & 651 \\
\hline & & درجة & درجة & درجة & 3 & & درجة & درجة & درجة \\
\hline & & 938 & 8610 & 26871 & 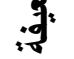 & & 10303 & 6492 & 1953 \\
\hline
\end{tabular}


مجلة كلية التربية، جامعة الأزهر، العدد: (183، الجزء الثاني) يوليو لسنة 2019م

\begin{tabular}{|c|c|c|c|c|c|c|c|c|c|}
\hline \multirow{4}{*}{ 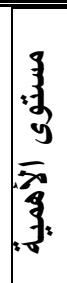 } & \multirow{4}{*}{$\begin{array}{l}\overline{3} \\
\overline{3} \\
\overline{7} \\
\text { j. }\end{array}$} & \multicolumn{3}{|c|}{ درجة الأهمية } & \multirow{4}{*}{ 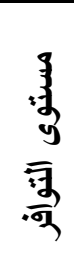 } & \multirow{4}{*}{$\begin{array}{l}\overline{3} \\
.3 \\
\overline{3} \\
3\end{array}$} & \multicolumn{3}{|c|}{ درجة التوافر } \\
\hline & & ضعيفة & متوسطة & كبيرة & & & ضعيفة & |متوسطة | & كبيرة \\
\hline & & ك & ك & ك & & & ك & ك & ك5 \\
\hline & & 938 & 4305 & 8957 & & & 10303 & 3246 & 651 \\
\hline & & & 419 & & & & 748 & م الكلي & المج \\
\hline
\end{tabular}

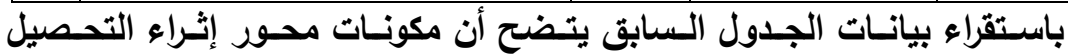

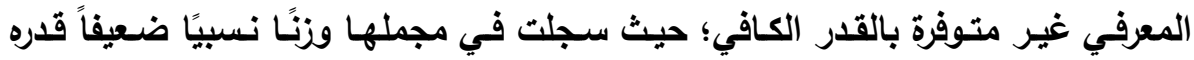

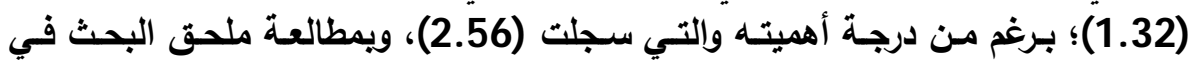

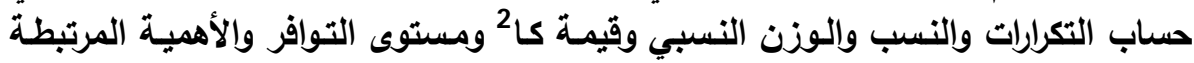
بعبارات محور إثراء التحصيل المعرفي، وجد أنه:

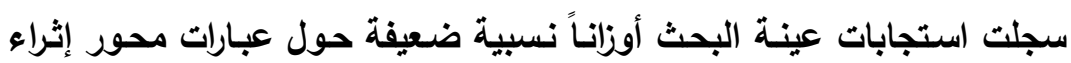

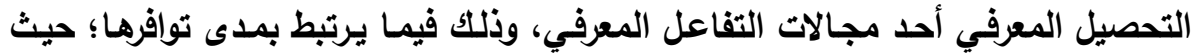

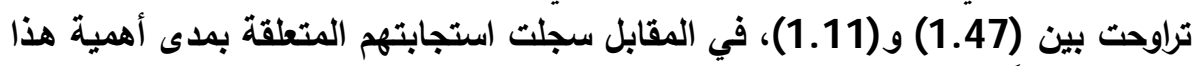
المحور أوزاناً نسبية مرتفعة تراوحت بين (2.66) و(2.49)، ويؤكد ذلك ضرورة فيكابن تفعيل هذا المجال بما يساعد في تنمية التفاعل المعرفي عبر شبكات نيكات التواصل الاجتماعي بصورة

وأكلد عينة البحث على أهمية تبنـي مستويات التحصيل المعرفية العليا، من

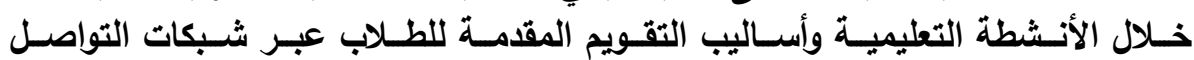

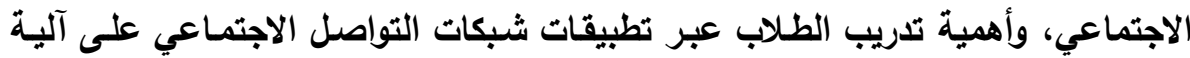

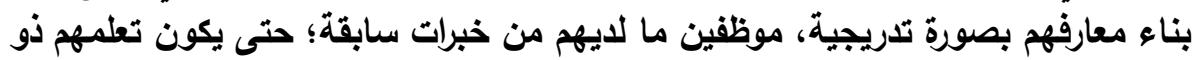

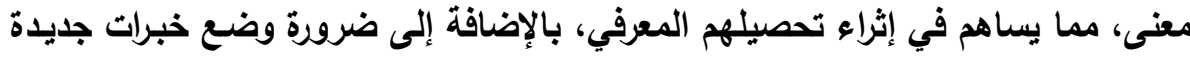

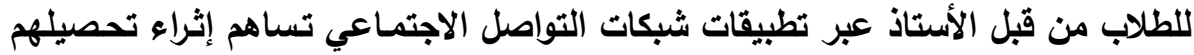

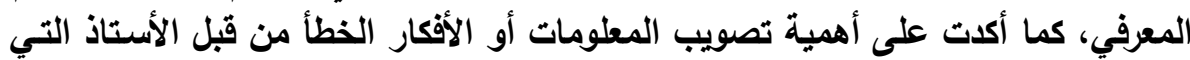

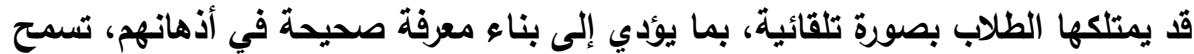

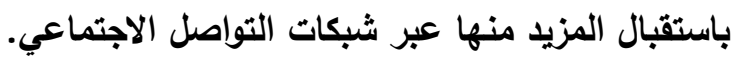

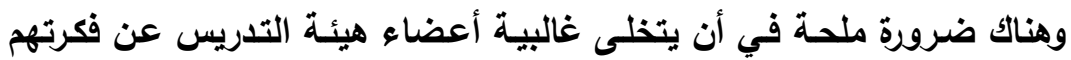

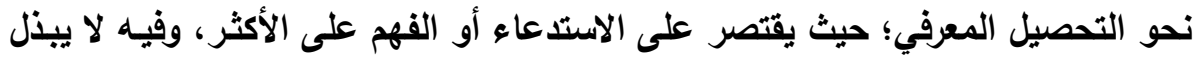

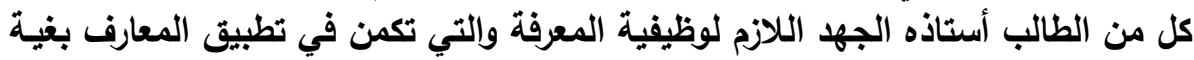

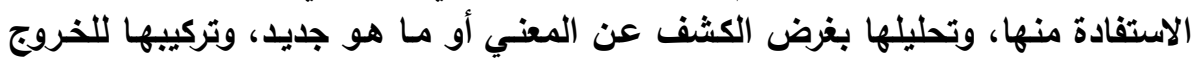

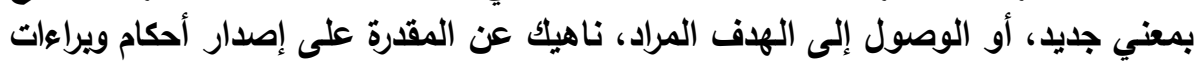


اختراع، وكل مـا تقدم يحث على تغييز النظرة للتحصيل المعرفي، وذلك بضرورة تبنـي

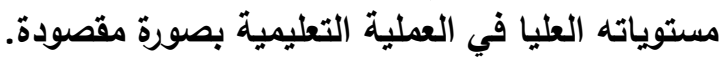

\section{المهور السابع: التغذية الراجعة والتعريز الفوري}

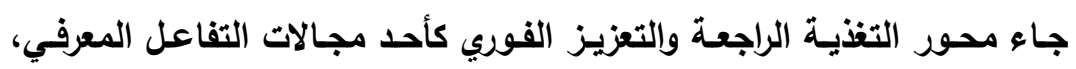

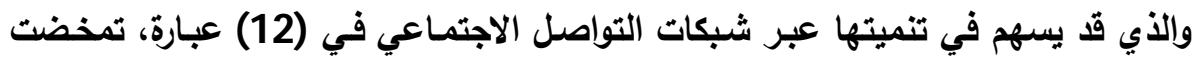

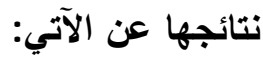

جدول (9)

درجة ومستوى التوافر والأهمية والوزن النسبي لمحور التغذية الراجعة والتعزيز الفوري كأحد مجالات تنمية التفاعل المعرفي عبر شبكات الأني التواصل الاجتماعي

\begin{tabular}{|c|c|c|c|c|c|c|c|c|c|}
\hline \multirow{4}{*}{ 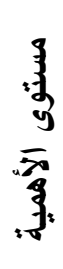 } & \multirow{4}{*}{ 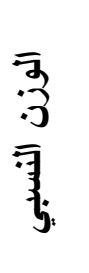 } & \multicolumn{3}{|c|}{ درجة الأهمية } & \multirow{4}{*}{ 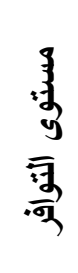 } & \multirow{4}{*}{$\begin{array}{l}3 \\
.3 \\
.7 \\
3\end{array}$} & \multicolumn{3}{|c|}{ درجة التوافر } \\
\hline & & | ضعيفة & متوسطة & كبيرة | & & & ضعيفة & متوسطة & كبيرة \\
\hline & & ك & ك & ك & & & ك5 & ك5 & ك5 \\
\hline & & 1116 & 4710 & 11214 & & & 10377 & 5734 & 929 \\
\hline \multirow{3}{*}{ 寻 } & \multirow{2}{*}{2.59} & درجة & درجة & درجة & \multirow{3}{*}{ 羿 } & \multirow{2}{*}{1.45} & درجة & درجة & درجة \\
\hline & & 1116 & 9420 & 33642 & & & \multicolumn{2}{|c|}{1037711468} & 2787 \\
\hline & \multicolumn{4}{|c|}{44178} & & \multicolumn{2}{|c|}{24632} & \multicolumn{2}{|c|}{ المجموع الكلي } \\
\hline
\end{tabular}

باستقراء بيانـات الجدول السابق يتضح أن مكونـات التفذيـة الراجعة والتعزيز

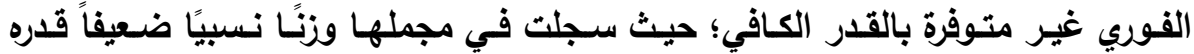

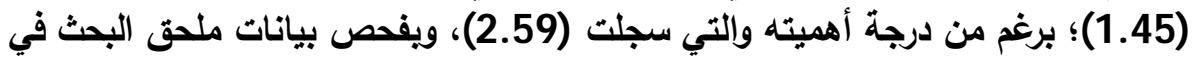

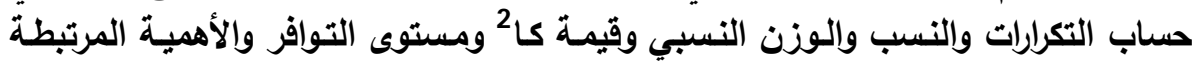

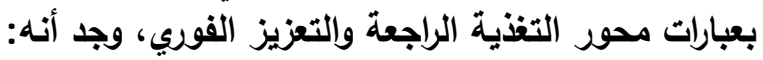

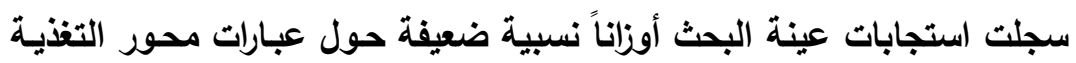

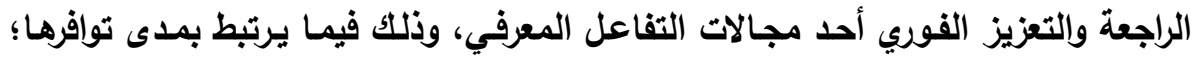

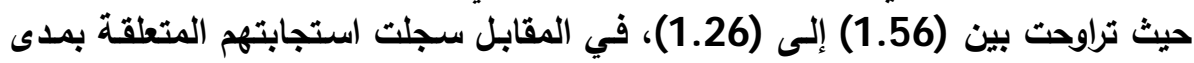

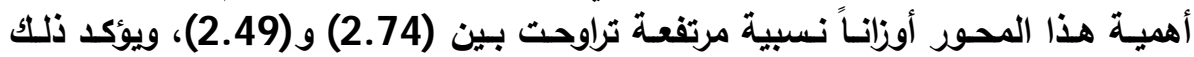

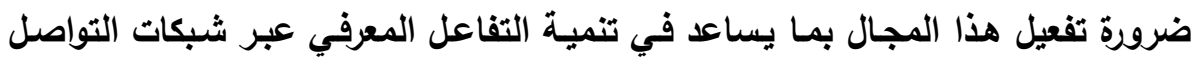


مجلة كلية التربية، جامعة الأزهر، العدد: (183، الجزء الثاني) يوليو لسنة 2019م

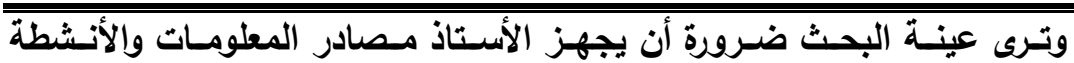

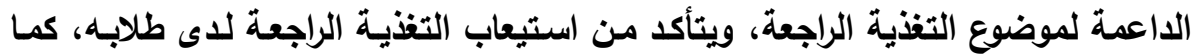

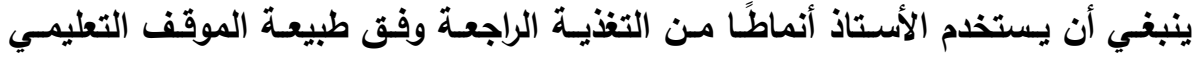

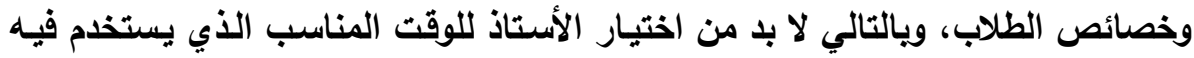

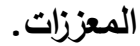

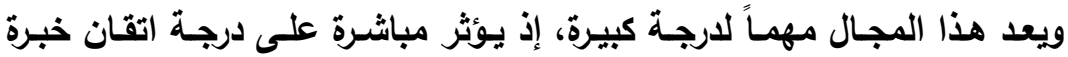

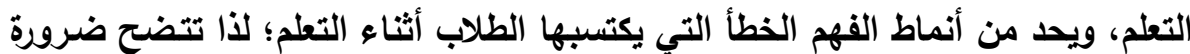

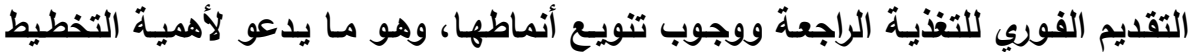

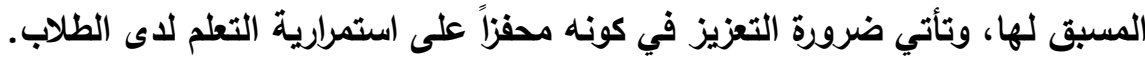

المحور الثاهن: صناعة المعلومهات

جاء محور صناعة المعلومات كأحد مجالات التفاعل المعرفي، والذي قدات يسهر في تنميتها عبر شبكات التواصل الاجتمـاعي في (12) عبارة، تمخضت نتائجها عن الاعن الآتي:

$$
\text { جدول (10) }
$$

درجة ومستوى التوافر والأهمية والوزن النسبي لمحور تنمية صناعة المعلومات

\begin{tabular}{|c|c|c|c|c|c|c|c|c|c|}
\hline \multirow{4}{*}{ 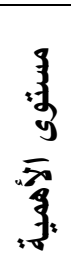 } & \multirow{4}{*}{$\begin{array}{l}\overline{3} \\
\overline{3} \\
\overline{3} \\
\overline{3}\end{array}$} & \multicolumn{3}{|c|}{ درجة الأهمية } & \multirow{4}{*}{ 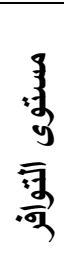 } & \multirow{4}{*}{$\begin{array}{l}\overline{3} \\
\overline{3} \\
\overline{7} \\
\text { j. }\end{array}$} & \multicolumn{3}{|c|}{ درجة التوافر } \\
\hline & & ضعيفة & متوسطة & كبيرة & & & ضعيفة & |متوسطة | & كبيرة \\
\hline & & S & S & ك & & & & ك & \\
\hline & & 1158 & 5459 & 10423 & & & 11994 & 4334 & 712 \\
\hline \multirow{3}{*}{$y_{i}$} & \multirow{2}{*}{2.54} & |درجة & درجة & درجة & & \multirow{2}{*}{1.34} & درجة & درجة & درجة \\
\hline & & 1158 & 10918 & 31269 & & & 11994 & 8668 & 2136 \\
\hline & & & \multicolumn{2}{|c|}{22798} & \multicolumn{2}{|c|}{ المجموع الكلي } \\
\hline
\end{tabular}

باستقراء بيانـات الجدول السابق يتضح أن مكونـات صناعة المعلومـات غير

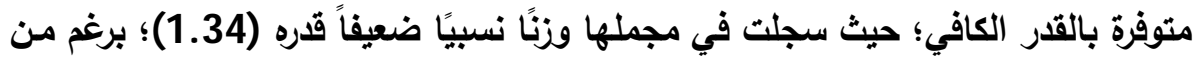

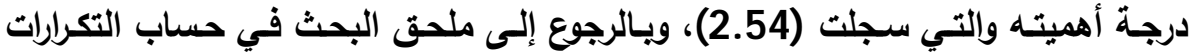

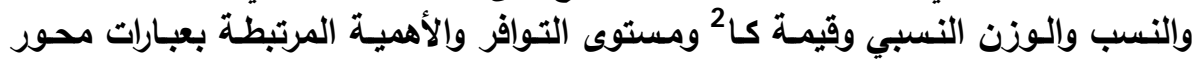
متطلبات صناعة المعلومات، وجد أنه: 


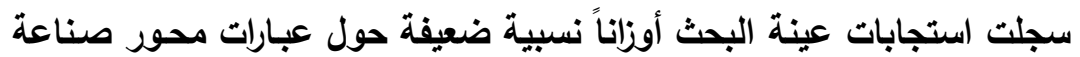

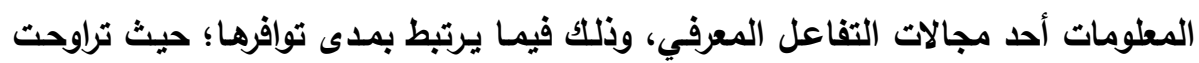

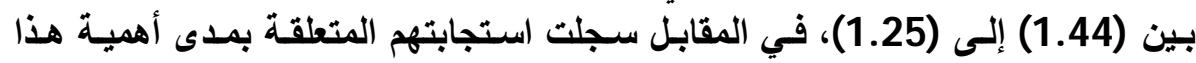

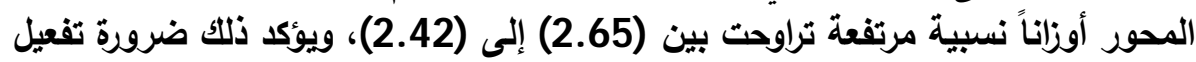
هذا المجال بما يساعد في تتمية التفاعل المعرفي عبر شبكات التواصل الاجتماعي بصورة

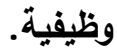

وأكلات عينة البحث على ضرورة تنقية المعلومات التي يتم الحصول عليها بغية

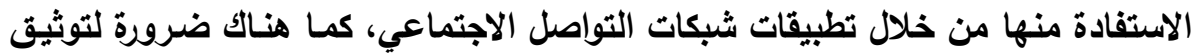

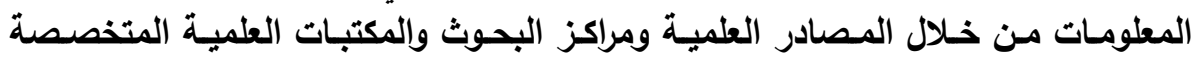

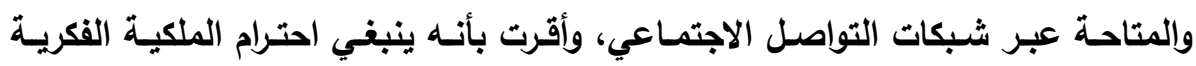

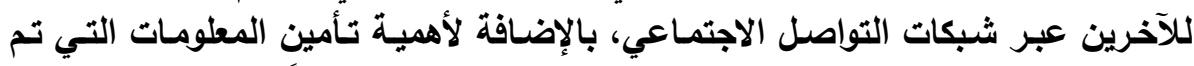

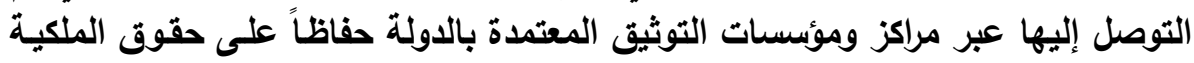

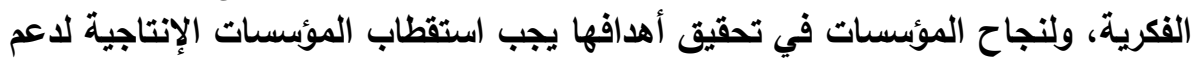

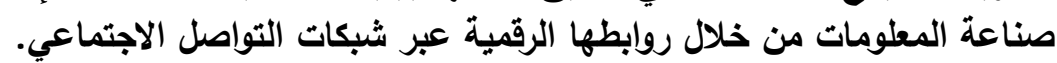

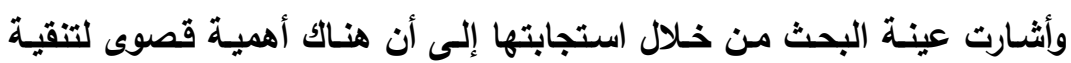

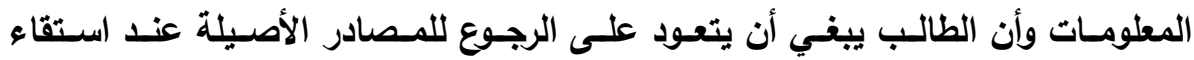

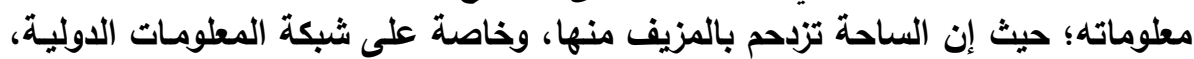

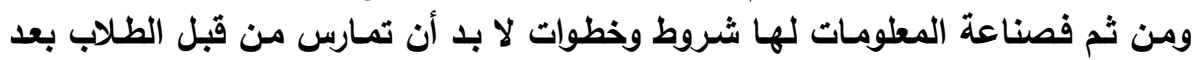

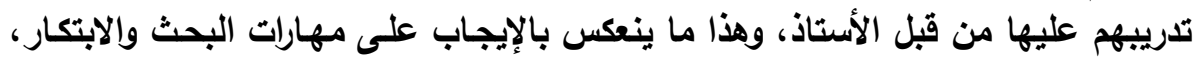
والتي تقترن بمهارات القرن الحادي والعشرين.

المور التاسع: قياس الإنجاز الأكاديمي

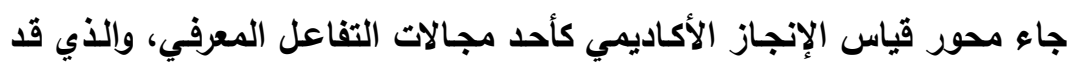
يسهم في تنميتها عبر شبكات التواصل الاجتماعي في (10) عبارات، تمخضت الأبـ نتائجها

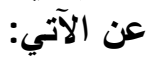


مجلة كلية التربية، جامعة الأزهر، العدد: (183، الجزء الثاني) يوليو لسنة 2019م

\section{جدول (11)}

درجة ومستوى التوافر والأهمية والوزن النسبي لمحور تنمية قياس الإنجاز الأكاديمي

\begin{tabular}{|c|c|c|c|c|c|c|c|c|c|}
\hline \multirow{4}{*}{ 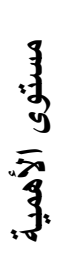 } & \multirow{4}{*}{$\begin{array}{l}\overline{3} \\
3 \\
\overline{7} \\
3\end{array}$} & \multicolumn{3}{|c|}{ درجة الأهمية } & \multirow{4}{*}{ 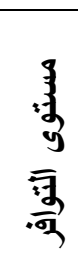 } & \multirow{4}{*}{ 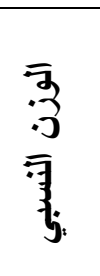 } & \multicolumn{3}{|c|}{ درجة التوافر } \\
\hline & & ضعيفة & متوسطة | متطب & كبيرة & & & |ضعيفة & متوسطة | متوة & كبيرة \\
\hline & & ك & ك & ك & & & ك5 & ك & ك5 \\
\hline & & 1023 & 4490 & 8687 & & & 10153 & 3338 & 709 \\
\hline \multirow{3}{*}{ 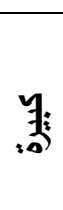 } & \multirow{2}{*}{2.54} & درجة & درجة & درجة & \multirow{3}{*}{ 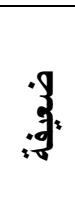 } & \multirow{2}{*}{1.33} & درجة & درجة & درجة \\
\hline & & 1023 & 8980 & 26061 & & & 10153 & 6676 & 2127 \\
\hline & \multicolumn{4}{|c|}{36064} & & \multicolumn{2}{|c|}{18956} & \multicolumn{2}{|c|}{ المجموع الكلى } \\
\hline
\end{tabular}

باستقراء بيانات الجدول السابق يتضح أن مكونات قياس الإنجاز الأكاديمي غير

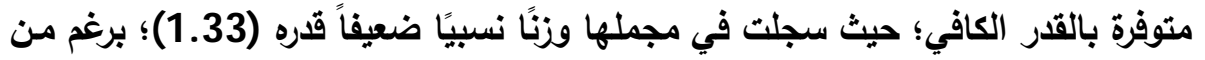

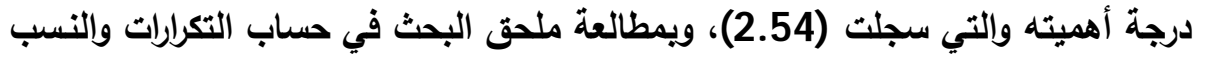

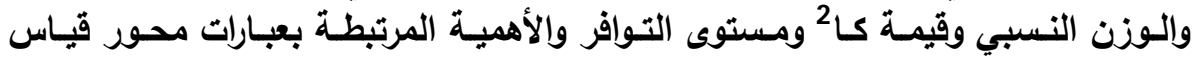
الإنجاز الأكاديمي، وجد أنه:

سجلت استجابات عينة البحث أوزاناً نسبية ضعيفة حول عبارات محور قياس

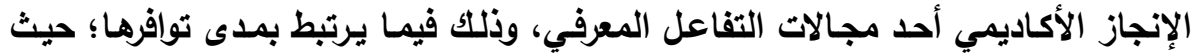

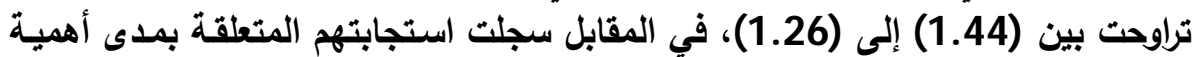
هذا المحور أوزاناً نسبية مرتفعة تراوحت بين (2.57) إلى (250)، ويؤكد ذلك ضرورة التهاب

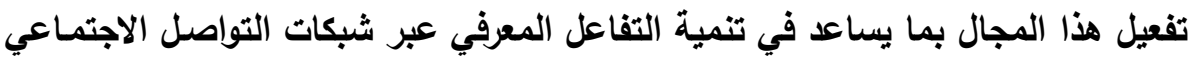

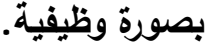

وأثشارت عينة البحث إلى أهمية أن يحرص الأستاذ على تنويع أسـاليب التقويم

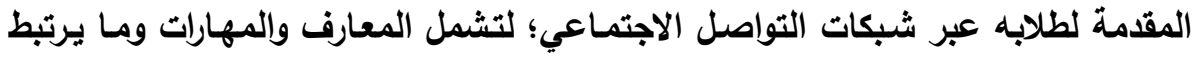

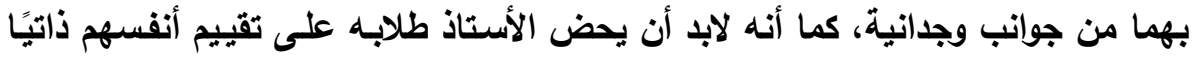

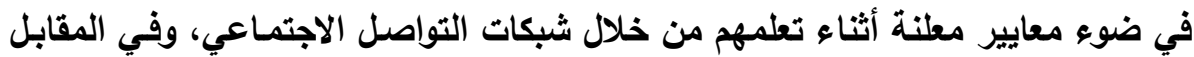

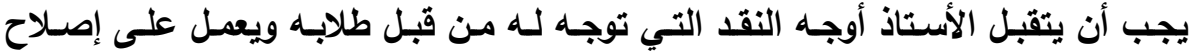

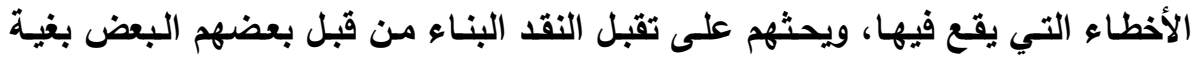
تحسين مستوى التعلم لايهم عبر شبكات التواصل الاجتماعي، كما ينبغي أن يعلن الأستاذ

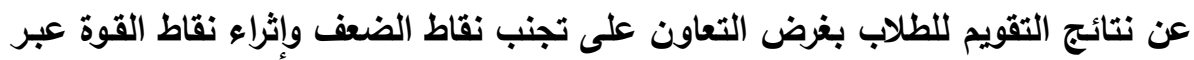

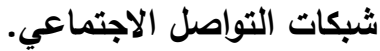


وتؤكلد استجابات عينة البحث على أن الإنجاز الأكاديمي ليس قاصراً على نواتج التهل

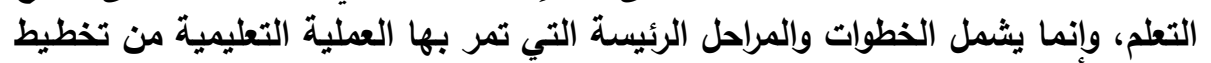

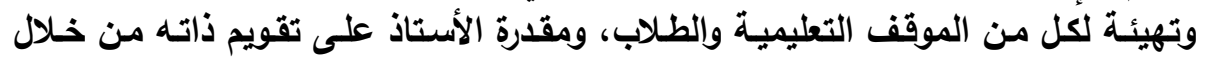

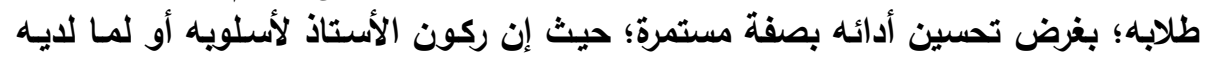

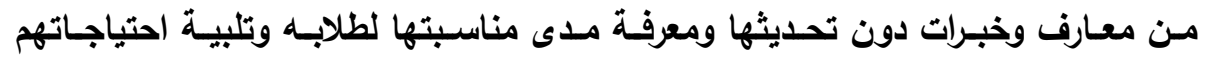

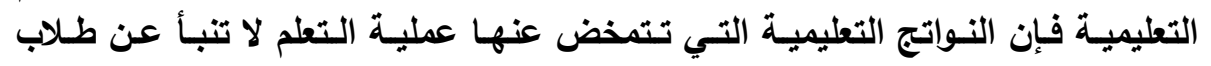
يمتلكون مهارات القرن الحادي والعشرين .

\section{المور العاشر - تحسين الموقف التعليسيمي}

جاء محور تحسين الموقف التعليمي كأحد مجالات التفاعل المعرفي، والذي قدي التهاتي يسهم في تنميتها عبر شبكات التواصل الاجتماعي في (15) عبارة، تمخضت نتائجها عن

جدول (12)

درجة ومستوى التوافر والأهمية والوزن النسبي لمحور تحسين الموقف التعليمي

\begin{tabular}{|c|c|c|c|c|c|c|c|c|c|}
\hline \multirow{4}{*}{ 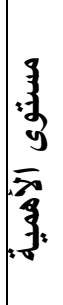 } & \multirow{4}{*}{$\begin{array}{l}\overline{3} \\
3 \\
\overline{3} \\
\overline{3}\end{array}$} & \multicolumn{3}{|c|}{ درجة الأهمية } & \multirow{4}{*}{ 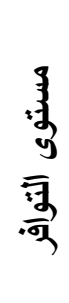 } & \multirow{4}{*}{$\begin{array}{l}\overline{3} \\
\overline{3} \\
\overline{7} \\
\overline{3}\end{array}$} & \multicolumn{3}{|c|}{ درجة التوافر } \\
\hline & & ضعيفة & متوسطة | & كبيرة & & & ضعيفة & متوسطة & كبيرة \\
\hline & & ك & ك & ك5 & & & ك & ك & ك \\
\hline & & 944 & 4350 & 8906 & & & $\begin{array}{c}1012 \\
1\end{array}$ & 3647 & 432 \\
\hline \multirow{3}{*}{ 寻: } & \multirow{2}{*}{2.56} & درجة & درجة & لدرجة & \multirow{3}{*}{ 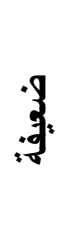 } & \multirow{2}{*}{1.32} & درجة & درجة & درجة \\
\hline & & 944 & 8700 & 26718 & & & $\begin{array}{c}1012 \\
1\end{array}$ & 7294 & 1296 \\
\hline & \multicolumn{4}{|c|}{36362} & & \multicolumn{2}{|c|}{18711} & \multicolumn{2}{|c|}{ المجموع الكلي } \\
\hline
\end{tabular}

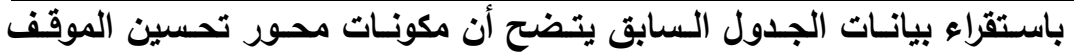

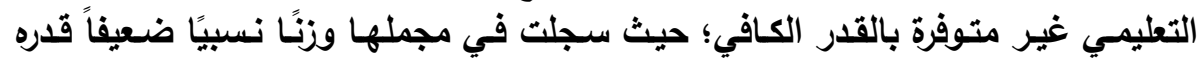
(1.32)؛ برغم من درجة أهميته والتي سجلت (2.56)، ويالنظر إلى بيانات ملحق البحث

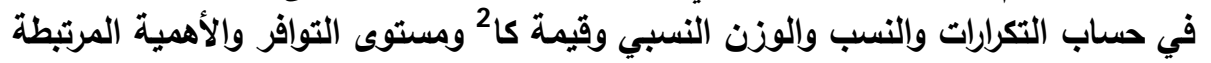
بعبارات محور تحسين الموقف التعليمي، وجد أنه:

سجلت استجابات عينة البحث أوزاناً نسبية ضعيفة حول عبارات محور تحسين

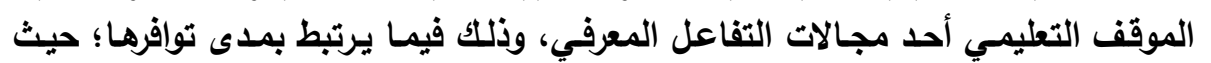


مجلة كلية التربية، جامعة الأزهر، العدد: (183، الجزء الثاني) يوليو لسنة 2019م

تراوحت بين (1.46) و(1.18)، في المقابل سجلت استجابتهم المتعلقة بمدى أهمية هذا لئل

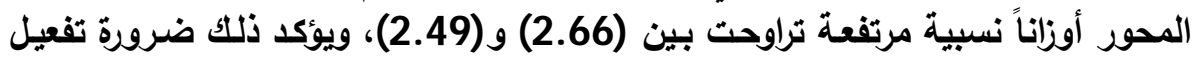
هذا المجال بما يساعد في تنمية التفاعل المعرفي عبر شبكات التواصل الاجتماعي بصورة

وظيفية.

أكلات عينة البحث على أهمية أن يعطي الأستاذ مساحات من الحريـة الأكاديمية

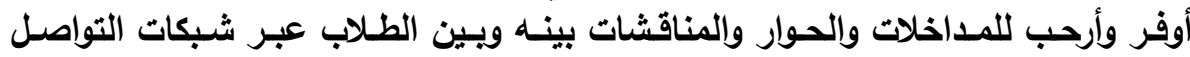

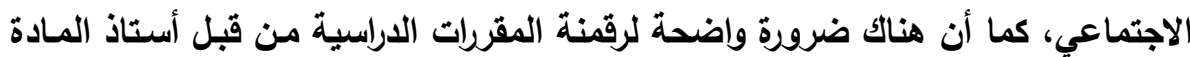
لسهولة تداولها بين الطلاب عبر شبكات التواصل الاجتماعي، كما أن التحسين يتوقف فئف

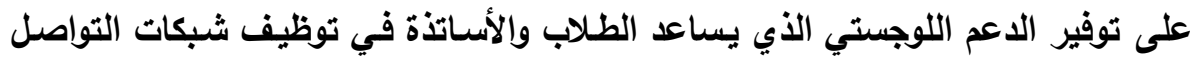

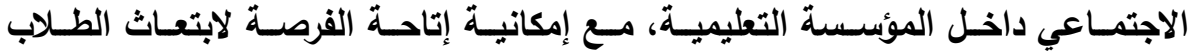

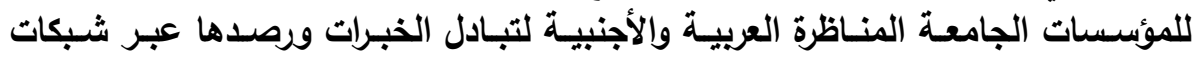

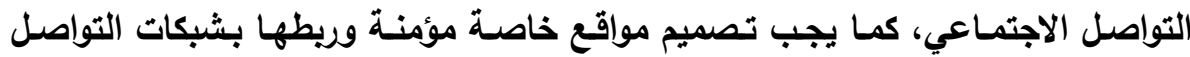
الاجتماعي يديرها الطلاب ويشرف عليها الأساتذة في كافة مجالات التعلم.

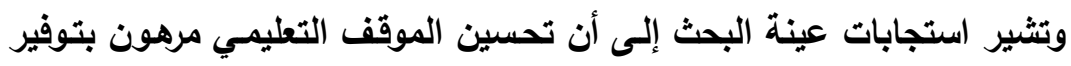

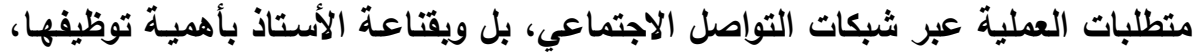

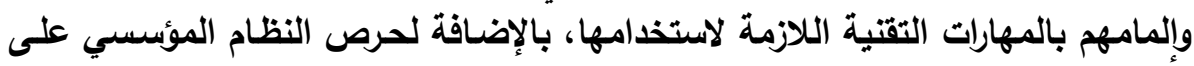
تقديم الدعم اللوجستي المستمر داخل المؤسسة التعليمية وخارجها، مع الإثراف المستمر من قبل المتخصصين على المستويين التقني والأكاديمي.

\section{نتائج الفروق بين متغيرات الدراسة:}

جاءت نتائج الفروق بين عينة البحث على استبانة الكشف عن درجـة توافر

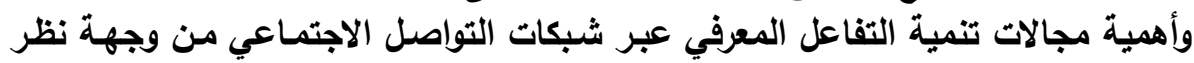
أعضاء هيئة التدريس، متمثلة في المتغيرات التالية:

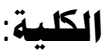

تقدم الجداول التالية عرضًا مختصرًا لنتائج الفروق بين عينة البحث حول محكي التوافر والأهمية والتي يمكن أن تعزي لمتغير الكلية فيما يلي: 
جدول (13)

نتائج تحليل التباين لتوضيح الفروق عن نتائج عينة البحث وفق (متغير الكلية) على بلى محكي التوافر والأهمية بالاستبانة

\begin{tabular}{|c|c|c|c|c|c|c|}
\hline الإحصائية & يمة (ف) & (التباين) المريعا & الحرية & مجموع المربعات & مصدر التباين & المحك \\
\hline 0.240 & \multirow{3}{*}{1.255} & 95.759 & 9 & 1761.827 & بين المجموعات & \multirow{3}{*}{ توافر } \\
\hline \multirow{2}{*}{ غير دالة } & & 58.147 & 1410 & 74807.285 & داخل المجموعات | & \\
\hline & & & 1419 & 76569.112 & المجموع & \\
\hline 0.350 & \multirow{3}{*}{1.113} & 57.604 & 9 & 518.432 & بين المجموعات & \multirow{3}{*}{ أهمية } \\
\hline \multirow{2}{*}{ غير دالة } & & 51.749 & 1410 & 72966.561 & داخل المجموعات | & \\
\hline & & & 1419 & 73484.994 & المجموع & \\
\hline
\end{tabular}

بالنظر إلى قيمة (ف) بالجدول السابق (24)، وجد أنها غير دالة إحصائيًا عند

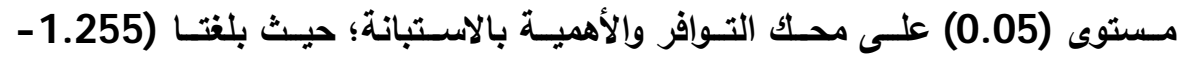

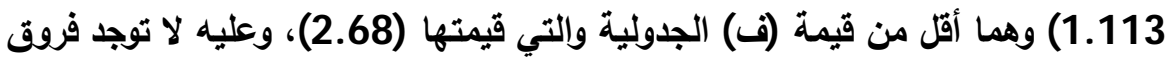

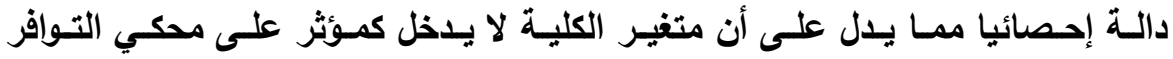

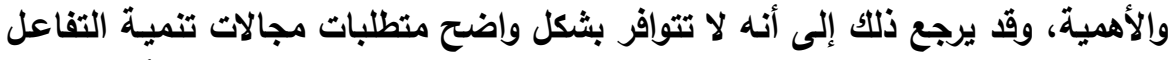

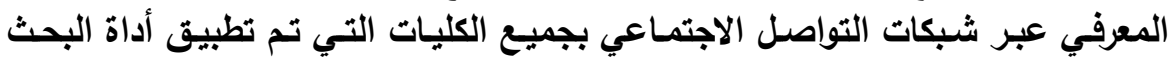

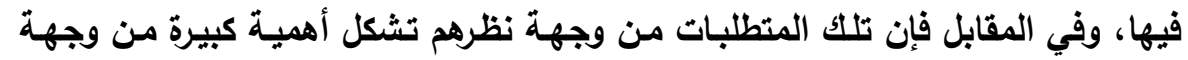

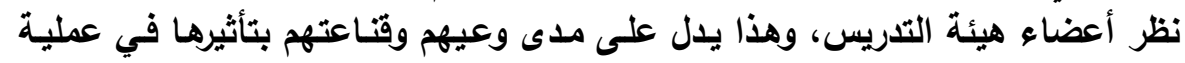

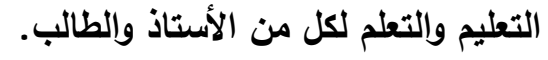

هتغير الدرجة العلميية:

تقدم الجداول التالية عرضًا مختصرًا لنتائج الفروق بين عينة البحث حول محكي التوافر والأهمية والتي يمكن أن تعزي لمتغير الدرجة العلمية فيما يلي: لتئي 
مجلة كلية التربية، جامعة الأزهر، العدد: (183، الجزء الثاني) يوليو لسنة 2019م

$$
\text { جدول (14) }
$$

نتائج تحليل التباين لتوضيح الفروق عن نتائج عينة البحث وفق (متغير الدرجة العلمية) على محكي التوافر والأهمية بالاستبانة

\begin{tabular}{|c|c|c|c|c|c|c|}
\hline الإحصائية & قيمة (ف) & لتوسط المربعات & الرجية & المربعات & مصدر التباين & المحك \\
\hline .000 & \multirow{3}{*}{24.498} & 1446.621 & 2 & 2893.243 & بين المجموعات & \multirow{3}{*}{ توافر | توا } \\
\hline \multirow{2}{*}{ دالة } & & 59.051 & 1417 & 83675.869 & داخل المجموعات & \\
\hline & & & 1419 & 86569.112 & المجموع & \\
\hline .005 & \multirow{3}{*}{5.233} & 269.383 & 2 & 538.766 & بين المجموعات & \multirow{3}{*}{ أهمية } \\
\hline \multirow{2}{*}{ دالة } & & 51.479 & 1417 & 72946.228 & داخل المجموعات & \\
\hline & & & 1419 & 73484.994 & المجموع & \\
\hline
\end{tabular}

بالنظر إلى قيمـة (ف) بالجدول السابق وجد أنها دالـة إحصائيًا عند مستوى (23.

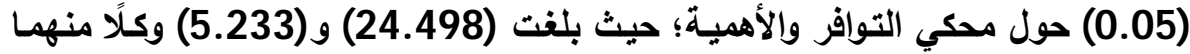

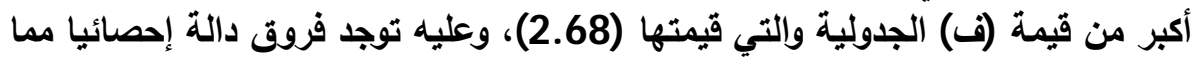

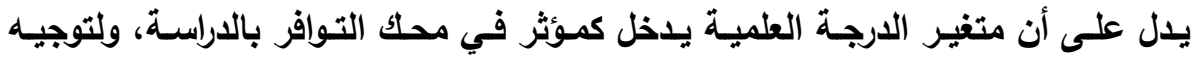

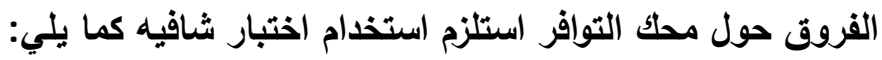


جدول (15)

نتائج اختبار شافيه لتوجيه الفروق بين عينة البحث وفق (متغير الارجة العلمية) على بلى محك التوافر بالاستبانة البن

\begin{tabular}{|c|c|c|c|c|}
\hline \multicolumn{3}{|c|}{ قيمة (ق) للمقارنة الطرفية بين المجموعات } & \multirow{2}{*}{ 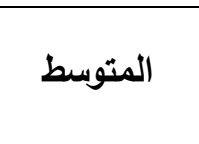 } & \multirow{2}{*}{ متفير الارجة } \\
\hline 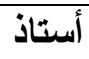 & أستاذ مساعد & 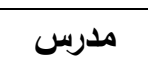 & & \\
\hline & & - & 145.7000 & 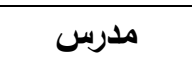 \\
\hline & - & $* 4.197$ & 149.8975 & أستاذ مساعد \\
\hline- & $* 2.418$ & $* 1.779$ & 147.4795 & 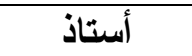 \\
\hline
\end{tabular}

باستقراء بيانات الجدول السابق يتضح أنه:

- يوجد فرق دال إحصائياً عند مستوى (0.05) وذلك بين مدرس وأستاذ

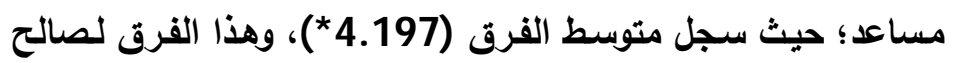

$$
\text { الأستاذ المساعد. }
$$

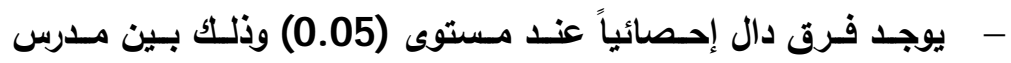

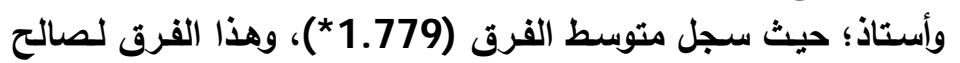

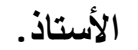

- - يوجد فرق دال إحصائياً عند مستوى (0.05) وذلك بين أستاذ مساعد

وأستاذ؛ حيث سجل متوسط الفئال الفرق (2.418*)، وهذا الفرق لصالح

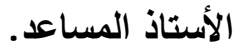

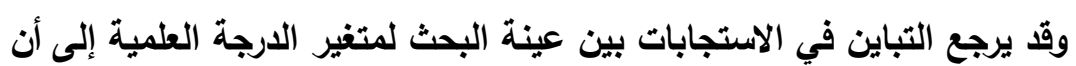

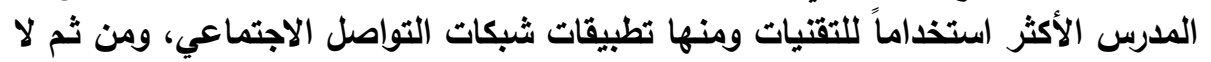

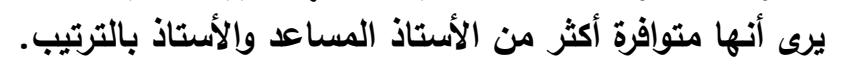

ولتوجيه الفروق على متغير الارجة العلمية الذي ياخل كمؤثر في محك الأهمية

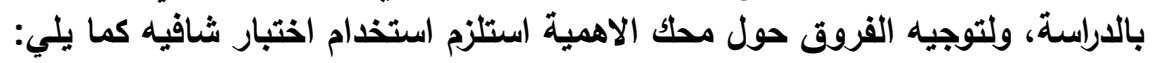


مجلة كلية التربية، جامعة الأزهر ، العدد: (183، الجزء الثاني) يوليو لسنة 2019م

$$
\text { جدول (16) زئ) }
$$

نتائج اختبار شافيه لتوجيه الفروق بين عينة البحث وفق (متغير الارجة) على محك الأهمية بالاستبانة

\begin{tabular}{|c|c|c|c|c|}
\hline \multicolumn{3}{|c|}{ قيمة (ق) للمقارنة الطرفية بين المجموعات } & \multirow{2}{*}{ 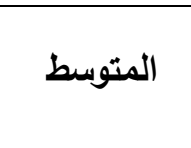 } & \multirow{2}{*}{ متغير الارجة } \\
\hline أستاذ & أستاذ مساعد & مدرس & & \\
\hline & & - & 272.2042 & مدرس \\
\hline & - & $* 1.894$ & 270.3100 & أستاذ مساعد \\
\hline - & 0.669 & 1.224 & 270.9795 & 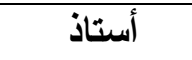 \\
\hline
\end{tabular}

(*) دالة عند مستوى (0.05)

باستقراء بيانات الجدول السابق يتضح أنه:

- يوجد فرق دال إحصائياً عند مستوى (0.05) وذلك بين مدرس وأستاذ مساعد؛

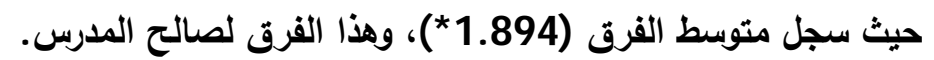

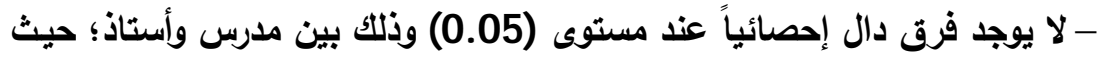

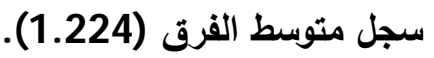

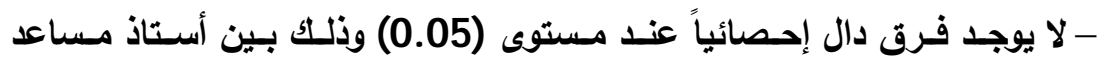
وأستاذ؛ حيث سجل متوسط الفرق إنائ (0.669).

وتثير نتيجة البحث إلى أن المدرس يرى أهمية لمجالات تنمية التفاعل المعرفي عبر شبكات التواصل الاجتماعي، قد يرجع لقتاعته بأهميتها في العملية التعليمية، وأنها ذات تأثثر قوي على طلاب المرحلة الجامعية.

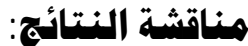

أثشارت نتائج البحث إلى أنه لا تتوافر المجالات وما يرتبط بها من متطلبات يمكن

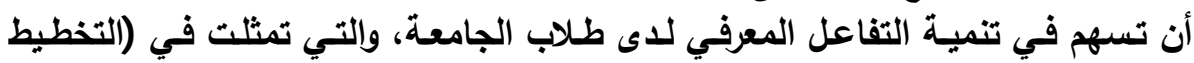

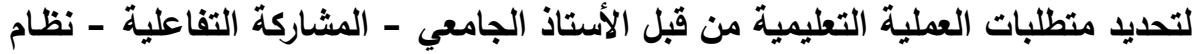

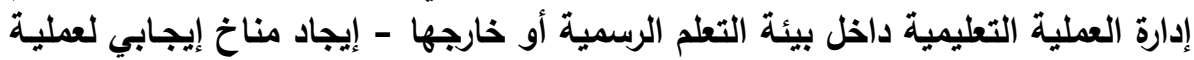

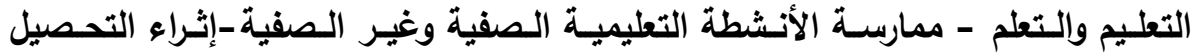

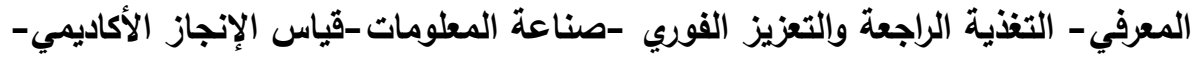

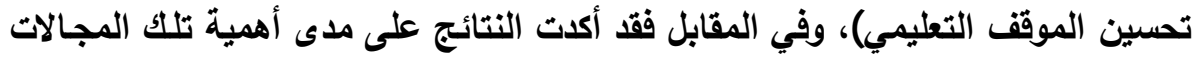

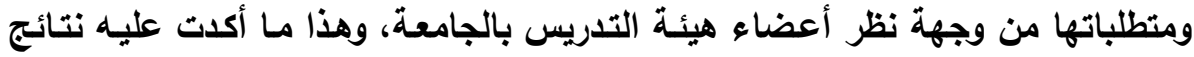


العديد من البحوث والدراسات السابقة والتي اهتمت بارسة أثر شبكات التواصل الاجتماعي

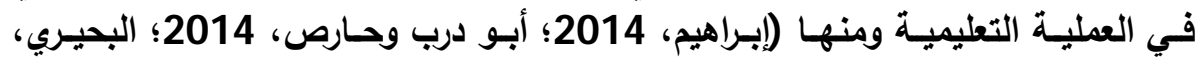

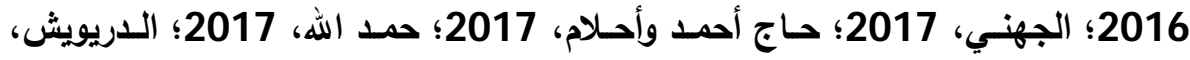

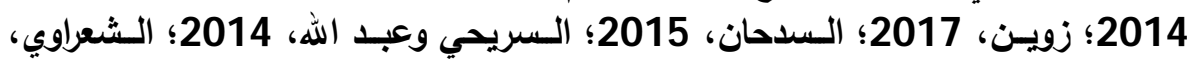

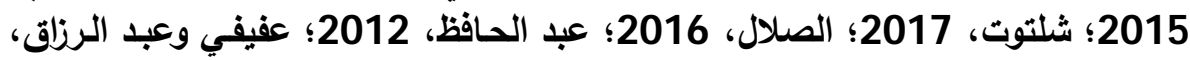

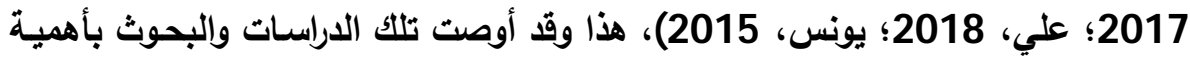

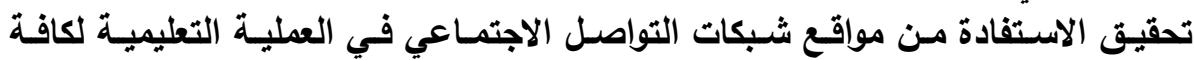

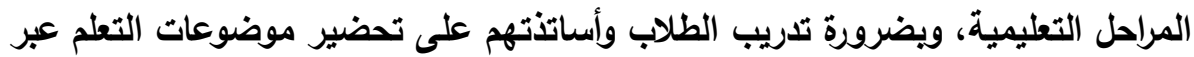

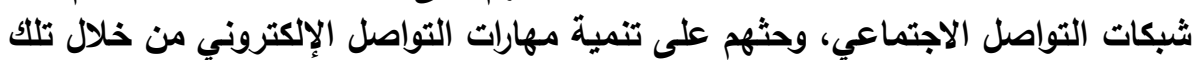

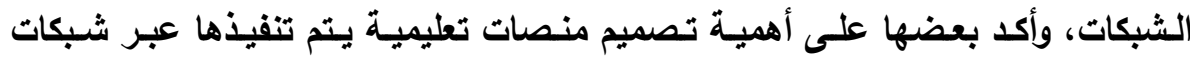

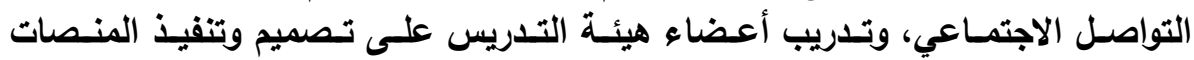

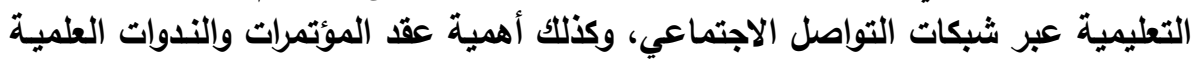

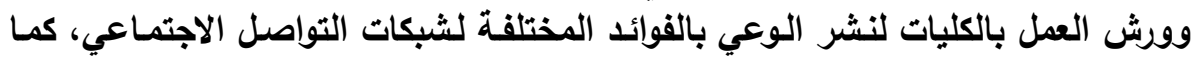

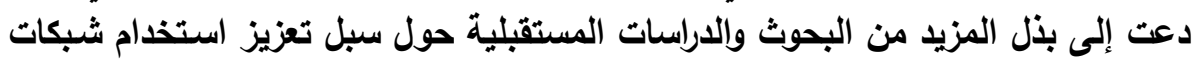
التواصل الاجتماعي لتسهيل وتعزيز التعليم.

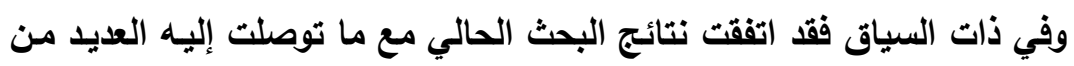

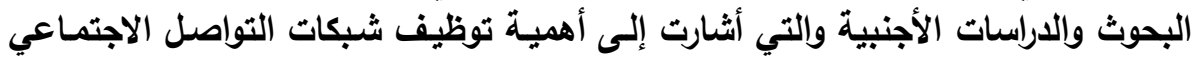

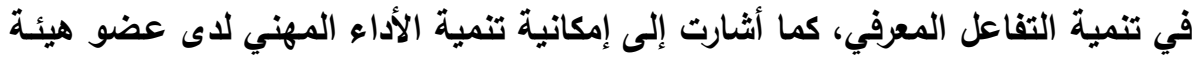

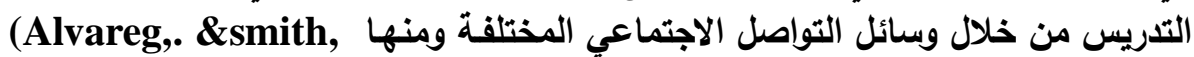
2013; Bennett, Owers, pitt, \& Tucker, 2010; Brady, HolComb, \& Smith, 2010; Buzzetto- More, 2012; Corbeil, \& Corbeil, 2011; Dalsgaard, 2013; Farb. \& Pregibon, 2011; Miah, Omar, \& Golding, 2012; Munguatosha, Muyinda, \& Lubega, 2011; Panckhurst, 2013; Stanciu, Mihai, \& Aleca, 2012; Tariq, Mehboob, yar-kan, \& ullah, 2012; Zaidieh, 2012) توصياتها على ضرورة توظيف شبكات التواصل الاجتماعي في العملية التعليمية، لدورها

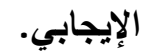


التصور الاقترع:

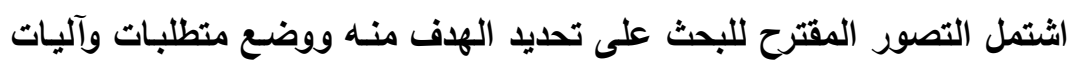

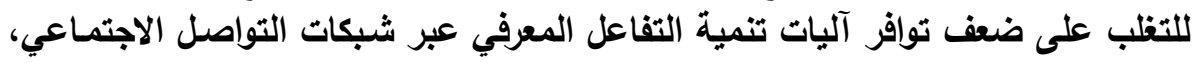

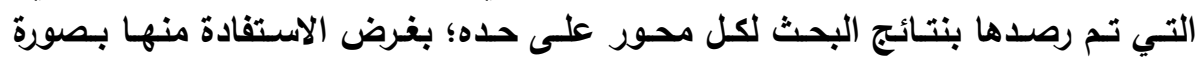

وظيفية.

الهدف هنه: تنسية التفاعل المعرفي عبر شبكات التواصل الاجتهماعي

تقوم فلسفة التصور المقترح بالبحث الحالي على تعرف مدى أهمية آليات تنمية

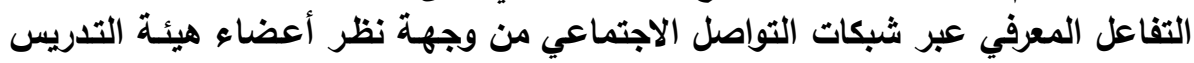

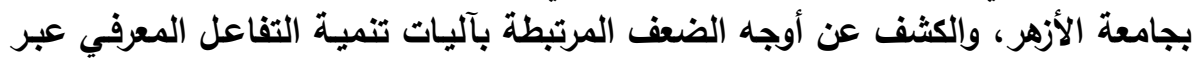

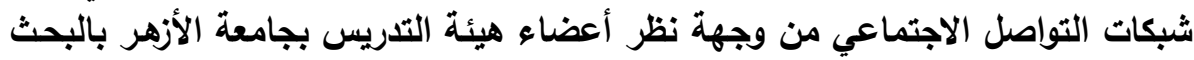

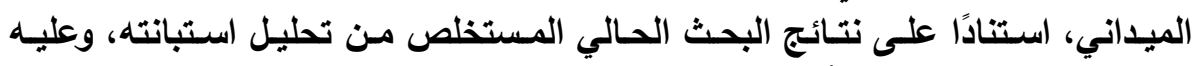

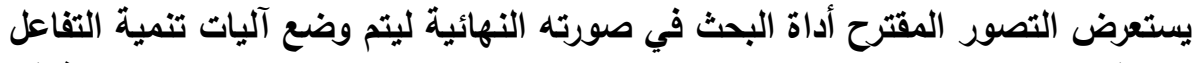

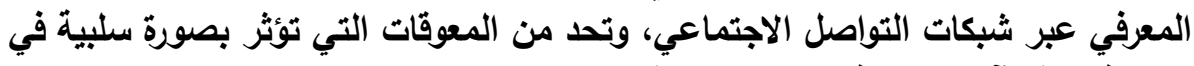

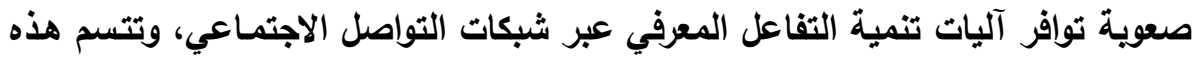

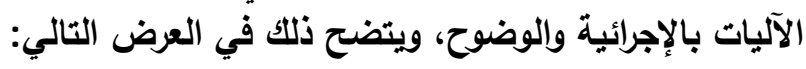

\section{المهور الأول- التخطيط لتمديد متطلبات العهملية التعليميسة هـن قبـل الأسـتاذ

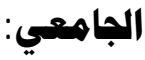

$$
\text { - - يحلل محتوى التعلم لاستخراج الخبرات المراد اكسابها للطلاب. }
$$
- - يرتب خبرات التعلم ترتيباً منطقياً.

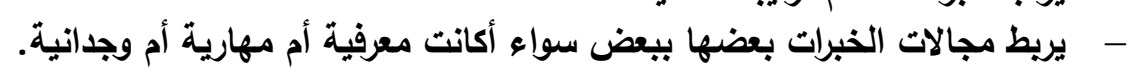

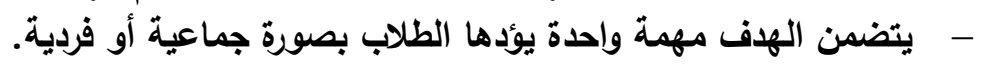

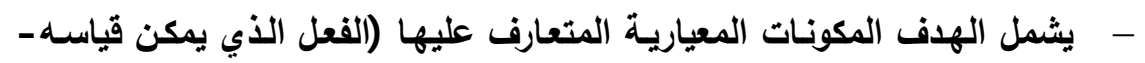

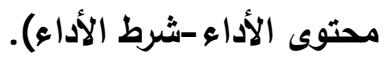

- - ت تضمن الأهداف مجالات التعلم المنشودة (المعرفية -المهارية -الوجدانية).

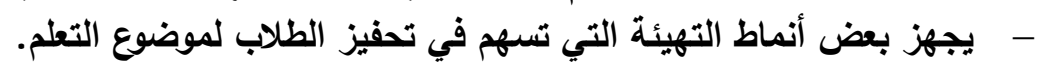

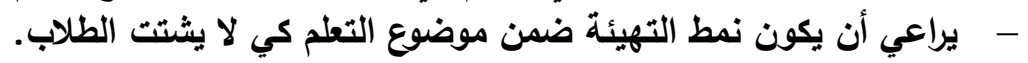

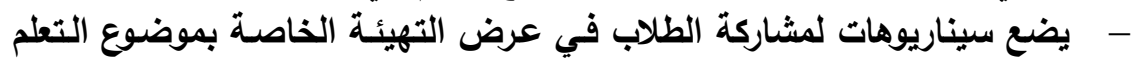
لزيادة فعاليتها.

- يقسم موضوع التعلم لعدد من الأنشطة التي يؤدي مهامها الطلاب بيسر .

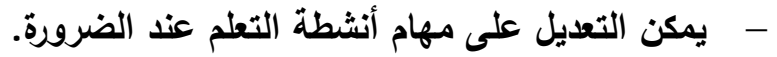

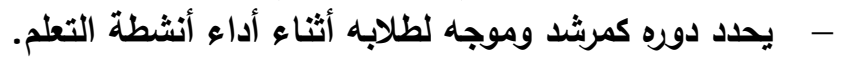


- - ينوع من طبيعة مهام أنثطة التعلم لتثمل المهمة الجماعية والفردية.

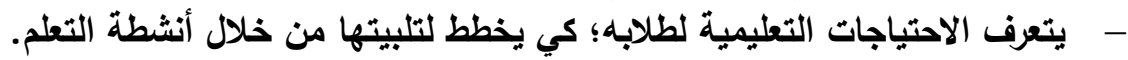
- - يراعي الفروق الفردية عند إعداد أنثطة التعلم لتلبي احتياجات جميع الطلاب.

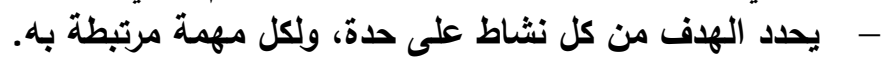

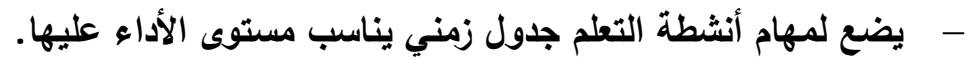

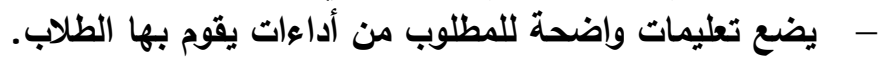

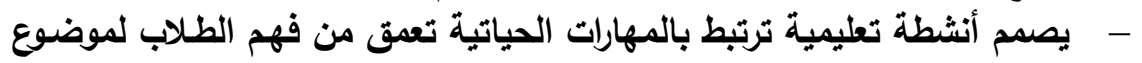
التعلم. - - يصمم أنشطة تعليمية ترتبط بقضايا ومشكلات مجتمعية ذات صلة بموضوعات التعلم. - - يستخلص العلاقات بين المفاهيم العلمية المتضمنة من الموضوعات التعليمية ووظيفتها الحياتية. - - ينوع من الأنثطة التعليمية؛ ليضع بدائل تتناسب مع خصائص الطلاب التعليمية

$$
\text { وتراعي الفروق والاحتياجات التعليمية. }
$$

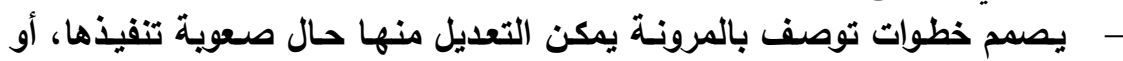

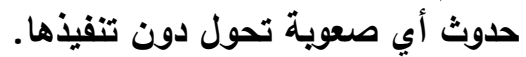
- - يسجل الأستاذ الصعويات التعليميـة والأخطاء التي تصدئ تصدر عن الطلاب أثنـاء

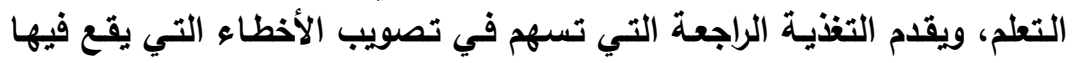
الطلاب. - - ينوع من أسـاليب تقديم التغذيـة الراجعة التي تسهم في تصحيح مسار التعلم بالنسبة للطلاب. - - ينوع من أسـاليب التقويم وفق نواتج التعلم المرتقب تقويمها مـا بين اختبارات

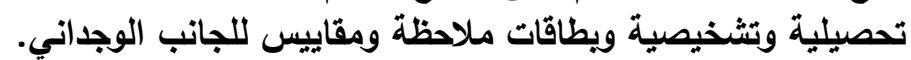
- براعي الفروق الفردية في المستوى التعليمي للطلاب عند تصميم أدوات التقويم المرتبطة بالتحقق من أهداف التعلم.

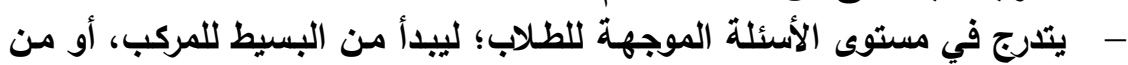

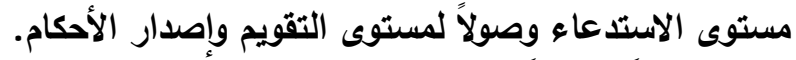

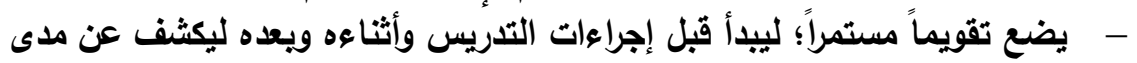
تحقق أهداف التعلم. - - يريط التقويم بمهام أنثطة التعلم، مع ضرورة تقويم مهارات التفكير العليا للى الطلاب. 
مجلة كلية التربية، جامعة الأزهر، العدد: (183، الجزء الثاني) يوليو لسنة 2019م

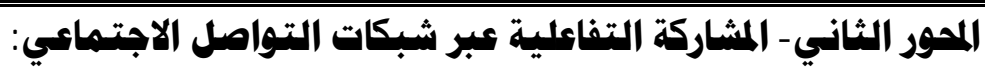

- - تنويع المصادر والمراجع الرقمية المرتبطة بالمادة الدراسية وإتاحتها عبر شبكات التواصل الاجتماعي.

- - توفير روابط المصادر والمراجع الرقمية المرتبطة بالمادة الدراسية واتاحتها عبر شبكات التواصل الاجتماعي.

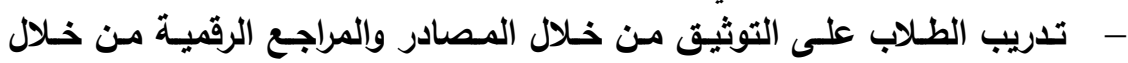
شبكات التواصل الاجتماعي في خطوات واضحة والئ ويسيطة.

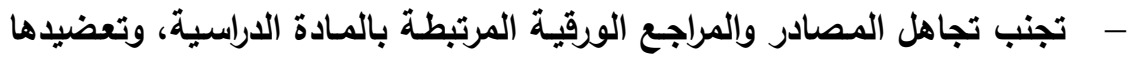
للمصادر والمراجع الرقمية. - - تنسيق العمل الجماعي بين الطلاب على مهام الأنشطة التعليمية عبر شبكات

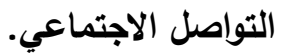
- - وضع معايير واضحة متفق عليها لتقويم نتائج مهام الأنشطة التعليمية بين

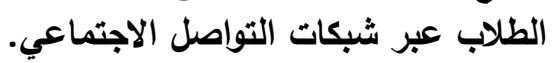
- - الحرص على تبادل نتائج مهام الأنشطة التعليميـة بين الطلاب عبر شبكات التواصل الاجتماعي. - - تقويم الأداء ذاتياً من قبل الطلاب والأستاذ بغية التحسين والتطوير عبر شبكات التواصل الاجتماعي.

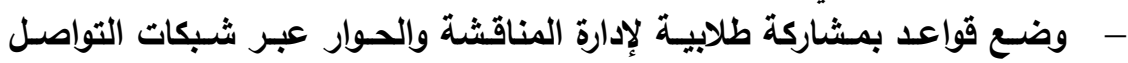

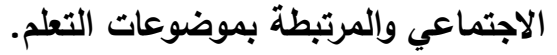

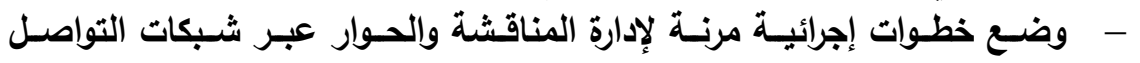

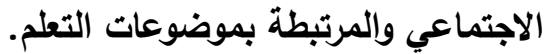

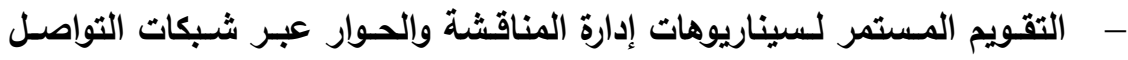

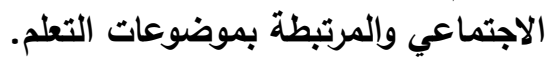

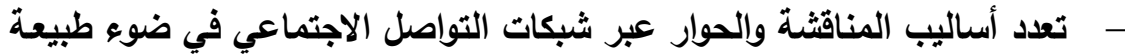
الموضوعات التعليمية التي يتم تناولها.

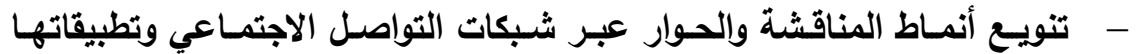
المتنوعة في ضوع توزيع الطلاب على مهام أنشطة التعلم .

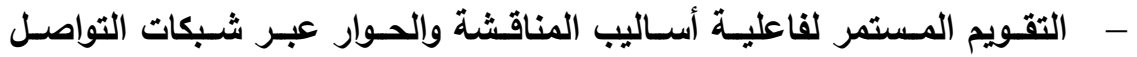

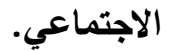

- - مث الأستاذ طلابه على الالتزام بقواعد المناقشة والحوار المتفق عليها سلفاً.

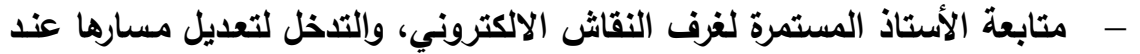
الحاجة لذلك. 
- - التنسيق مع الخبراء والمتخصصين في المجالات المختلفة عند التخطيط لموضوع

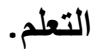

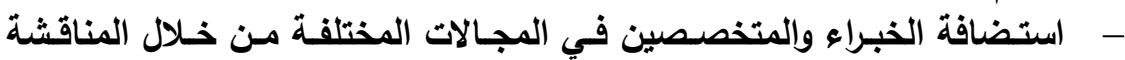

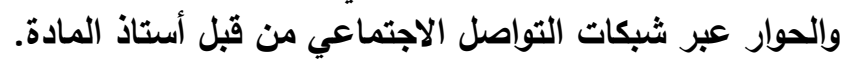

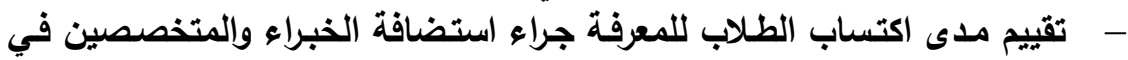

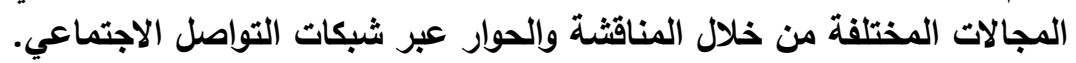

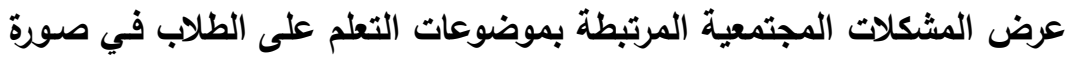
تستثير تفكيرهم عبر شبكات التواصل الاجتماعي.

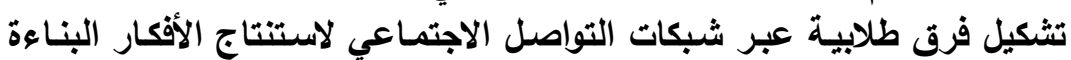

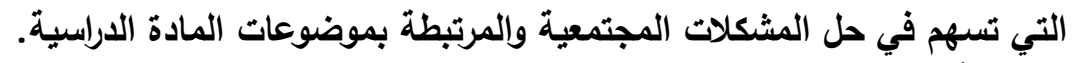

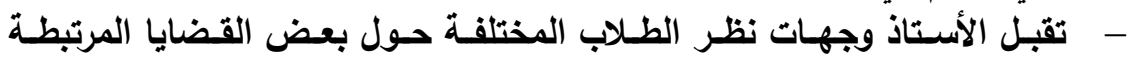
بموضوعات التعلم عبر شبكات التواصل الإبت الاجتماعي.

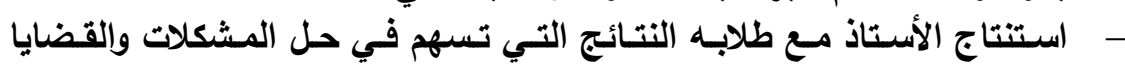

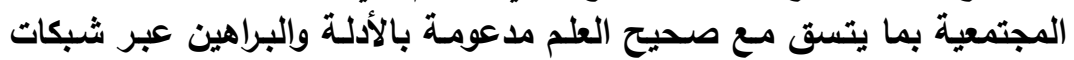
التواصل الاجتماعي.

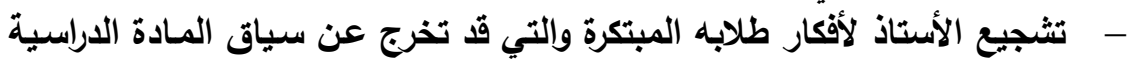

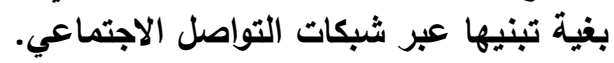

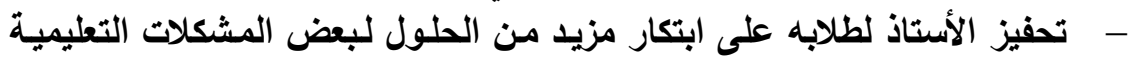

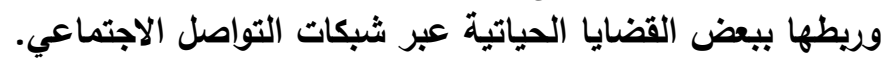

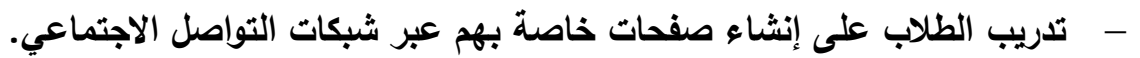

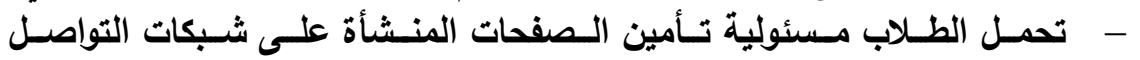

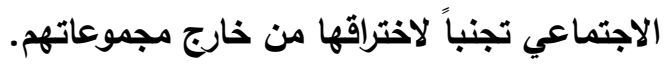

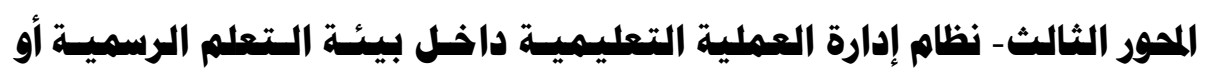

- - يعمل الأستاذ على إدارة العملية التعليمية عبر شبكات التواصل الاجتمـاعي من خلال إيجاد مناخ اجتماعي إيجابي.

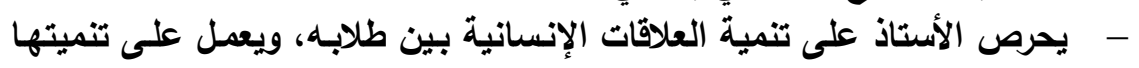

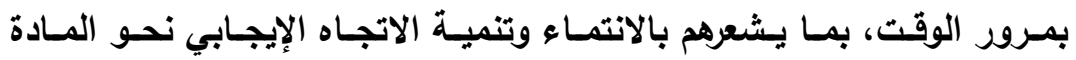

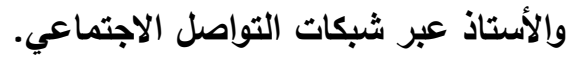

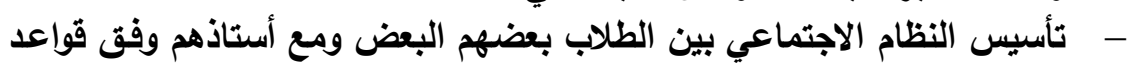

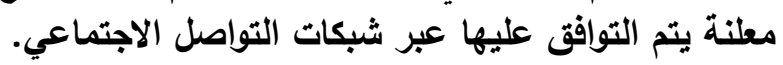


مجلة كلية التربية، جامعة الأزهر، العدد: (183، الجزء الثاني) يوليو لسنة 2019م

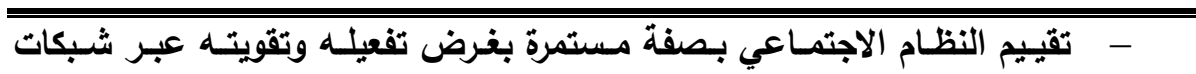

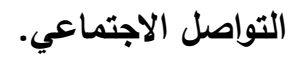

- - الحرص على تنمية الأنماط السلوكية المرغوب فيها، وتعضيدها بصفة مستمرة

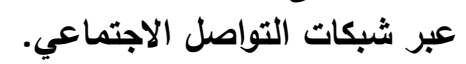

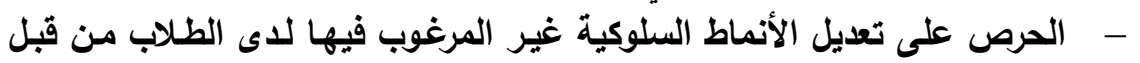
أستاذهم عبر شبكات التواصل الاجتماعي.

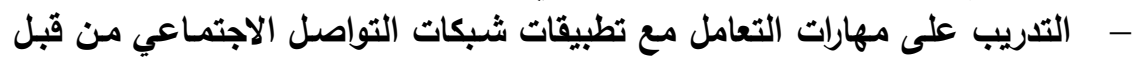
الأستاذ بثكل مستمر لمواكبة التحديثات المرتبطة بهات التهات

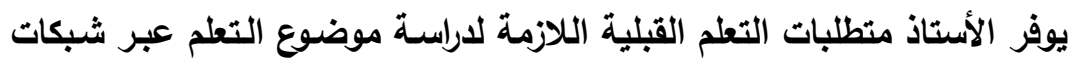

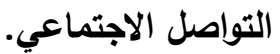
- - يقيم الأستاذ طلابـه بصفة مستمرة ليتأكلد من حدوث التعلم للدى طلابـه عبر شبكات التواصل الاجتماعي.

- يحاول الأستاذ أن يلتزم بمخططه الاجئمي، المسبق للتعلم؛ مما يساعداه على إدارة العملية

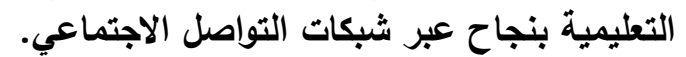

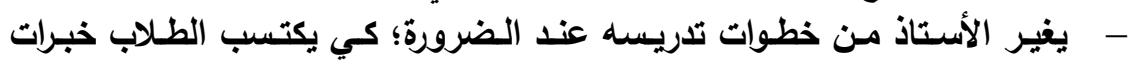

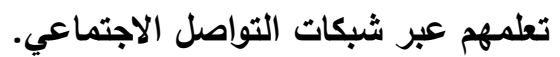

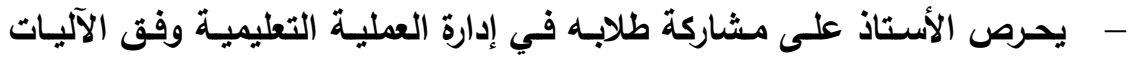

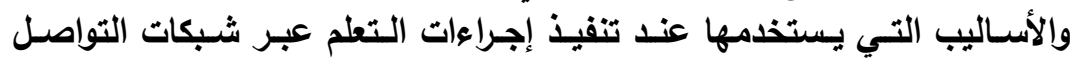
الاجتماعي. - - مرورة امتلاك الأستاذ مهارة إدارة الوقت خلال تنفيذ إجراءات التعلم عبر شبكات

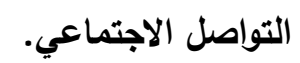
- - مرص الأستاذ على استثمار ما يتوافر من إمكانـات متاحة في البيئة التعليميـة عبر شبكات التواصل الاجتماعي.

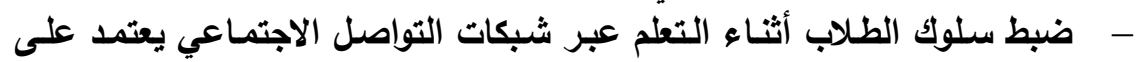
مدى التزامهم بقواعد العمل المتفق عليها سلفاً.

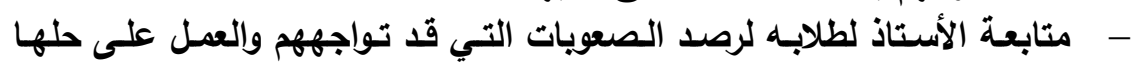

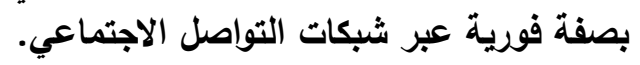

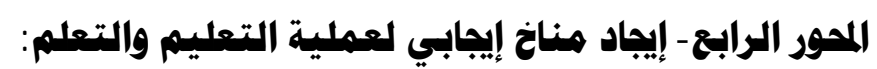

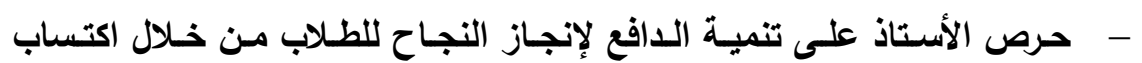

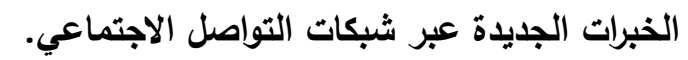

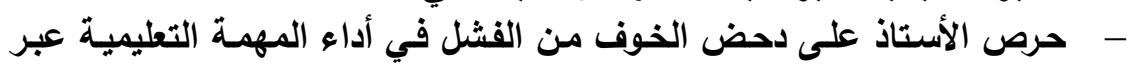
شبكات التواصل الاجتماعي. 
- - تسجيل الأستاذ بمشاركة طلابـه لآرائهم وتعليقاتهم نحو القضايا والمشكلات

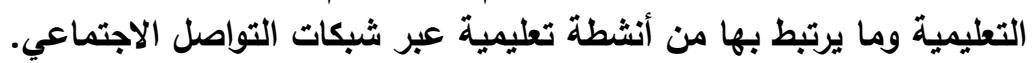

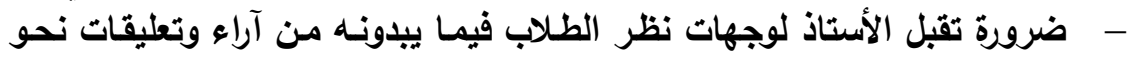

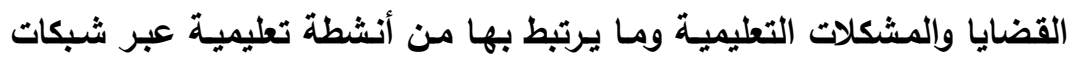

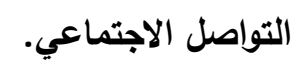

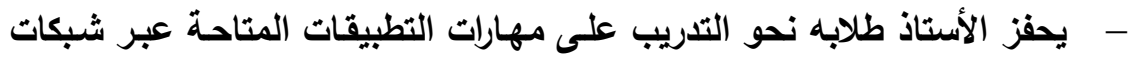

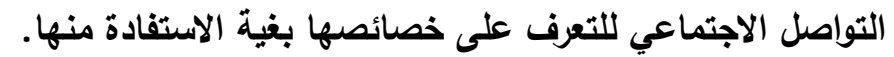

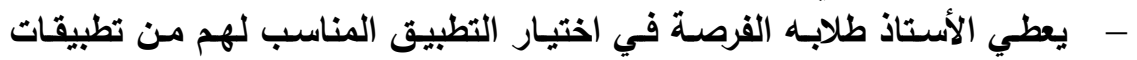
شبكات التواصل الاجتماعي.

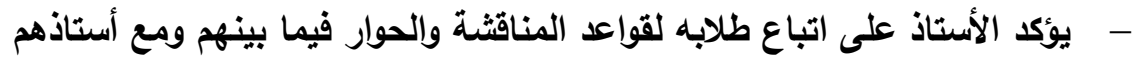

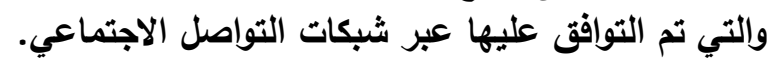

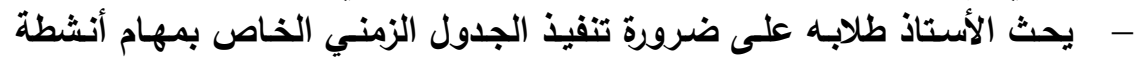

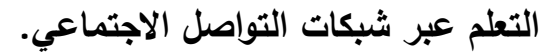

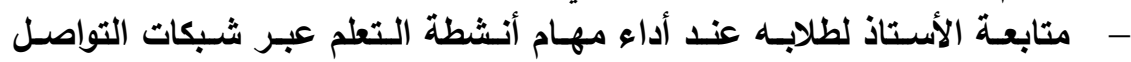

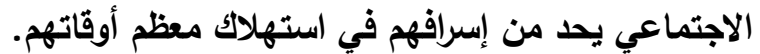

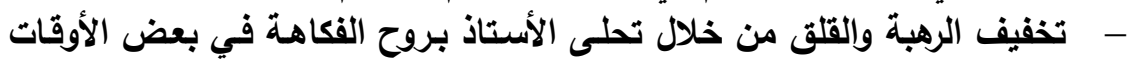

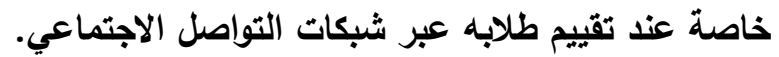

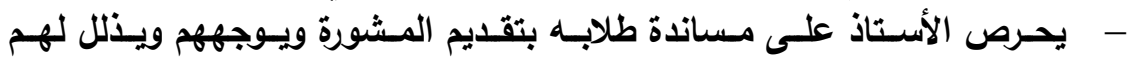

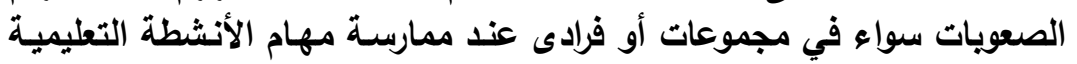
عبر شبكات التواصل الاجتماعي.

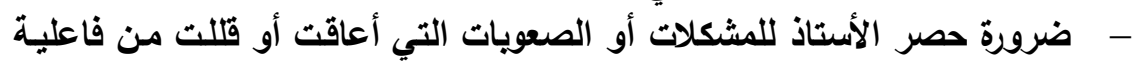

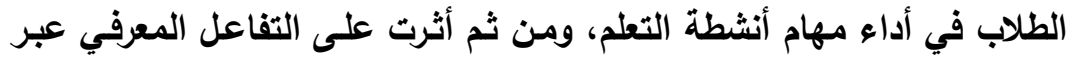
شبكات التواصل الاجتماعي.

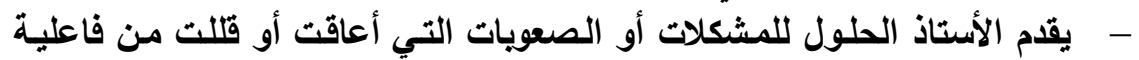

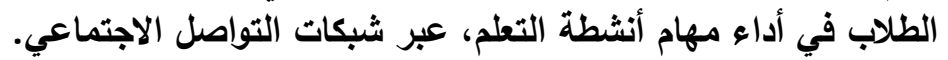

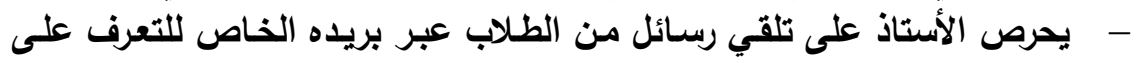

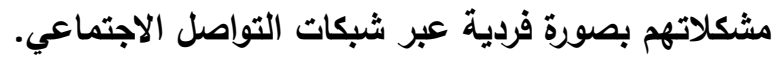

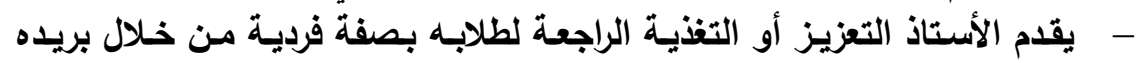

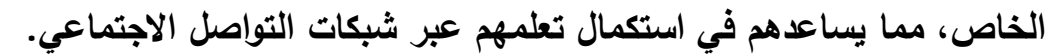

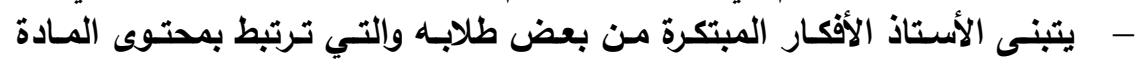
الاراسية عبر شبكات التواصل الاجتماعي. 
مجلة كلية التربية، جامعة الأزهر، العدد: (183، الجزء الثاني) يوليو لسنة 2019م

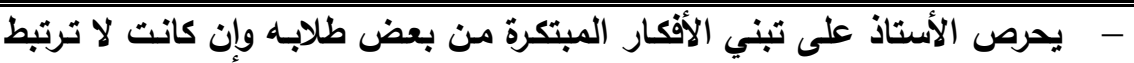

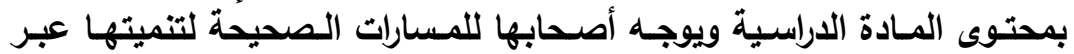
شبكات التواصل الاجتماعي.

\section{الحمور الخامس - همارسة الأنشطة التعليمية الصفية وغير الصفية:}

- - يحرص الأستاذ دوماً على تهيئة المناخ المناسب للطلاب عبر شبكات التواصل

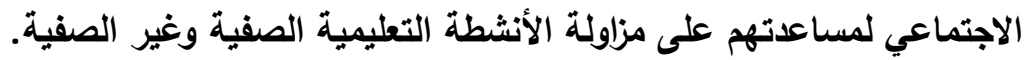

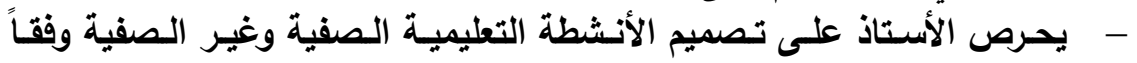

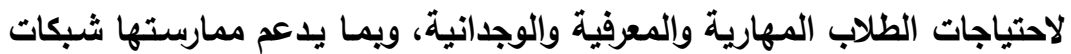

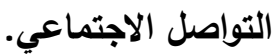

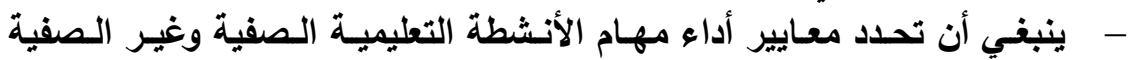

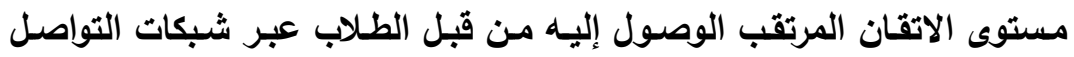

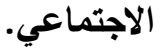

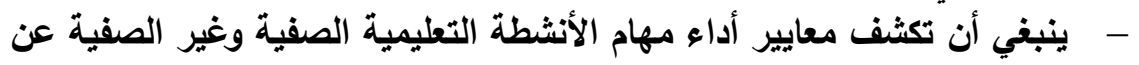

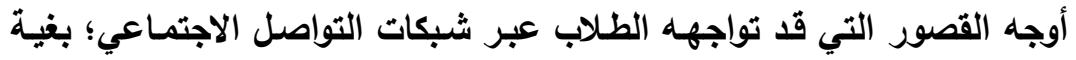
معالجتها. - - مرورة توعية الأستاذ لطلابه بشأن ممارسـة الأنشطة التعليمية الصفية وغير

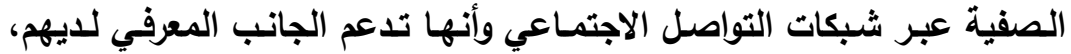
وتسهم في تحقيق أهداف العلية التعليمية. - - يحرص الأستاذ على تنمية الرقابة الذاتية للطلاب على أداء الدية ممارستهم على مهام

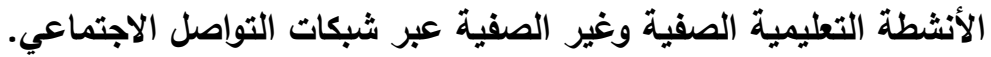

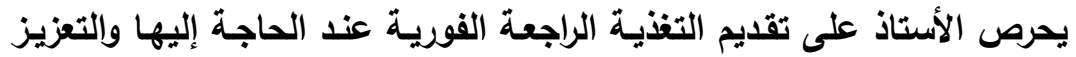

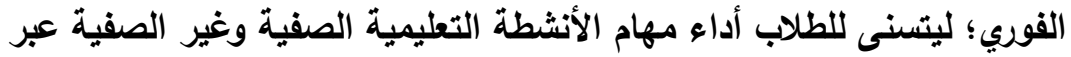
شبكات التواصل الاجتماعي.

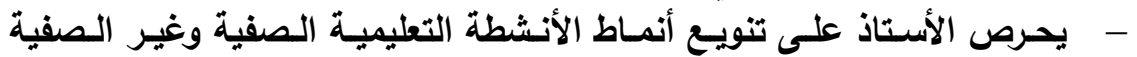

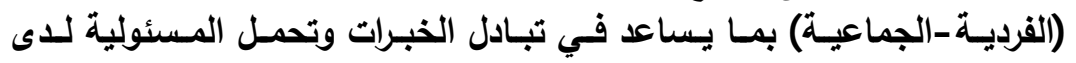

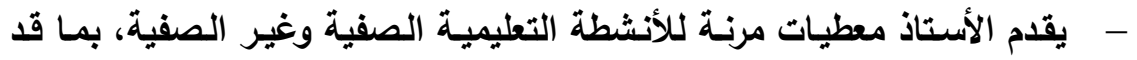

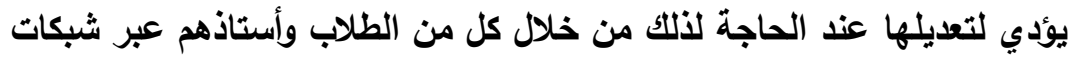

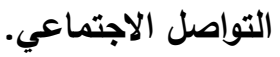

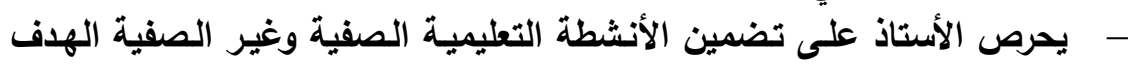

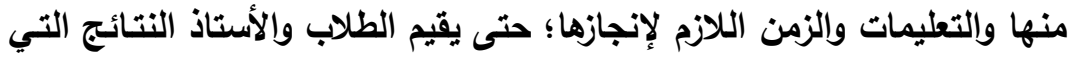
يتم التوصل إليها. 
- - يستخلص الأستاذ بمشاركة طلابهـ المحتوى المعرفي من خـلال مهام الأنشطة

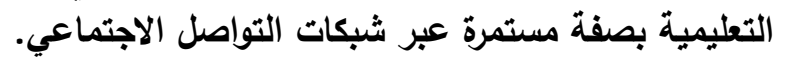

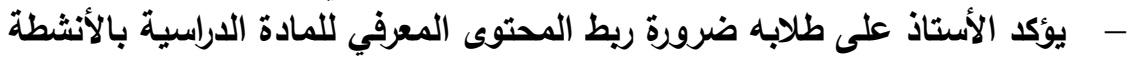

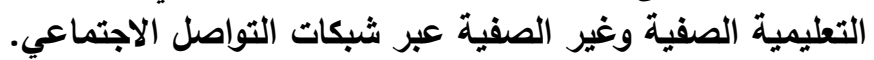

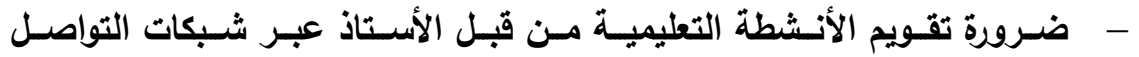

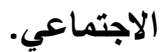
- - مرورة أن يحدث الأستاذ تكاملاً بين الأنثطة اللاصفية مـع الصفية في تحقيق أهدافها عبر شبكات التواصل الاجتماعي.

\section{المهور السادس - إثراء التصصيل المهرفي:}

- - تصميم أنشطة تعليميـة تستهـف تنميـة مستويات التحصيل العليـا من تحليل

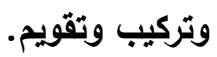

- - الحد من الأهداف التعليمية التي تتطلب مستويات التفكير الدنيا ومنها التذكر أو

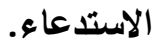
- - تصميم أساليب تقويم تكثف عن مدى تحقق الأهداف المعرفية في المستويات العليا.

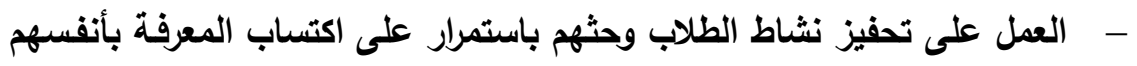

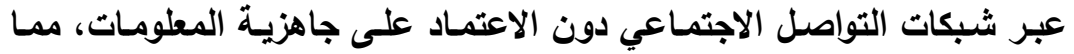

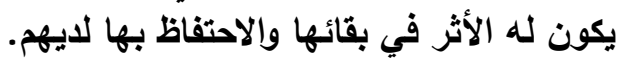

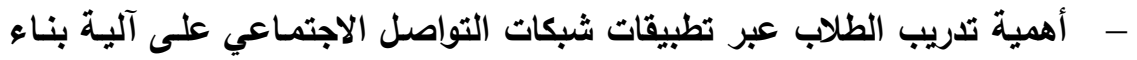

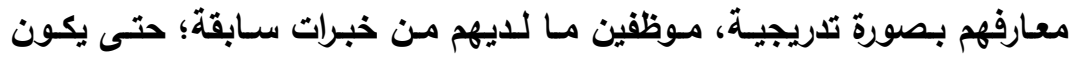

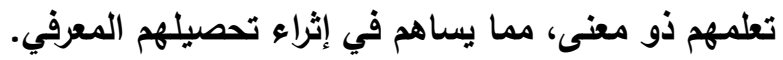

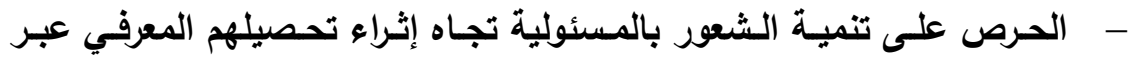

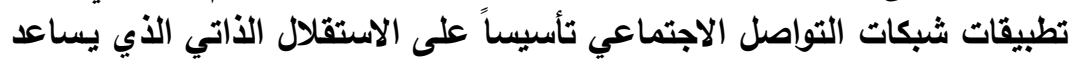
على زيادة الدافعية نحو التعلم.

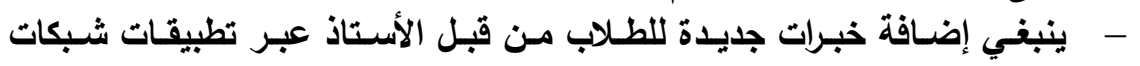

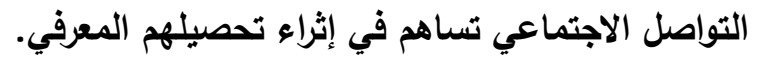

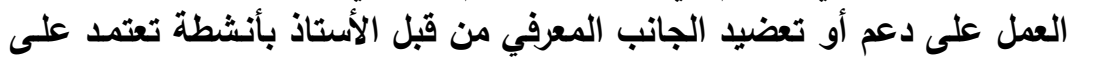

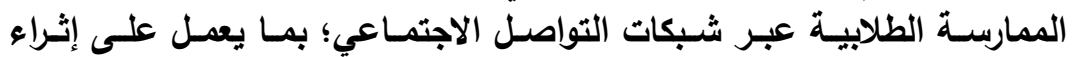
التحصيل المعرفي للطلاب.

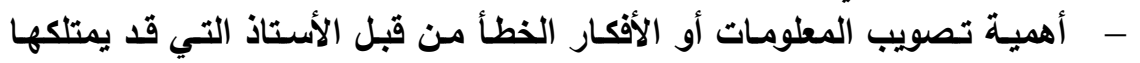

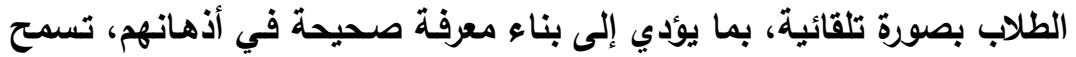

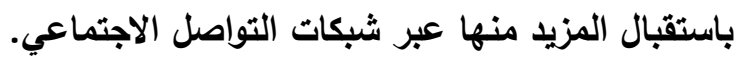


مجلة كلية التربية، جامعة الأزهر، العدد: (183، الجزء الثاني) يوليو لسنة 2019م

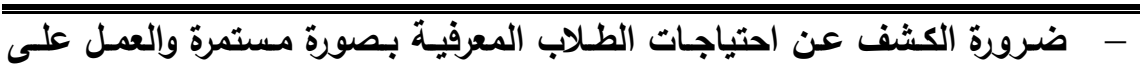

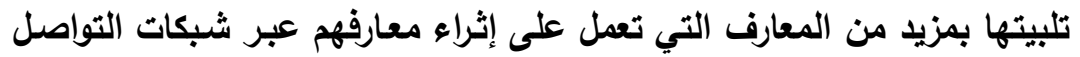

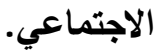

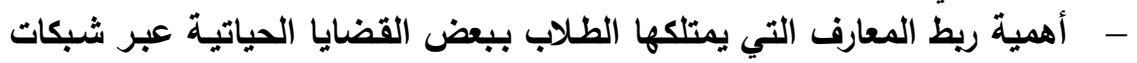

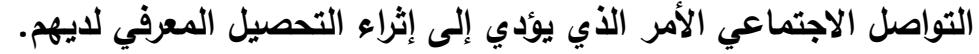

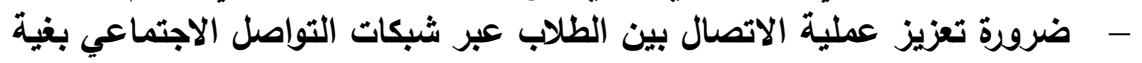

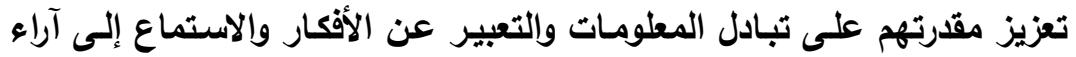

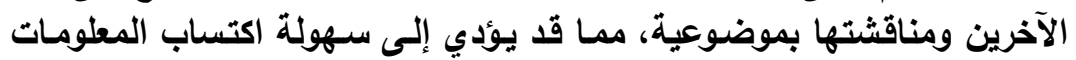

ويالتالي يعمل على إثراء التحصيل المعرفي لايهم.

\section{المحور السابع- التغذية الراجعة والتعريز الفوري:}

- - في مرحلة التخطيط وما بعد التدريس ينبغي أن يجزة الأستاذ مصادر المعلومات

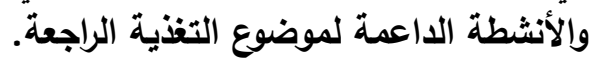

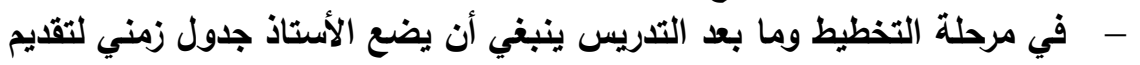
التغذية الراجعة. - - ضرورة تأكد الأستاذ من استيعاب التغذية الراجعة لاى طلابه بإعادة التقويم في

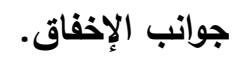

- - العمل على تصويب الأخطاء من خلال إعادة المحاولة من قبل الطلاب .

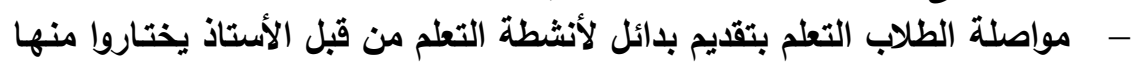

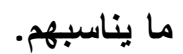

- - ينبغي أن يعدد الأستاذ في مرحلة التخطيط من أنماط التغذية الراجعة وفق طبيعة

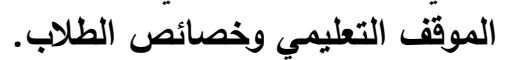

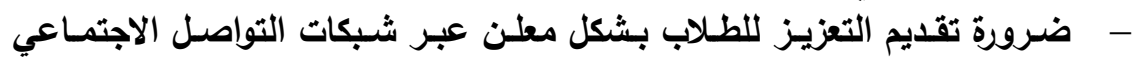

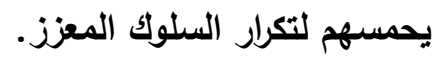
- - ينبغي أن يكثر الأستاذ من استخدام جمل صحيحة ذات تأثير كبير وفعال في

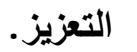
- - مصداقية مشاعر الأستاذ والتي تبدو في الجمل والكلمات المستخدمة في التعزيز من قبله - - الحرص على استخدام التعزيز بشكل متقطع من قبل الأستاذ.

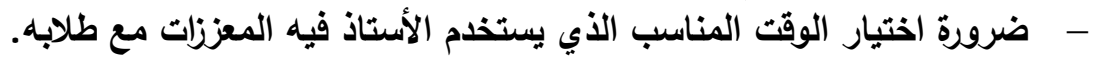
- - - ضرورة اختيار الأستاذ المعززات التي تتوافق مع طبيعة الطلاب. 


\section{المهور الثاهن- صناعة المعلوهات:}

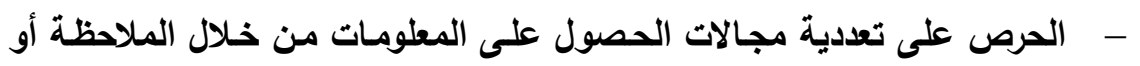

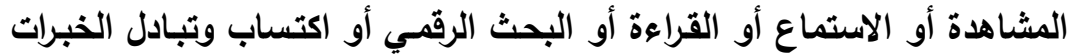

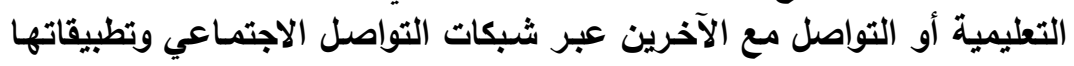
المختلفة.

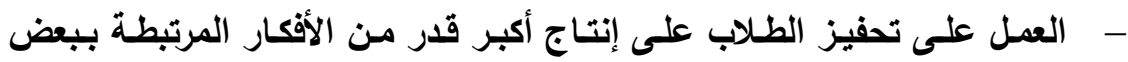

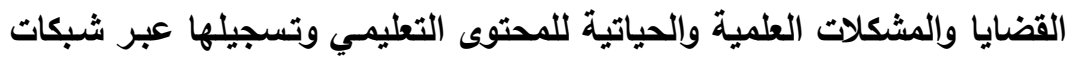

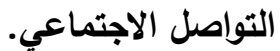

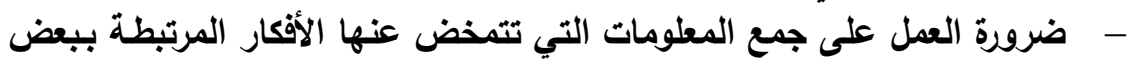

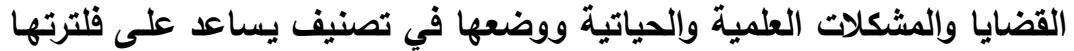

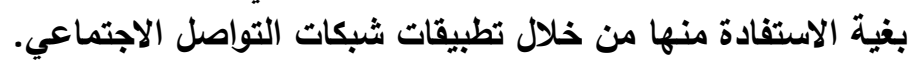

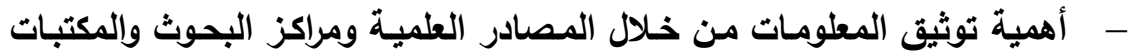

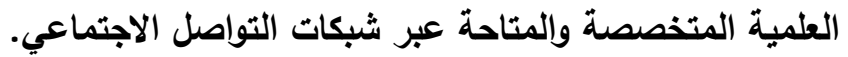

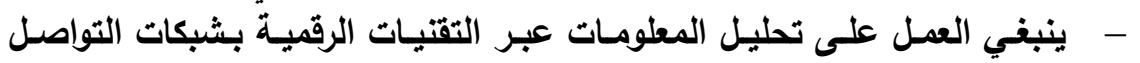

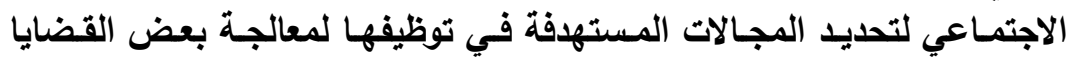

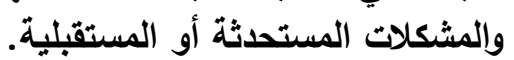

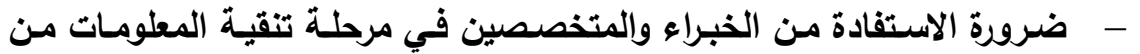

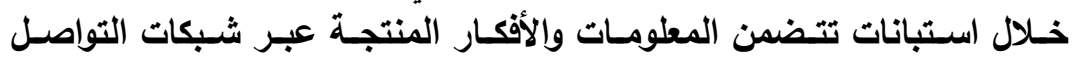

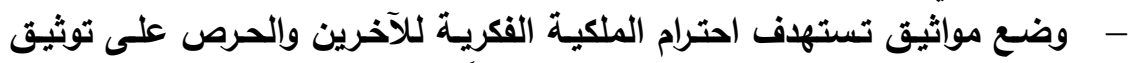

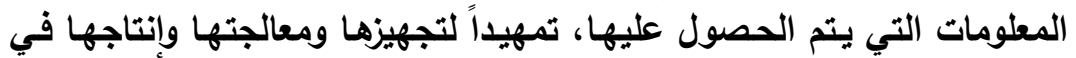

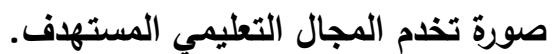

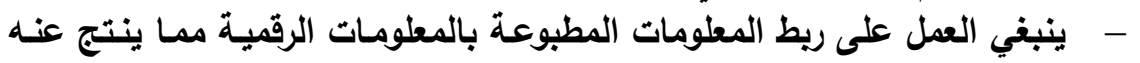

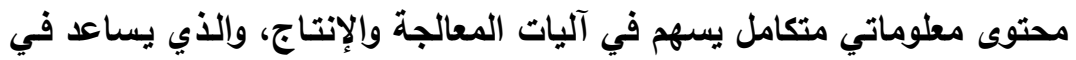
تنمية الابتكار بشكل وظيفي لدئي الطيلاب.

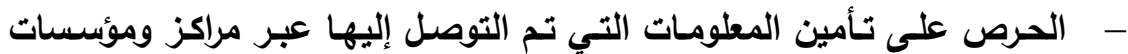

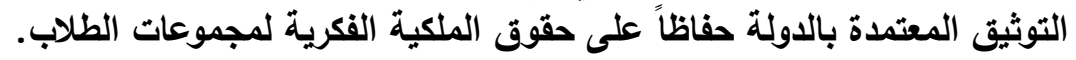

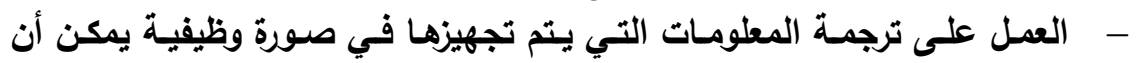

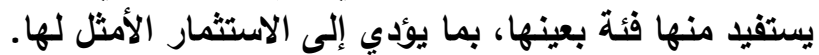

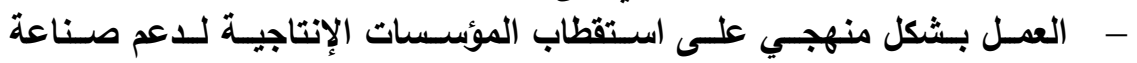

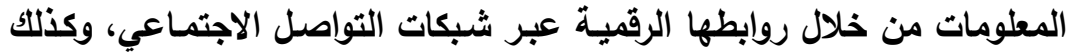
مؤسسات البحث العلمي الداعمة للأفكار المبتكرة. 
مجلة كلية التربية، جامعة الأزهر ، العدد: (183، الجزء الثاني) يوليو لسنة 2019م

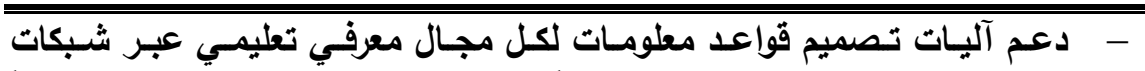

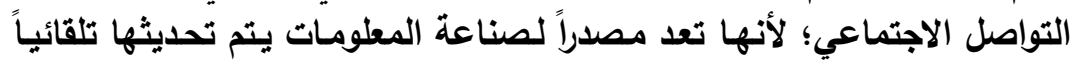

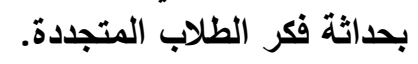

\section{المهور التاسع - قياس الإنهاز الأكاديمي:}

- - ضرورة تصميم الأستاذ لأدوات تستهدف نمط التقويم المعتمد على الأداء عبر شبكات التواصل الاجتماعي.

- - ينبغي أن يؤسس التقويم المعتمد على الأداء على على قياس مهارات التفكير العليا

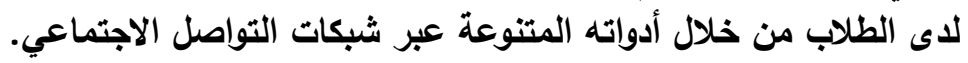

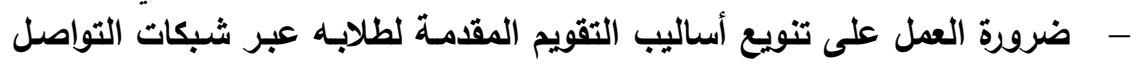

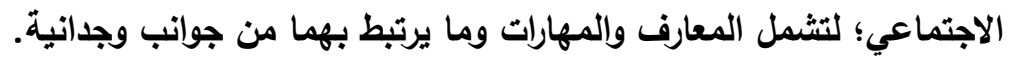

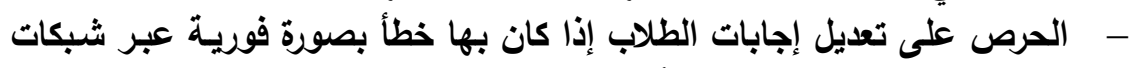

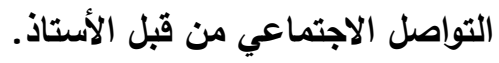
- - إمكانية إتاحة الفرصة للطلاب للعمل على تصويب أخطائهم عبر شبكات التواصل الاجتماعي. - - ينبه الأستاذ طلابه بأهمية التقييم الأتي وثمرته التي تسهم في تحسين مخرجات

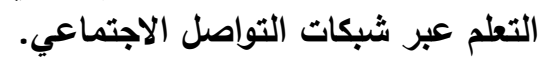

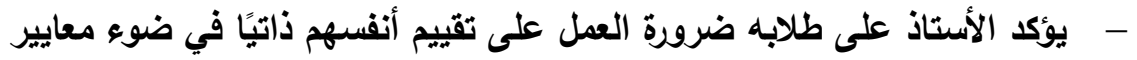

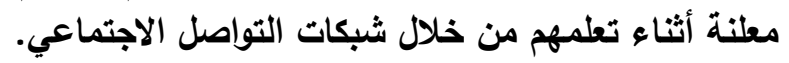

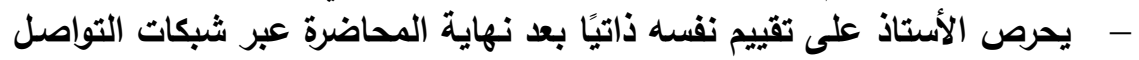

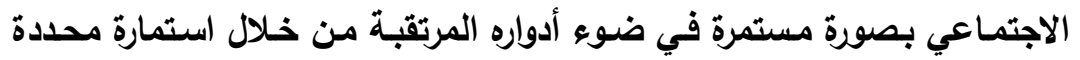

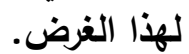
- - الاستفادة من التقييم الذاتي بوضع الحلول التي تساعده في التظلب على جوانب

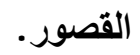
- - يتيح الأستاذ الفرصة لنقده من قبل طلابه بشكل معياري بعد تدريس كل موضوع عبر شبكات التواصل الاجتماعي.

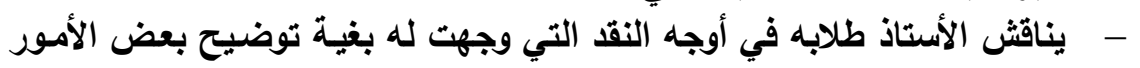
التي لم يلاحظونها.

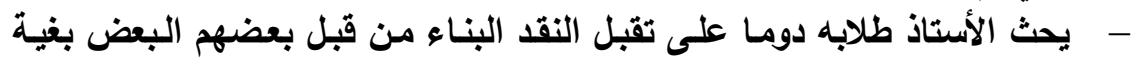

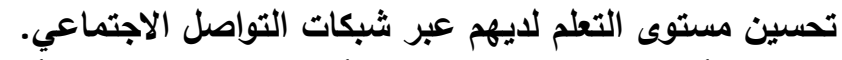

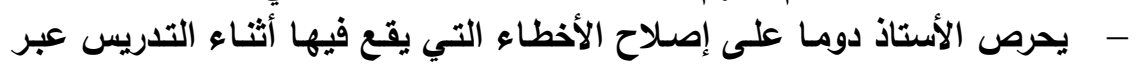
شبكات التواصل الاجتماعي. 
- - الحرص على تبادل الخبرات المهنية مـع ذوي الخبرة من تخطيط وتنفيذ وتقويم طريقة عرض للمحاضرة عبر شبكات التواصل الاجتمات الجماعي.

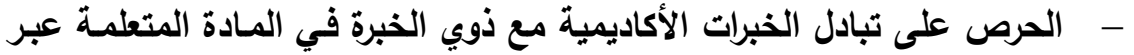

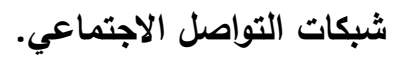

- - حصر الصعويات التي حالت دون تنفيذ بعض مهام التعلم في الزمن المحدد لها عبر شبكات التواصل الاجتماعي. - - نشر معايير التقويم ومفاتيح التصحيح للتأكد من موضعيته من خلاعل الطلاب التصاعي عبر شبكات التواصل الاجتماعي.

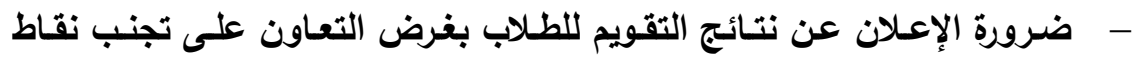
الضعف وإثراء نقاط القوة عبر شبكات التواصن التابل الاجتماعي.

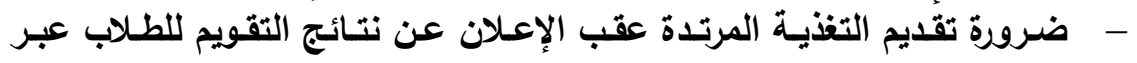

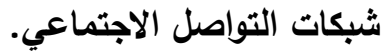

\section{المهور العاشر - تصسين الموقف التعليسمي:}

- تجنب حصر الطلاب في طيات محتوى محدود.

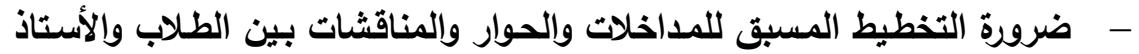
عبر شبكات التواصل الاجتماعي. - - يهتم الأستاذ بتوفير قار كافي من الحرية الأكاديمية لطلابه.

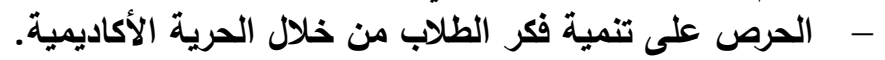

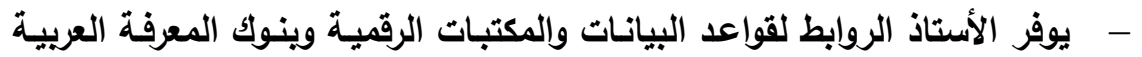

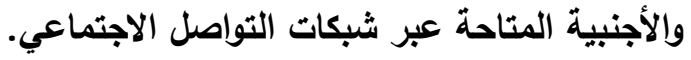

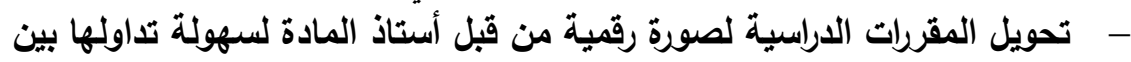
الطلاب عبر شبكات التواصل الاجتماعي.

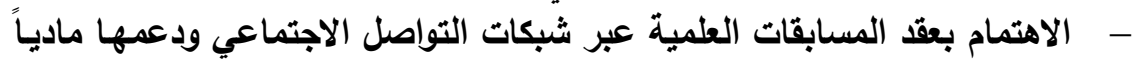
من قبل المؤسسة التعليمية. - - مرورة الاثراف على المسابقات العلميـة عبر شبكات التواصل الاجتمـاعي من قبل المتخصصين.

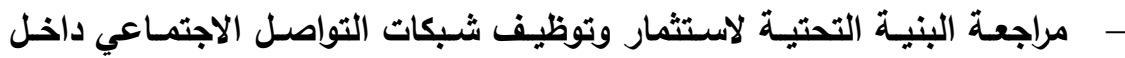

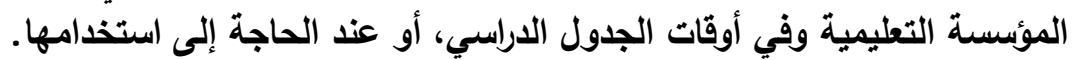

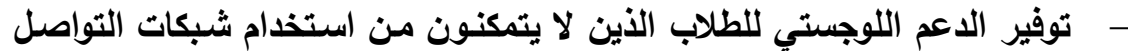

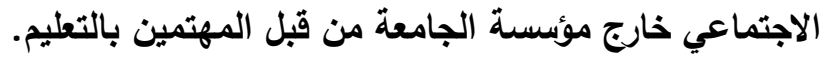

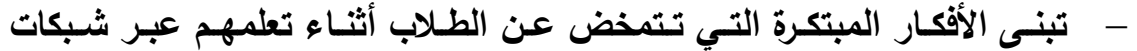
التواصل الاجتماعي بواسطة حاضنة معلوماتية بحثية. 
مجلة كلية التربية، جامعة الأزهر ، العدد: (183، الجزء الثاني) يوليو لسنة 2019م

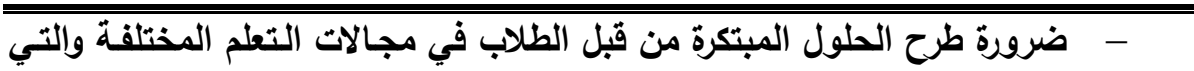

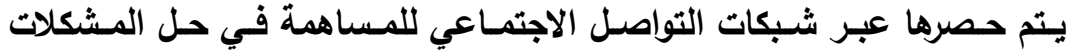
والقضايا المجتمعية.

- - تنظيم التبادل المعرفي والثقافي بين مؤسسة جامعة الأزهر بكلياتها والمناظرة لها

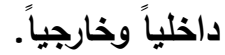

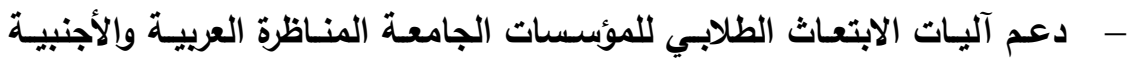

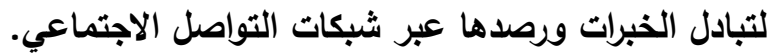

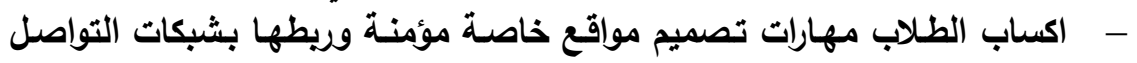

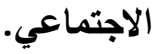

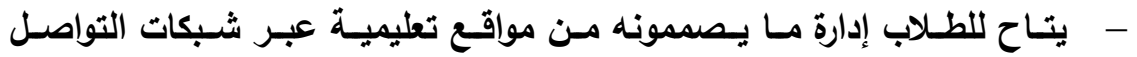

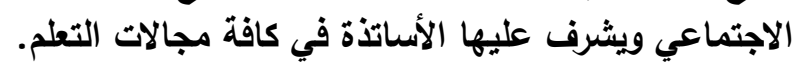

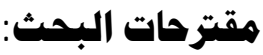

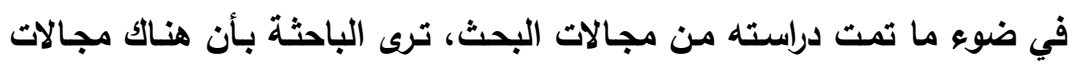

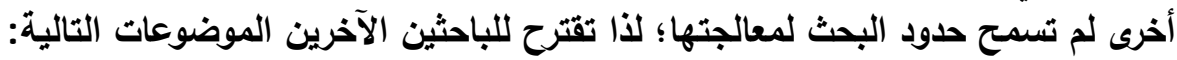
- - وضـع استراتيجية لتوظيف شبكات التواصل الاجتمـاعي في العملية التعليميـة

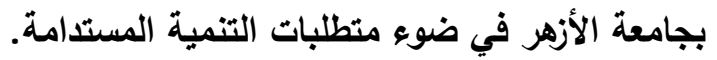

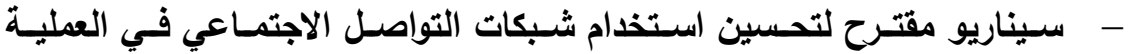

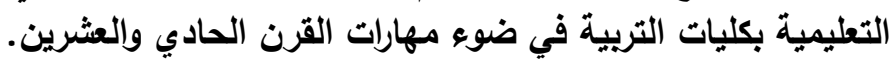

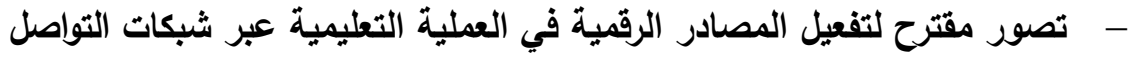

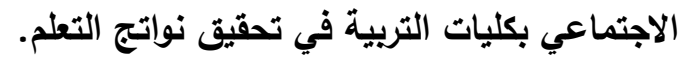

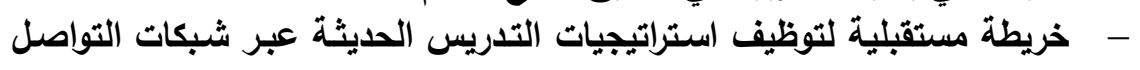

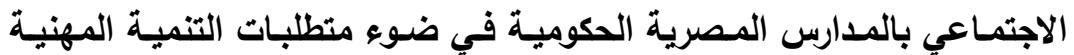
للمعلم. 


\section{المراجع}

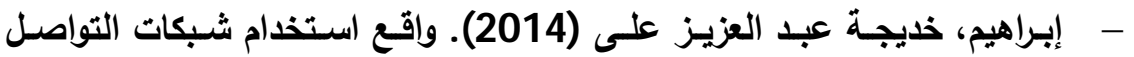

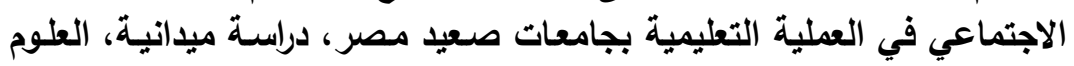

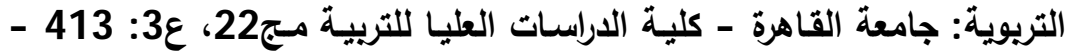

- - أبو درب، علام علي محمد، وحارص عبد الجابر عبد اللاه عمـار (2014) ـ أثز

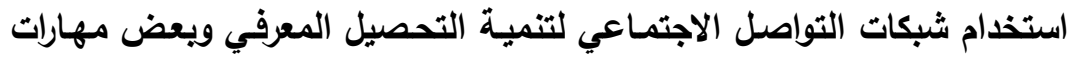

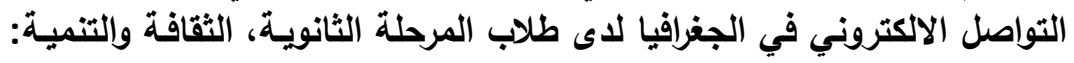

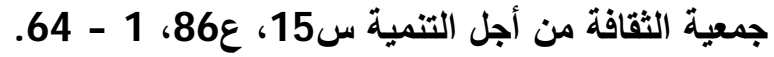

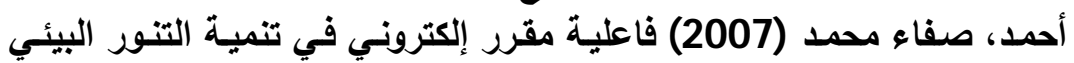

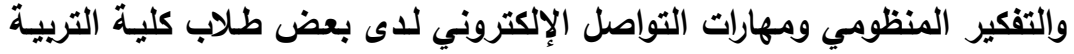

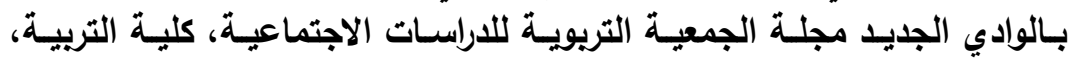

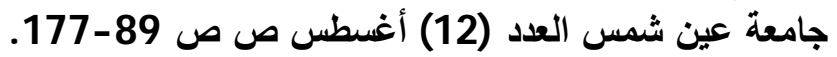

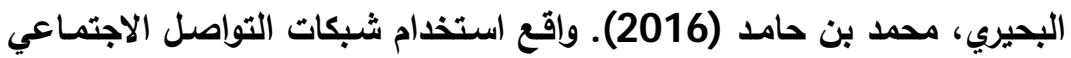

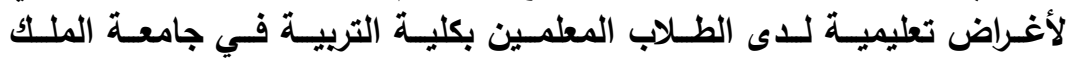

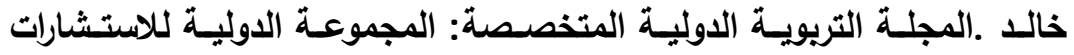

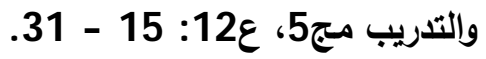

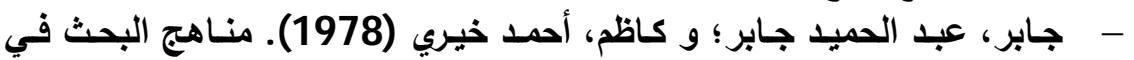

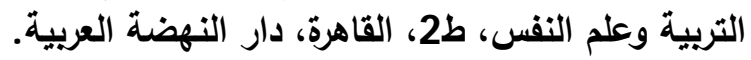
الجهني، خالد عبدالله الميلبي(2017) ـ أثر استخدام شبكات التهات التواصل التهل الاجتماعي

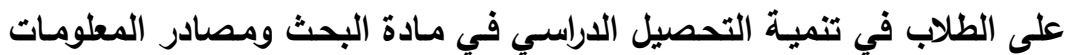

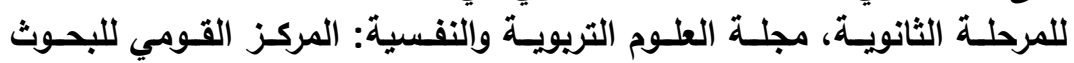
غزة مج1، ع4، 126 - 136.

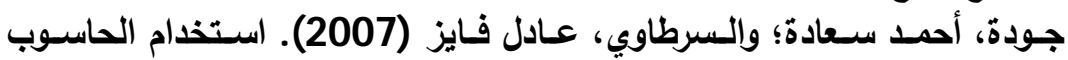
والانترنت في ميادين التربية والتعليم، الأردن: دار الثروق للتشائ والنشر والتوزيع.

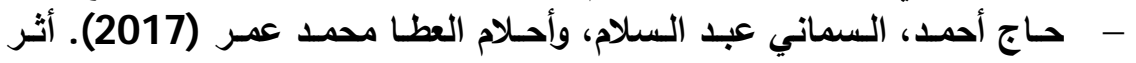

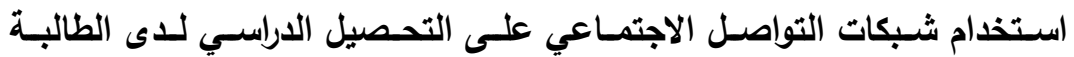

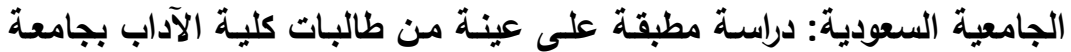

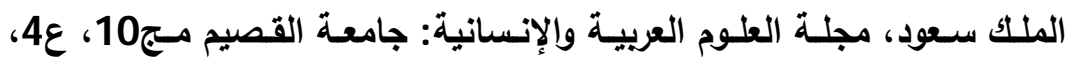
.2342 - 2287 - - الحلفاوي، وليد سالم (2011). التعليم الإكترونـي تطبيقات مستحدثة، القاهرة:

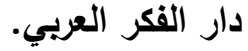


مجلة كلية التربية، جامعة الأزهر ، العدد: (183، الجزء الثاني) يوليو لسنة 2019م

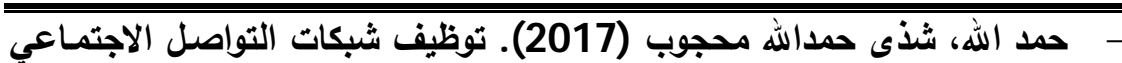

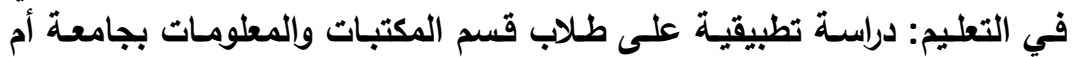

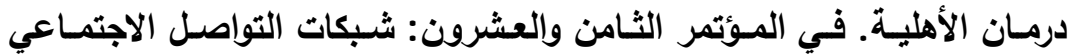

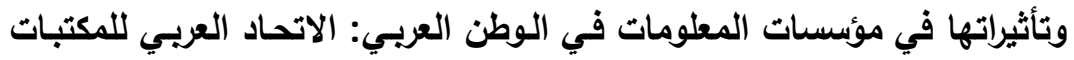

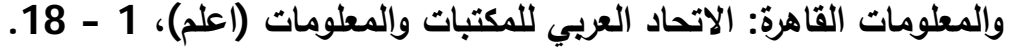

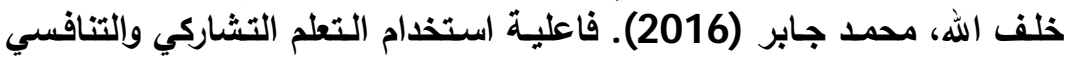

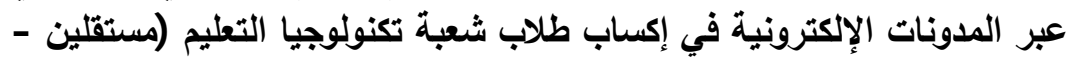

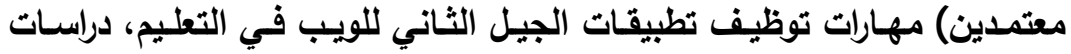

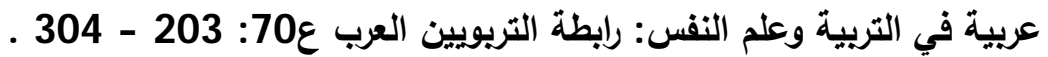

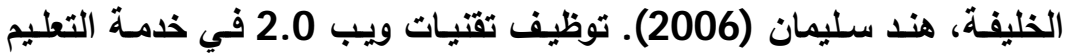

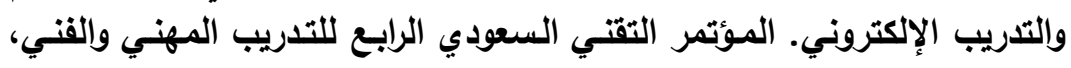

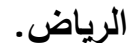

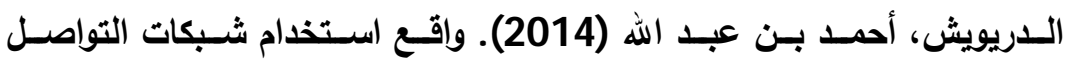

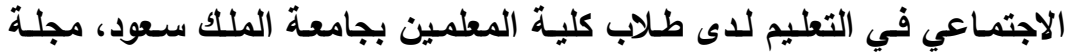

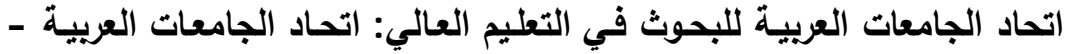

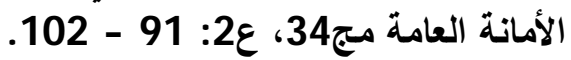

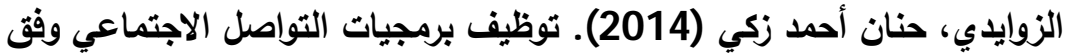

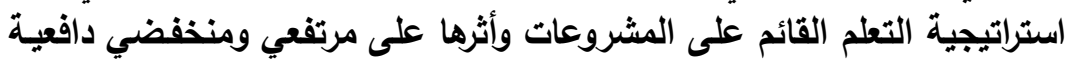

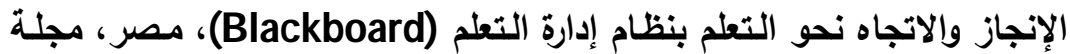

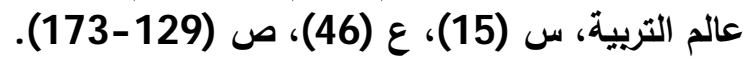

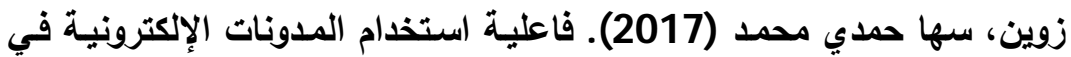
تدريس الجغرافيا على تنمية مهارات المواطنة الرقمية لدى الطالب المعلم بكلية

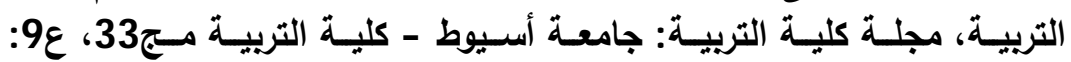
.531 - 461

السدحان، عبد الرحمن بن عبد العزيز (2015). واقع استخدام شبكات التواصل

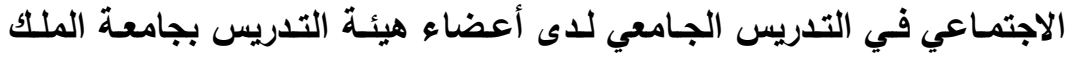

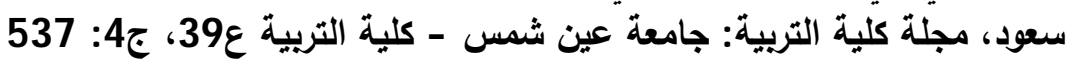

- - السريحي، منسى داخـل، وعبد الله خـازم السهري (2014) ـ شـبكات التواصـل

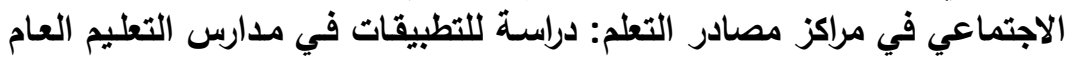

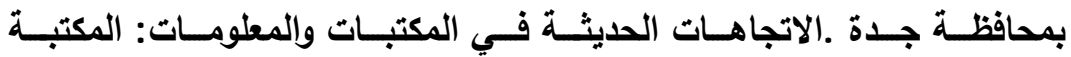
الأكاديمية مج 21، ع ع 41، 97 - 122 


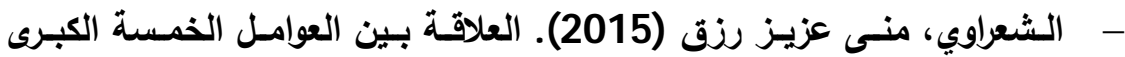

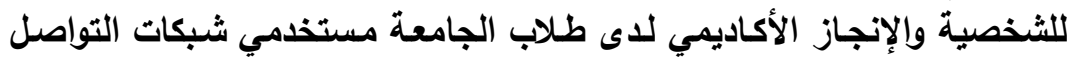
الاجتماعي، مجلة كلية التربية: جامعة بورسعيد - كلية التربية ع18، 1096 . 1122 - شفيق، حسنين (2011). الاعلام الجديد، عمان: دار الفكر.

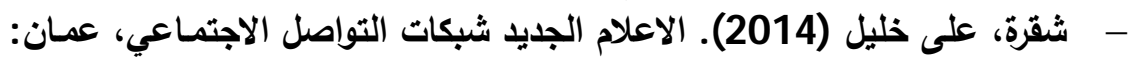
دار أسامة للنشر والتوزيع. - شلتوت، محمد شوقي (2017). أثر برنامج تدريبي مقترح قائم على المقرات

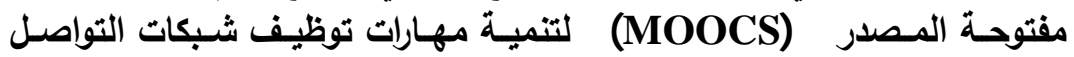
الاجتمـاعي كمنصات تعليميـة لمعلمـي مدارس التعليم العـام .العلـوم التربويـة:

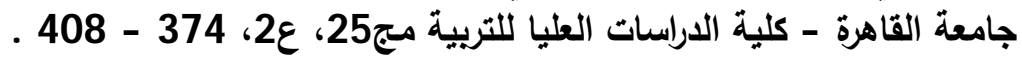

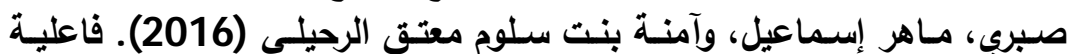

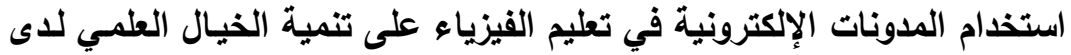

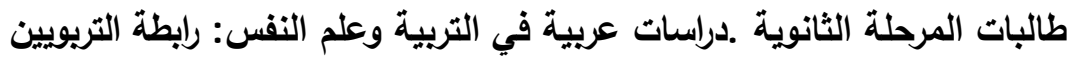
العرب ع69: 39 - 39 - 84.

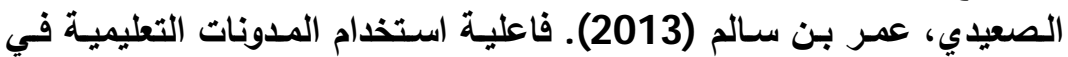

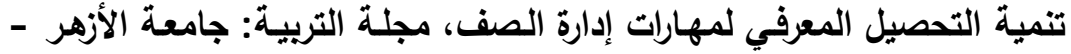

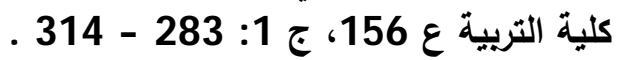

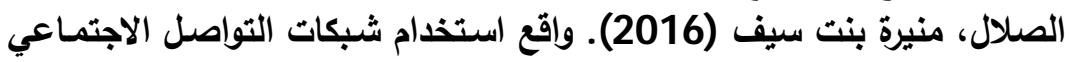

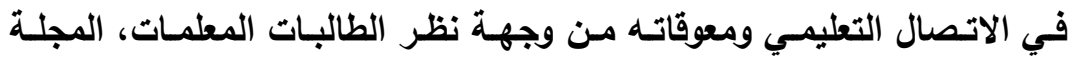

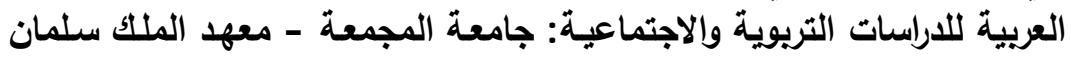

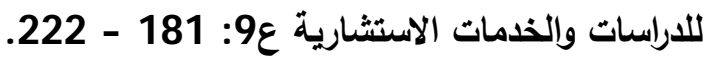

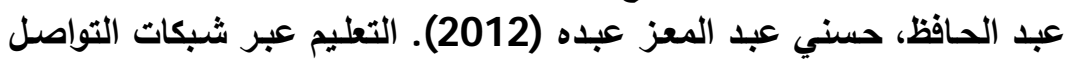

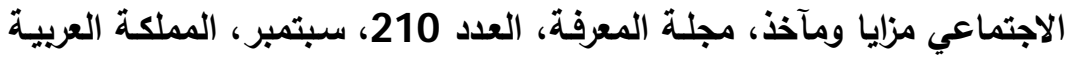

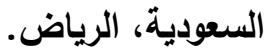
عبد الحي، أسماء الهادي إبراهيم (2013). الأبعاد التريويـة للتواصل الثقافي الثيافي

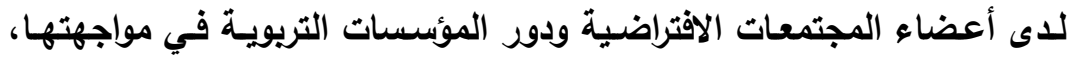

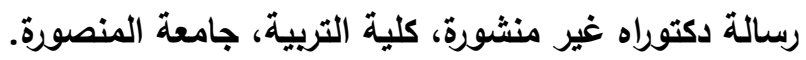

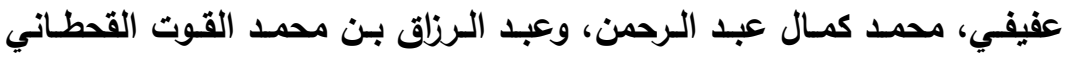

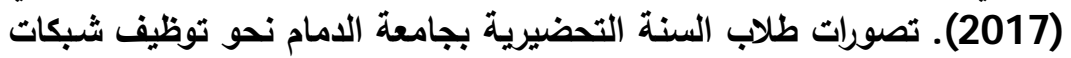

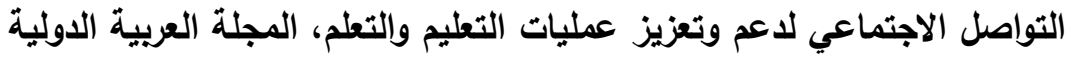

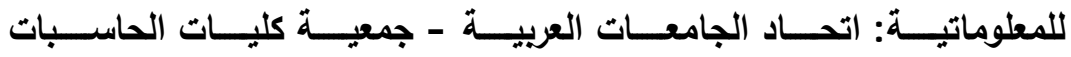
والمعلومات مج5، ع9، 1 - 16. 
مجلة كلية التربية، جامعة الأزهر، العدد: (183، الجزء الثاني) يوليو لسنة 2019م

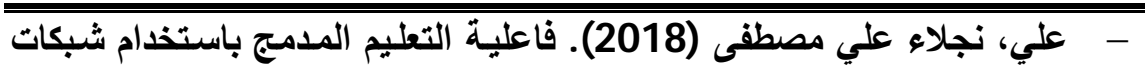

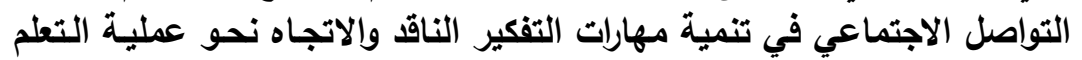

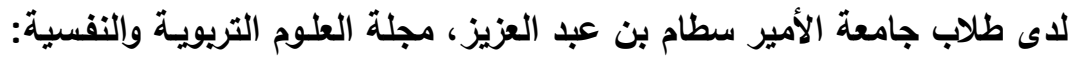

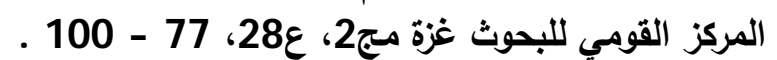

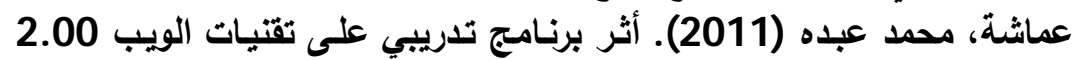

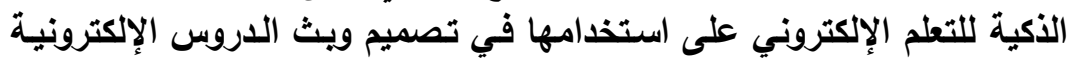

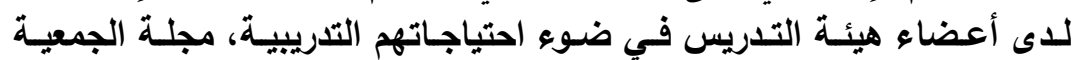

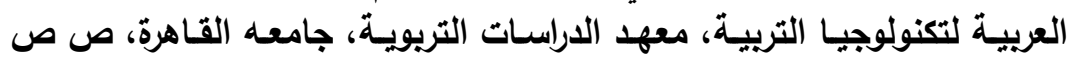
.323 - 273

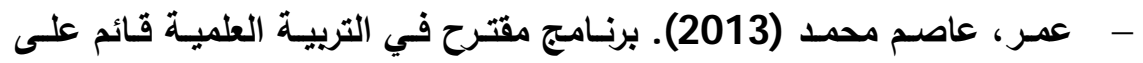

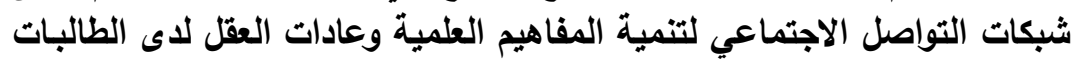

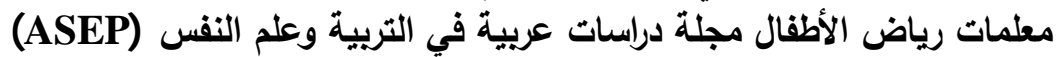

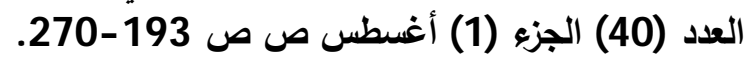

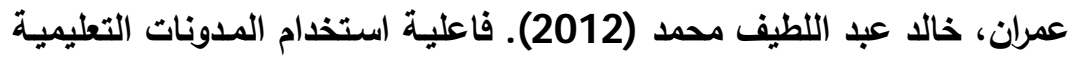

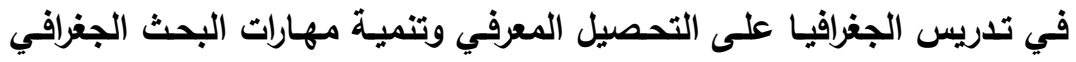

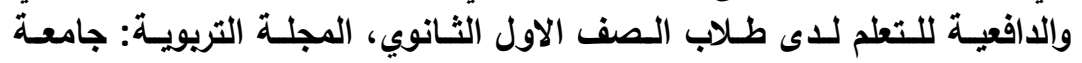
سوهاج - كلية التربية ج31: 353 - 425. كمال، أحمد بدوي أحمد (2016) ، فاعلية استخدام المدونات التعليمية في تنمية

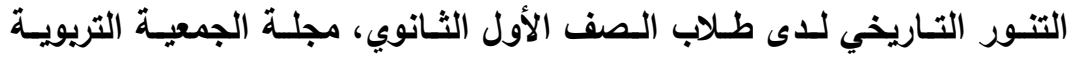

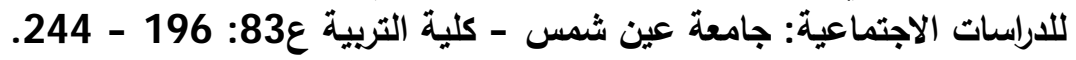

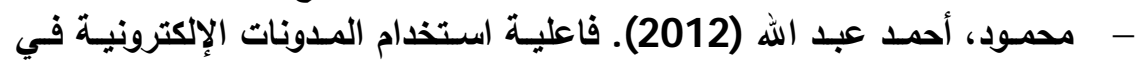

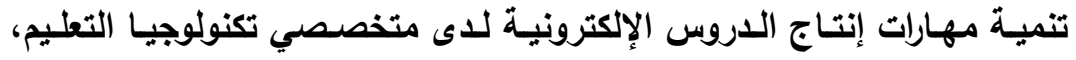

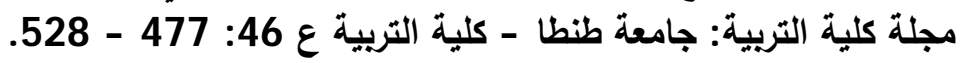

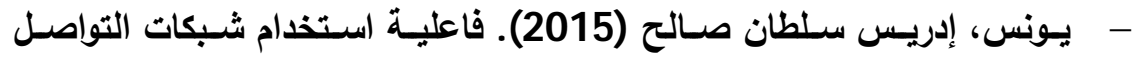

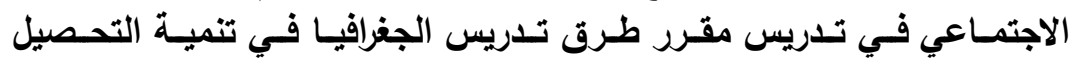

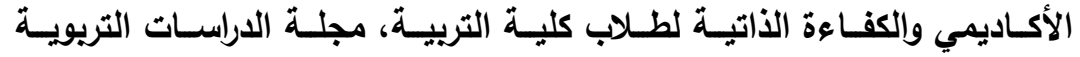
والنفسية: جامعة السلطان قابوس مج9 ولاعة، ع1، 197 - 210. 
- Alvareg, I. M. \&smith, M. O. (2013). Learning in social Networks: Rationale and Idea for its Implementation in Higher Education. Journal of Education Sciences. x 22. pp. 315-325.

- Arqcuero , J. L. \& Romero, E. (2011). Using Social Network Sites in Higher Educational: an Experience in Business Studies. Congreso International de Innovaction Docente Universidad Polite Cnica de Cartagena, Cmn 37/3. Cartagena 6, 7y 8 Dejulio.

- Baecelos, Gilmara T; \& Batista, Silvia Cristina F. (2013). Use of Social Networks in Teacher Training Programs: A Case Study. International Journal on New Trends in Education and Their Implications, Volume: 4 Issue: 1 Article: 01.

- Bandyopadhyay.S, Shaw.V, Banerjee.A and Nag.D,(2013). Social Knowledge Management: Use of Social Media for Disseminating Informal Wisdom of Elderly to the Youth, International Journal of Knowledge, Innovation and Entrepreneurship Volume 1 Nos. 1- 2, 2013, pp.107-115.

- Baran, B. (2010), Facebook as a formal instructional environment. British Journal of Educational Technology,41(6)146-149.

- Bennett, J., Owers, M., pitt, M. \& Tucker, M. ( 2010). Workplace Impact of Social Networking. Property Management. Vol. 28, Issue 3. pp. 138-148.

- Bicena, H. \& Cavus, N. (2011), Social network sites usage habits of undergraduate students: case study of Facebook. Social and Behavioral Sciences, 28 (1), 943- 947.

- Bissessar, Charmaine S. (2014). Facebook as an Informal Teacher Professional Development Tool. Australian Journal of Teacher Education, Vol. 39, No. 2.

- Boulos Kamel, S. W. (2007). The emerging Web 2.0 social software: an enabling suite of sociable technologies in health and health care education. health information\& libraries journal, 24 (1), 11-13.

- Brady, K. p. , HolComb, L. B. \& Smith, B. V. ( 2010). The Use of Alternative Social Networking Sites in Higher Educational Settings: A case Study of the E- Learning Benefits of Ning in Education. Journal of AlternativeOnline Learning. Vol. 9. No. 2. pp. 151-170.

- Buzzetto- More, N. A. (2012). Social Networking in Undergraduate Education, Interdisciplinary Journal of Information. Knowledge and Management Special Section on Social Networking, Teaching and Learning. Vol. 7. pp. 63-90. 
مجلة كلية التربية، جامعة الأزهر، العدد: (183، الجزء الثاني) يوليو لسنة 2019م

- Charoensukmongkol.P and Sasatanum.P,(2017), Social media use for CRM and business performance satisfaction: The moderating roles of social skills and social media sales intensity, Asia Pacific Management Review , Mar 2017, Vol. 22 Issue 1, pp 25-34.

- Corbeil, J. R. \& Corbeil, M. E. (2011). The Birth of a Social Networking Phenomenon. Cutting-edge Technologies Higher Education. Vol. 1. pp 13-32.

- Coutinho, Clara Pereira; \& Lisbôa, Eliana Santana. (2013). Social networks as spaces for informal teacher professional development: challenges and opportunities. Int. J. Web Based Communities, Vol. 9, No. 2.

- Dalsgaard, C. (2013). Social Networking Sites: Transparency in Online Education. Denmark: Institute of Information and Media Studies, Uuniversity of Aarhus, available at:http://eunis. dk/paper/p41. pdf (Retrieved on: 4/10/2013).

- Ellison, N,Stein Field, C Lampe, C (2007) The Benefits of Face Book Friends Social Capital Collage Students Use of Online Social Network Sites Journal of Computer Mediated Communication Vol 12, Issue 4.

- Farb. A. G. \& Pregibon, N. (2011). Informational Brief on Social NetWorking in Education. New York: Comprehensive Center.

- Gulbahar, Y. (2013). Social Networks from Higher Education Students Perspective. Anadolu Journal of Educational Sciences International. Vol. 3. No. 2. pp. 22-32.

- Hagan, Teresa. (2013). The Potential of Online Technologies and Social Media in 21st Century Teacher Professional Development and Practice: A Mixed Methods Study Exploring Teachers' Personal

- Jain, N. K., Verma, A., Verma, R. S. \&taiwari, P. (2012). Going social: the impact of social networking in promoting education. International Journal of Computer Science, 9 (1), 483-485

- Judd, R. G. \& Johnston, L. B. (2012). Ethical Consequences of Using Network Sites for Students in Professional Social Work Programs. Journal of Social Work - Values and Ethics. Vol.9. No. 1. pp. 5-12.

- Kuppuswamy, S. (2010). the Impact of Social Networking Web Sites on the Educaton of Youth. International Journal of Virtual Communicates and Social Networking. Vol. 2. No.1. pp. 67 - 79. 
- lego- Munoz, C. \& towner, t. L. (2009). Opening Facebook: How to Use Facebook in the College Classroom. This Paper Was Prepared for Presentational the 2009 Society for Information Technology and Teacher Education Conference in Charleston, Southe Caroline.

- Lei, C.; Krilavicius, T.; Zhang, N.; Wan, K.; Man, K. (2012). Using web 2.0 tools to enhance learning in higher education: A case study in technological education. Presented at International Multi-Conference of Engineers and Computer Scientists (IMECS), Hong Kong, China. 1153-1156.

- Lianghuan Liu, Long Wang Feng Fu. (2008). Empiricalanalysis of online social networks in the age of Web 2.0. ELSEVIER - Physica A 387 ،675-684.

- Manca, Stefania.(2014). Teachers' professional development in online social networking sites. EdMedia.Professional Development and/ or Classroom Use of Online Technologies in Ireland and the United States of America. A dissertation presented for the degree of Professional Doctorate in Education. Dublin City University.

- Miah, M., Omar, A. \& Golding, M. A. (2012). Effect of Social Networking on Adolescent Education. Proceedings of the Informations Systems Educator Conference. Neor Learns , Louisiana. USA. Vol. 29. No. 1927.

- Munguatosha, G. M. , Muyinda, P. B. \& Lubega, J. T. (2011). A social Networked Learning Adoption Model for Higher Education Institutions in Developing Countries. On The Horizon. Vol. 19. Issue: 4. pp. 307 - 320.

- Munoz, C \& Towner T. (2009). Opining Facebook: How to Use Facebook in the College Classroom. Conference Paper, Information Technology and Teacher Education conference. Charleston. South Carolina. USA.

- Ophus, J. D. \& Abbitt, J. T. (2009). Exploring the Potential Perceptions of Social Networking Systems in University Courses. Merlot Journal of Online Learning and Teaching. Vol. 5. No. 4, pp. 639-648.

- Panckhurst, R. (2013). Communities of Practice, Using the oOpen Web As a Collaborative Learning Platform, (NRSuniversity paul - valery - mont pellier3, Debra marsh. available at: http://halshs. archieves -ouvertes. fr/docs/00/29/18/74/pdf/panchhurstmarsh-findal. pdf. (Retrieved on: 4/10/2013). 
مجلة كلية التربية، جامعة الأزهر، العدد: (183، الجزء الثاني) يوليو لسنة 2019م

- Ractham, P.; Fi rpo, D.. (2011). Using social networking technology to enhance learning in higher education: A case study using Facebook. Presented at the 44th Hawaii International Conference on System Sciences (HICSS).

- Rob Mancabelli Richardson. (2007). High-Tech Inspires the Read/Write Website. Education Digest 72 ، (9)18-14 .

- Roblyer, M., Mcdaniel, M., Webb, M., Herman, J. \& Witty, j. (2010). Findings on And perceptions of social networking sites. The Internet and Higher Education ,13(3), 134-140

- Stanciu, F. , Mihai, F. \& Aleca, O. (2012). Social Networking as an Alternative Environment for Education. Accounting and Management Information Systems. Vol. 11. No. 1. Pp $56-75$.

- Tariq, W. Mehboob, M. , yar-kan, M. A. \& ullah, F. (2012). The Impact of Social Media and Social Networks on Education and Students of Pakistan. International Journal of Computer Science. Vol. 9. pp. 407-411.

- ZaidiehJ. (2012).The use of social networking in education: challenges and opportunities. World of Computer Science and Information Technology Journal, (2), 18-21.

- Zanamwe, N.; Rupere, T. \& Kuf, O. (2013). Use of Social Networking Technologies in Higher Education in Zimbabwe: A learners' perspective. International Journal of Computer and Information Technology, 2(1), 8-18. 